Aida Bebeachibuli

\title{
Espectroscopia Ramsey em um chafariz atômico.
}

São Carlos - SP

Novembro de 2007 


\section{Aida Bebeachibuli}

\section{Espectroscopia Ramsey em um chafariz atômico.}

Tese de Doutorado apresentada ao Instituto de Física de São Carlos - IFSC \USP - em física como parte dos requisitos à obtenção do título de Doutora em Ciências: Física Básica

Orientador:

Vanderlei Salvador Bagnato

Universidade de São Paulo

Instituto de Física de São Carlos

São Carlos - SP

Novembro de 2007 
"Não é no espaço que devo procurar a minha dignidade, mas na direção do meu pensamento. Não deverei tê-la mais se possuir mundos. Pela amplidão, o universo me envolve e me traga como um átomo; pelo pensamento eu compreendo o mundo."

\section{Blaise Pascal, Pensées}

"Aos meu pais, Romeo e Marcelle, e a minha irmã, Tanja.". 
Ao Prof. Vanderlei Salvador Bagnato meus sinceros agradecimentos pelos ensinamentos e convivência nos últimos oito anos. A única forma de retribuir é escrevendo essa tese com muito carinho.

Ao meu AMIGO e orientador por MÉRITO Dr. Daniel Varela Magalhães. A teoria do balão realmente funciona.

À minha banca, Dr. Claudio Lenz, Dra. Selma Junqueira, Dr. Klaus Werner Capelle e Dr. Lucio Acioli, obrigada pelo paciência na leitura da tese.

Aos meus pais, Romeo e Marcelle. Não sei como demonstrar o amor que sinto por vocês. Muito obrigada pelo carinho e, principalmente, pelo apoio que vocês tem me dado.

Às minhas irmãs, Tanja e Giana, e ao meu irmão, André, só tenho uma coisa para dizer: Amigo é coisa para se guardar, do lado esquerdo do peito. Amo vocês.

À minha mais nova e querida amiga, Stella. Alguém como você não se conhece em qualquer esquina. Você é muito especial. Não tenho palavras para agradecer todo o apoio que você me deu.

À Juliana pela amizade e agradáveis bate-papo regados por muitos cafezinhos ao longo desses oito anos.

Aos mais novos relojoeiros: Renato e Diego. Passo a vocês a responsabilidade de dar corda nos nossos relógios.

À equipe da eletrônica, João Marcelo, Elizeu, Edson, Orlando, Matão, Pink, e aos mais novos integrantes, Denis e Leandro. Sempre dispostos a providenciar tudo para ontem. É claro, não me esquecerei da agradável companhia na hora do lanche.

À equipe da oficina mecânica, Seu Gilberto, Evaldo, Leandro, Carlinhos, Pereira, Gilmar, sempre prestativos e criteriosos no que fazem.

Às secretárias Isabel, Bene, Wladerez e as bibliotecárias Neusa, Maria Cristina e Betânia.

À equipe atômica, Kilvia, Cristina, Jorge, Emmanuel, Edmir e Renato. 


\section{Resumo}

Apresentamos os aspectos mais relevantes para se realizar um chafariz a átomos frios de ${ }^{133} \mathrm{Cs}$, para operá-lo como um padrão primário de tempo e freqüência para realizar a definição do segundo. O objetivo principal desse trabalho foi a otimização do sistema experimental do chafariz de átomos em duas partes críticas: a região de interação e o sistema de detecção. Além disso, otimizamos as diversas fases da manipulação óptica que fazem parte do ciclo de operação de um chafariz com o intuito de aumentar a relação sinal ruído na região de detecção. Quando os átomos são lançados com uma velocidade de $3,39 \mathrm{~ms}^{-1}$, atingem o ápice a $60 \mathrm{~cm}$ acima da região de captura e passam 360ms na região de vôo livre. A temperatura dos átomos na região de detecção não ultrapassa $15,5 \mu K$ e a diferença de população observada através das Franjas de Ramsey, que são a assinatura característica de um padrão de frequiência atômico, tem a largura a meia altura de $1,4 \mathrm{~Hz}$. A largura de linha e a relação sinal ruído da franja implicam em uma estabilidade a curto prazo de 5, $18 \times 10^{-12}$. Alguns causadores de deslocamentos de freqüência como a radiação de corpo negro, o efeito Doppler de segunda ordem, o efeito gravitacional e o efeito Zeeman de segunda ordem foram avaliados.

Palavras-chave: Padrão de freqüência atômico, relógio atômico, espectroscopia Ramsey, césio, Metrologia 


\section{Abstract}

We present some relevant aspects for the realization of a ${ }^{133} \mathrm{Cs}$ fountain, intended to operate as a primary frequency standard to realize the definition of the second. The main goal of this work is the optimization of the experimental setup of the atomic fountain in its most critical parts: the interaction region and the detection system. Furthermore, the several phases of the optical manipulation which concern the operation cycle of an atomic fountain were also optimized. These procedures allowed us to increase the signal to noise ratio in the detection signal. When the launching velocity is about $3.39 \mathrm{~m} / \mathrm{s}$, the atoms reach the apogee about $60 \mathrm{~cm}$ above the capture region and spend $360 \mathrm{~ms}$ in the free flight zone. The atomic ensemble temperature in the detection region is about $15.5 \mu \mathrm{K}$ and the population difference between the two fundamental level is measured through the Ramsey fringe with a linewidth of $1.4 \mathrm{~Hz}$. This linewidth, allied to the obtained $\mathrm{S} / \mathrm{N}$ resulted in the measured short-term stability of $5.18 \times 10^{-12}$. Some frequency shift as the black body radiation shift, gravitational shift, second order Doppler shift and second order Zeeman shift were measured.

Key-words: Atomic frequency standar, atomic clock, Ramsey spectroscopy, cesium, metrology 


\section{Lista de Tabelas}

1 Deslocamentos de Freqüência . . . . . . . . . . p. 105

2 Constantes Fundamentais da Física . . . . . . . . . . . p. 126

3 Parâmetros do Átomo de ${ }^{133}$ Cs. . . . . . . . . . . . . . . p. p. 127 


\section{Lista de Figuras}

1 Princípio de funcionamento de um padrão de frequiência atômico passivo. A frequiência do oscilador macroscópico, $v$, é estabilizada na freqüência de ressonância através de um sistema de realimentação: o oscilador externo fornece um sinal de interrogação a um ensemble atômico e um sistema eletrônico coleta o sinal de resposta emitido pelo átomos e calcula um sinal de erro. Esse sinal de erro é usado para corrigir a freqüência do oscilador local. O processo é repetitivo e a frequiência do oscilador local é ajustada para um valor mais próximo da freqüência natural atômica. . . . . . . . . p. 21

2 Diagrama dos níveis de energia dos átomos de ${ }^{133} C s$. A freqüência relógio corresponde à transição hiperfina $6^{2} S_{\frac{1}{2}}\left|F=3, m_{F}=0\right\rangle \leftrightarrow$ $6^{2} S_{\frac{1}{2}}\left|F=4, m_{F}=0\right\rangle$ do estado fundamental. Nela também estão esquematizadas as transições ópticas mais relevantes utilizadas em um chafariz atômico, como a transição utilizada no aprisionamento magnetico-óptico, na detecção e no rebombeio dos átomos. . . . . .

3 Método de Ramsey de campos separados de interrogação. O átomo interage com a primeira região de interação durante um tempo $\tau$, passa por uma região livre de microondas durante um intervalo de tempo T e finalmente, em $T+\tau$ os átomos interagem novamente com o campo de microondas. Ao longo de toda a região de interrogação os átomos sentem um campo magnético estático paralelo ao campo magnético oscilatório que define seu eixo de quantização. . . . . . . .

4 Franja de Ramsey típica obtida em um padrão de frequiência atômico tipo chafariz para um pulso $b=\frac{\pi}{2}$, quando $T=360 \mathrm{~ms}$ e $\tau=12 \mathrm{~ms}$. . p. 26

5 Franja central obtida com um padrão de freqüência atômico tipo chafariz. A freqüência relógio é obtida através da escravização da franja central ao efetuar uma modulação em torno da freqüência, $v_{0}$, a meia altura. . . . . . . . . . . . . . . p. 27 
6 Vista geral do padrão de frequiência tipo chafariz do Instituto de Física de São Carlos da Universidade de São Paulo. Nela vemos as quatro partes principais da sua montagem experimental: a bancada óptica, o sistema de vácuo, a sintetização de microondas e o sistema de controle. . . . . . . . . . . . . . . p. 35

7 Esquema experimental do sistema de vácuo do Chafariz Atômico. O ciclo de funcionamento é formado por etapas distintas para realizar a interrogação dos átomos de ${ }^{133}$ Cs. Primeiro os átomos são aprisionados utilizando-se a técnica de armadilha magneto-óptico (MOT) e melado. Em seguida, arremessados na vertical por meio da técnica de melado em movimento, fazem um vôo balístico passando duas vezes pela mesma cavidade de microondas. Desse modo, os átomos são submetidos a dois campos oscilatórios separados por uma região livre de campo oscilatório. Por fim, a nuvem atinge a zona de detecção, que verifica as populações em cada um dos níveis de energia $6^{2} S_{1 / 2}(F=3)$ e $6^{2} S_{1 / 2}(F=4)$, estabelecendo a eficácia com que a transição foi estimulada. . . . . . . . . . . . p. 36

8 Seqüência temporal do padrão de freqüência tipo chafariz do CePOF. p.43

9 Imagens do sistema de vácuo do chafariz atômico. Ela é constituída pela câmara de aprisionamento e pela região de vôo livre. A região de vôo livre está situada acima da câmara de aprisionamento. Nela observamos a disposição das cavidades de preparação e interrogação, a blindagem magnética e o conjunto de bobinas de compensação do campo magnético. O sistema de detecção encontra-se a $19 \mathrm{~cm}$ abaixo da câmara de aprisionamento. . . . . . . . . . . p.45

10 Imagem da região de captura e da região de detecção. A região de aprisionamento contém 11 janelas e a região de detecção contém 5 janelas soldadas em tubos sobre a câmara de aprisionamento. Todas as janelas possuem cobertura anti-refletora para infra-vermelho. . . p.46 
11 Disposição das cavidades de interrogação e de preparação soldadas por brasagem ao tubo de vôo livre, formando uma única estrutura rígida do sistema de vácuo. Ao longo do tubo de vôo livre foram posicionadas três cintas térmicas para manter a uniformidade térmica do tubo e três sondas PT100 para medir a temperatura. . . . . . . p.47

12 Disposição da bobina $C$-field, da blindagem magnética e das bobinas de compensação para definir o eixo de quantização dos átomos e evitar que campos magnéticos espúrios mascarem a freqüência da transição relógio. . . . . . . . . . . . . . . . p. . p 48

13 Imagem do sistema de detecção rigidamente acoplada à estrutura de vácuo. Os feixes são produzidos na parte externa da estrutura e a seguir introduzidos por meio de uma das janelas dessa região. . . . . .

14 O solenóide $C$-field e a blindagem magnética. O solenóide é espiralmente enrolado com fio de cobre em torno de um cilindro de aluminio com 3,41 voltas/cm. A blindagem magnética da Fountain é composta por dois cilindros concêntricos separados por uma distância de $5 \mathrm{~cm}$. . . . . . . . . . . . . . . . p. 50

15 Caracterização da bobina C-field. . . . . . . . . . . . . . . p.51

16 Efeito da blindagem magnética sobre o campo magnético local. . . . p.51

17 Fonte de corrente para alimentar a bobina do C-field. . . . . . . . p. 52

18 Diagrama de blocos da fonte de corrente. . . . . . . . p.53

19 Perfil do campo magnético nas vizinhanças da blindagem magnética. p.54

20 Estabilidade temporal do campo magnético local nas vizinhanças da cavidade após a pré-regulagem das bobinas de compensação. . . . . p.54

21 (a) Esquema da disposição das cavidades no tubo da estrutura de vácuo. A cavidade tem geometria retangular com dimensões a na direção $x$ e $b\langle a$ na direção $y$. A onda eletromagnética propaga-se na direção $z$ cuja dimensão d é múltiplo inteiro de $\frac{\lambda}{2}$. (b) Configuração do campo magnético dentro da cavidade para o modo $T E_{102}$. . . . p.56

22 Sintonia da freqüência de ressonância da cavidade como função da temperatura. . . . . . . . . . . . . . p. 58 
23 Esquema utilizado para medir a sintonia da cavidade como função da temperatura. . . . . . . . . . . . . . . . . 58

24 Variação da amplitude da probabilidade de transição como função da potência injetada na cavidade de microondas. Vemos que há diversas oscilações de Rabi entre os dois níveis hiperfinos do estado fundamental. A amplitude máxima corresponde à potência que é necessária para submeter os átomos a dois pulsos $\frac{\pi}{2} \ldots \ldots \ldots$ p. . . . 61

25 Densidade espectral da radiação de corpo negro para quatro temperaturas diferentes. Para o césio, a frequiência do desdobramento hiperfino no estado fundamental, $v_{0}$, e a transição de dipolo elétrico mais baixa permitida, $v_{d}$, estão indicadas. . . . . . . p.63

26 Esquema do sistema de vácuo do chafariz atômico com a posição dos termistores na região de vôo livre. . . . . . . . . . . . p.64

27 Variação da temperatura durante o dia medida através de um dos PT100 sobre o tubo de vôo livre. . . . . . . . . . . . p.65

28 Diagrama esquemático da cadeia de síntese de $9192631770 \mathrm{~Hz}$ para a interrogação dos átomos de ${ }^{133} C s . \ldots \ldots$. . . . . . . 67

29 Níveis de energia da linha $D_{2}$ do ${ }^{133} C s$ com as transições utilizadas para resfriar e detectar os átomos. . . . . . . . . . p.70

30 Visualização geral da mesa óptica. . . . . . . . . . . . . p. 71

31 Diagrama esquemático da mesa óptica do padrão de átomos frios. . p.72

32 Diagrama esquemático com as frequiências de sintonia do feixe de resfriamento obtidas com os AOM de $280 \mathrm{MHz}$ e de $80 \mathrm{MHz}$ posicionados sobre a mesa óptica. $v_{0}$ corresponde à freqüência de transição cíclica $6^{2} S_{\frac{1}{2}}(F=4) \longrightarrow 6^{2} P_{\frac{3}{2}}(F=5) \cdot v_{C O}$ corresponde a freqüuencia de referência, cross-over entre as transições $6^{2} S_{\frac{1}{2}}(F=4) \longrightarrow 6^{2} P_{\frac{3}{2}}(F=5)$ e $6^{2} S_{\frac{1}{2}}(F=4) \longrightarrow 6^{2} P_{\frac{3}{2}}(F=4)$, utilizada para travar o laser mestre. Assim, a frequiência de saída do feixe do MOPA está $154,5 \mathrm{MHz}$ deslocado da transição atômica. Após a dupla passagem pelo modulador de $80 \mathrm{MHz}$, o feixe de resfriamento está deslocado em freqüência da ordem de uma largura de linha natural da transição do ${ }^{133} \mathrm{Cs}$, $\approx 5,3 M H z \ldots \ldots \ldots \ldots \ldots \ldots$ 
33 Orientação dos feixes superiores e inferiores que fazem um ângulo de aproximadamente $35^{\circ}$ com a horizontal e a bobina de aprisionamento está no plano y. . . . . . . . . . . . . p. 75

34 Imagem de átomos capturados na armadilha magneto-óptica. . . . . p. 76

35 (a)Temperatura dos átomos para diferentes valores de deslocamento de frequiência, apenas com MOT. (b)Eficiência de captura para diferentes valores de detuning. . . . . . . . . . . . . p. 77

36 Temperatura dos átomos para diferentes valores de deslocamentos passando da fase de armadilha magneto óptica para a fase de molasses. Durante a fase de MOT a freqüência do laser de resfriamento foi mantida $1,7 \Gamma$ deslocada da transição de ressonância. Número final de átomos para diferentes valores de deslocamentos de freqüência passando da fase de MOT para a fase de melado óptico. p.79

37 (a) Velocidades iniciais obtidas anteriormente com o valor de freqüência de lançamento e com o tempo de vôo dos átomos. A discrepância entre o valor teórico e experimental é atribuído ao não travamento de fase entre os diferentes $\mathrm{VCO}$ s que fazem o lançamento dos átomos. (b)Velocidades iniciais obtidas após a correção do ângulo do braço de lançamento. . . . . . . . . . . . . . p p 81

38 Sinal de TOF para diferentes alturas de lançamento. . . . . . . . p. 82

39 Temperatura dos átomos para diferentes valores de deslocamento de freqüência durante o processo do resfriamento sub-Doppler. . . . . p. 82

40 Temperatura dos átomos para diferentes valores de atenuação de

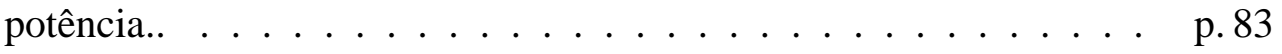

41 Diagrama do sistema de absorção saturada em célula de vapor de ${ }^{133} \mathrm{C} s$ utilizado para travar o laser de diodo na linha $D_{2} \ldots \ldots$. . . p. 86

42 Diagrama esquemático do sistema de travamento do laser de diodo de cavidade estendida. . . . . . . . . . . . . p. 87

43 Diagrama esquemático do controle de travamento de fase e de freqüência entre dois AOMs dos feixes de aprisionamento $\ldots \ldots \ldots$ p. . . . . 88 
44 (a) Sistema de detecção do chafariz atômico do CePOF. Ele está fortemente acoplado ao sistema de vácuo (b) Diagrama esquemático do sistema de detecção. Nele são gerados dois feixes de luz, O primeiro contém apenas a luz do laser mestre, $6^{2} S_{1 / 2}|F=4\rangle \leftrightarrow$ $6^{2} P_{3 / 2}|F=5\rangle$, o segundo é uma composição do laser mestre e do laser de rebombeio, $6^{2} S_{1 / 2}|F=3\rangle \leftrightarrow 6^{2} P_{3 / 2}|F=4\rangle$. Uma parte do feixe mestre é desviado por um cubo polarizador. . . . . . . . . p.92

45 A detecção no chafariz atômico é feita por meio da medida da fluorescência dos átomos por dois feixes de luz laser separados de $6 \mathrm{~mm}$. Um deles é ressonante com a transição $6^{2} S_{1 / 2}|F=4\rangle \leftrightarrow 6^{2} P_{3 / 2} \mid F=$ $5\rangle$ e o outro é uma superposição deste com um feixe de rebombeio $\left(6^{2} S_{1 / 2}|F=3\rangle \leftrightarrow 6^{2} P_{3 / 2}|F=4\rangle \ldots \ldots \ldots \ldots\right.$

46 Sinal de fluorescência dos átomos em queda livre. A região em destaque mostra o efeito de crosstalk entre as duas regiões de detecção. p.93

47 Sinal de fluorescência dos átomos em queda livre após a otimização da coleta do sinal de detecção. A região em destaque mostra a redução do efeito de crosstalk entre as duas regiões de detecção. p.94

48 Número de átomos detectados como função da distância percorrida pelo átomo após o lançamento. Esse número cai em uma ordem de grandeza para distâncias superiores $136,26 \mathrm{~cm}$, isto é, $15,58 \mathrm{~cm}$ acima da primeira cavidade. . . . . . . . . . p. 96

49 Franja de Ramsey obtida com uma velocidade de lançamento é $v_{0}=$ $3,39 \mathrm{~m} / \mathrm{s}$. Os átomos atingem $15,58 \mathrm{~cm}$ acima da cavidade de preparação, passam 17,27 ms durante cada passagem pela cavidade de interrogação e $220,38 \mathrm{~ms}$ na região de vôo livre. . . . . . . . . . . . . p.97

50 Franja central da ressonância de Ramsey com uma largura de aproximadamente $1,4 \mathrm{~Hz} \ldots \ldots \ldots \ldots$. . . . . . . . . . . . . . . . . . . . .

51 Interface do programa de controle do chafariz atômico do CePOF implementado em LabView que mostra também o controle dos deslocamentos de freqüência do laser mestre e a atenuação do sinal de

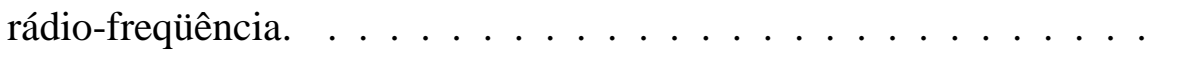


52 Estabilidade calculada através da Variância de Allan como função do tempo de integração e para $T_{C}=5,2 s$ e $Q_{a t}=6,56 \times 10^{10} \mathrm{a}$ estabilidade $\sigma_{y}(\tau)=5,18 \times 10^{-12} \tau^{-1 / 2} \ldots \ldots \ldots \ldots$. . . . . 101

53 Princípio do Resfriamento Doppler. . . . . . . . . . . . . . p. 121

54 a) Resfriamento Doppler no referencial do laboratório; (b) No referencial próprio de um átomo com velocidade $v$. . . . . . . . . . . p. 122

55 Esquema do processo de aprisionamento magneto-óptico sobre uma transição de freqüência $\omega_{0}$. Os feixes de aprisionamento $+k \mathrm{e}-k$ são circularmente polarizados, $\sigma^{+}$e $\sigma^{-}$, de modo que exercem também uma força de aprisionamento. . . . . . . . . . . . . . . . . p. 123 


\section{Sumário}

1 Introdução $\quad$ p. 13

2 Princípios de Operação de um Padrão de Freqüência Atômico p. 19

2.1 Introdução . . . . . . . . . . . . . . . . . . . . . p. 19

2.2 O método de Ramsey de campos separados de interrogação . . . . . p. 22

2.3 Avaliação de um Padrão de Freqüência Atômico . . . . . . . . . . . p. 27

2.4 Estabilidade . . . . . . . . . . . . . . . p. 30

3 Chafariz Atômico de ${ }^{133}$ Cs operado como um Padrão Primário de $\begin{array}{lr}\text { Tempo e Freqüência } & \text { p.33 }\end{array}$

3.1 Introdução . . . . . . . . . . . . . . . p. 33

3.2 Processo Cíclico do Chafariz Atômico . . . . . . . . . . p. 36

3.3 Ciclo de funcionamento do chafariz atômico . . . . . . . . . p.39

4 Sistema de Vácuo do Chafariz Atômico de ${ }^{133}$ Cs $\quad$ p. 44

4.1 Sistema de Vácuo do Chafariz Atômico . . . . . . . . . . . p. 45

4.2 Controle de Campo Magnético . . . . . . . . . . . . . . . p.49

4.3 Cavidade de Microondas . . . . . . . . . . . . . p.53

4.4 Controle de Temperatura . . . . . . . . . . . . . . p. 61

4.5 Sintetizador de Microondas . . . . . . . . . . . . . p. 64

5 Sistema Óptico do Chafariz Atômico r 69

5.1 Introdução . . . . . . . . . . . . . . . . . . . p. 69 
5.2 Montagem Óptica . . . . . . . . . . . . . . . . p.71

5.3 Laser de Diodo de cavidade estendida e o seu sistema de controle . . p.84

5.4 Circuitos de controle e Suprimento de Rádio-Freqüência para Moduladores Acusto-Ópticos . . . . . . . . . . . . p. 87

6 Detecção e Controle no Chafariz de Átomos p.90

6.1 Introdução . . . . . . . . . . . . . . p. 90

6.2 Montagem Óptica do Sistema de Detecção . . . . . . . . . . . . . p.91

6.3 Estabilidade de Freqüência do Chafariz de Átomos . . . . . . . . . p.98

6.4 Exatidão do Chafariz Atômico . . . . . . . . . . . . . . . p. 102

6.4.1 Efeito Gravitacional e o Efeito Doppler de segunda ordem · p. 102

6.4.2 Radiação de Corpo Negro . . . . . . . . . . . . . . p. 104

6.4.3 Efeito Zeeman de Segunda Ordem . . . . . . . . . . . . p. 104

7 Conclusão e Próximos Passos 106

$\begin{array}{ll}\text { Referências } & \text { p. } 110\end{array}$

$\begin{array}{ll}\text { Apêndice A - Probabilidade de Ramsey } & \text { p. } 115\end{array}$

A.1 Interrogação de Ramsey . . . . . . . . . . . . . . . . . p. 115

A.2 Cálculo de Erro do Deslocamento da Frequiência Atômica . . . . . . p. 118

Apêndice B - Manipulação Óptica dos Átomos em um Chafariz de Átomos p. 120

B.1 Resfriamento Doppler . . . . . . . . . . . . . . . p. 120

B.2 Aprisionamento Magneto Óptico . . . . . . . . . . . . . . . p. 122

B.3 Resfriamento sub-Doppler por Efeito Sisyphus . . . . . . . . . . . p. 124

Apêndice C - Constantes Fundamentais da Física e do Átomo de ${ }^{133}$ Cs $\quad$ p. 126

C.1 Constantes Físicas . . . . . . . . . . . . . . . . p. 126 
C.2 Átomo de ${ }^{133} \mathrm{Cs} \ldots \ldots \ldots \ldots \ldots$. . . . . . . . . . . 127 


\section{$1 \quad$ Introdução}

Metrologia científica de tempo e frequiência deixou de ser uma opção para ser uma necessidade dentro da sociedade moderna. A capacidade de medir o tempo com precisão é o fator determinante para diversos desenvolvimentos técnicos e industriais. Áreas como telecomunicações, informática e aviação não existem nos dias atuais sem metrologia de tempo e frequiência. O Brasil, como país em franco crescimento, deve se voltar para este campo com seriedade e maturidade. Para a consolidação dessa área é necessário haver um esforço conjunto em avançar e desenvolver em suas diversas áreas. Essa tese é parte deste esforço onde colocamos pela primeira vez em operação em nosso laboratório um chafariz atômico como padrão primário de tempo e freqüência.

Ao longo da história, diversos instrumentos para medir a passagem do tempo foram desenvolvidos. Um marco no desenvolvimento dos relógios de precisão aconteceu em 1714, quando após um desastre marítimo atribuído à imprecisão dos instrumentos de medida na época para determinar a posição do navio no mar, o parlamento Britânico lançou o Ato da Longitude. Uma vez que a longitude pode ser determinada a partir da posição do Sol e das estrelas com o auxílio de um bom relógio, ganharia um prêmio aquele que desenvolvesse um cronômetro para determinar a longitude no mar com meio grau de precisão (1).

A navegação sempre foi um dos maiores estímulos para a busca de relógios mais precisos. Atualmente, ela continua sendo uma das principais utilizações desses instrumentos de medida, mas não é a única a se beneficiar com a aplicabilidade de sinais de frequiência ultra-estáveis. A importância dos relógios e osciladores de precisão 
abrange diversas áreas da ciência e tecnologia, desde os testes da relatividade geral até a sincronização dos sistemas de comunicação digital, além da sua utilização para determinar outras unidades fundamentais como o metro e o volt.

A principal característica de um bom relógio é a de fornecer um sinal periódico e constante ao longo do tempo. A freqüência de qualquer evento arbitrário, como a oscilação mecânica de um pêndulo ou a oscilação quântica de um dipolo atômico, pode ser usada para definir a unidade básica de tempo, que é o segundo.

Para associar o átomo a um bom oscilador, vamos imaginar o caso de um átomo com dois níveis de energia $E_{1}$ e $E_{2}$, onde $\left.E_{2}\right\rangle E_{1}$. Através dos estudos de Bohr, em meados de 1910, descobriu-se que os níveis de energia dos átomos são quantizados e a diferença de energia que separa os seus níveis é dada pela relação de Bohr, $h v_{0}=E_{2}-$ $E_{1}$ (2) (3). Quando o sistema é submetido a uma radiação eletromagnética, esse campo interage com a distribuição de carga do sistema de modo a promover uma transição entre os estados atômicos. Quando a freqüência de radiação for exatamente igual à frequiência de Bohr, a probabilidade de ocorrer esta transição é máxima. Essa relação entre freqüência e energia, combinada com o fato dos átomos absorverem/emitirem somente certos quanta de energia, é um fenômeno bem importante para os relojoeiros, pois sugere que os átomos podem ser usados como osciladores de referência (1) e a frequiência de ressonância, absorvida ou emitida, é uma propriedade intrínseca do átomo. Esta propriedade confere ao oscilador atômico uma extraordinária reprodutibilidade, além de uma exatidão jamais alcançada por qualquer outro oscilador macroscópico.

Os átomos escolhidos como referência em um padrão de freqü6encia atômico podem ser considerados como um sistema de dois níveis, onde é possível prepará-los em um dos dois estados, excitar coerentemente a transição entre dois níveis de energia e finalmente detectar e medir a ressonância atômica $\left(v_{0}\right)$. As transições excitadas devem apresentar como característica principal um alto fator de qualidade $(Q)$ o que permite obter a precisão e a exatidão desejada de um oscilador atômico. O fator de qualidade $\mathrm{Q}$ é dada pela relação $Q=\frac{v_{0}}{\Delta v}$, onde $v_{0}$ é a freqüência de ressonância do átomo escolhido 
e $\Delta v$ corresponde a largura de linha com que a transição é medida. Uma boa escolha são as transições de dipolo magnético onde as freqüências envolvidas estão na região da microondas. Além disso, o tempo de vida do momento magnético em um dado estado é relativamente longo, o que permite ao átomo desenvolver diversos ciclos de oscilação entre dois níveis antes de serem perturbados por um agente externo.

A escolha dos átomos de ${ }^{133} C s$ como base para a definição do segundo, feita em 1967 e fundamentou-se no conhecimento acumulado que se dispunha desse átomo na época e a tecnologia disponível para se medir o espectro de ressonância. Ele apresentava diversas vantagens sobre outros átomos ou moléculas. Feixes atômicos de césio são fáceis de serem produzidos e detectados e possuem baixa sensibilidade a campos magnéticos externos (ele é o elemento menos sensível do grupo dos alcalinos). Além disso, a diferença de energia entre os seus subníveis Zeeman da estrutura hiperfina do estado fundamental é a maior de todas entre os átomos alcalinos, com freqüência de ressonância de $9192631770 \mathrm{~Hz}$, e essa frequiência apresentava condições compatíveis com o estado da arte de geração de microondas, com características desejadas para interrogar os átomos em um padrão de freqüência atômico.

Uma vez que os átomos de césio apresentam alta freqüência de ressonância, o fator de qualidade atômico passa a ser determinado pela largura de ressonância observada onde um alto valor de $Q$ é alcançado com um alto valor de $v_{0}$ e baixa largura de linha $\Delta v$. No entanto, a largura de linha é determinada pela incerteza advinda do princípio de incerteza de Heisenberg, $\Delta E \Delta t \geq \frac{\hbar}{2}$, onde t é o tempo de duração da observação de uma transição. Dessa forma conclui-se que uma das maneiras de melhorar cada vez mais um padrão de frequiência atômico é aumentar o tempo de interação do átomo com a radiação eletromagnética. Na prática, no entanto, esse aumento irrestrito está limitado por diversas dificuldades técnicas como o de manter a intensidade do feixe atômico ao longo de todo o comprimento $l$ de uma região de interação e, principalmente, o de manter uniforme o campo magnético estático sentido pelos átomos, durante o processo de interrogação, importante para manter sua freqüência de ressonância ao longo da 
cavidade.

Uma forma de contornar o problema foi desenvolvida em 1950 por N.F. Ramsey através do método de dois campos oscilatórios separados (4-6). Nesse método de interrogação, os átomos estão efetivamente acoplados a duas perturbações oscilatórias durante um tempo $\tau$ e separadas por um intervalo de tempo $T$, $\operatorname{com} \tau \ll T$. A probabilidade de transição como função do deslocamento de freqüência medida por meio desse método de interrogação é conhecida como Franja de Ramsey, e a sua largura de linha a meia altura vale $\Delta v=\frac{1}{T}$. Quanto maior for o $T$, mais sensível será a interrogação dos átomos discriminados, e cada vez mais a freqüência é resolvida.

Ao trabalharmos com transições de dipolo magnético, como é o caso dos átomos de ${ }^{133}$ Cs utilizados para reproduzir o segundo, operamos o padrão de freqüência atômico em temperaturas usuais entre $30^{\circ} \mathrm{C}$ e $60^{\circ} \mathrm{C}$, dependendo do átomo. A diferença de energia entre os níveis hiperfinos do estado fundamental escolhido como referência encontra-se na faixa de microondas o que é menor que a sua energia térmica. Dessa forma, a população dos átomos no ensemble estará igualmente distribuída entre os dois níveis hiperfinos do estado fundamental. Como o sinal de ressonância medido é proporcional à diferença de população, a relação sinal ruído, $(S / N)$ será muito pequena e a estabilidade do padrão de freqüência atômico é prejudicada caso nenhum processo para criar uma diferença de população entre os níveis atômicos antes que estes entrem na região de interrogação (7). Uma forma de se conseguir popular um dos níveis de energia do átomo às custas do outro é utilizando-se fontes de luz coerentes e monocromáticas através de um processo de bombeamento óptico (8). Nos padrões de freqüência atômicos de césio essa técnica só foi introduzida em 1970 com o advento dos lasers de estado sólido (9) e esses padrões operados opticamente apresentaram performances superiores aos instrumentos de medida disponíveis na época.

Com o surgimento das técnicas de resfriamento atômico (9-11) foi possível impulsionar o desenvolvimento de novos padrões de freqüência que operam com feixes a baixíssima velocidade (12). Neste caso utiliza-se um arranjo de três pares de feixes 
laser perpendiculares entre si e um gradiente de campo magnético para resfriar átomos de césio a temperaturas da ordem de $\mu \mathrm{K}$. Além de trabalhar com feixes a baixíssima velocidade, no chafariz o método de Ramsey de dois campos oscilatórios separados é aplicado através de uma única cavidade de microondas posicionada acima da região de aprisionamento magneto-óptico. Dessa forma, os átomos são lançados verticalmente para cima e iniciam um vôo balístico onde passam uma vez pela cavidade de microondas, atingem um ápice e finalmente, pela ação da gravidade, caem passando novamente através da mesma cavidade de microondas.

De 1950 até final da década de $80(6,12)$ diversas foram as tentativas em se operar um chafariz atômico (13). O primeiro chafariz a átomos de ${ }^{133} C s$ operado como um padrão primário de freqüência foi desenvolvida pelo grupo do Observatório de Paris na França (14) seguido pelo chafariz atômico NIST-F1 do National Institute of Standards and Technology (NIST) em Boulder nos USA (15) e o chafariz CSF1 do Physikalisch-Technishe Bundesanstalt (PTB) em Braunschweig/Alemanha (16). Nessa última década outros países passaram a fazer parte dos que possuem um padrão primário de frequiência tipo chafariz atômico. Entre esses padrões podemos citar o CsF1 do Instituto Elettrotecnico Nazionale (IEN) (17) de Torino/Itália, o CsF1 do National Physical Laboratory em Teddington na Inglaterra (NPL)(18), além de países como o Japão (19), a China (20) e a Corea (21).

Com todos os avanços na física atômica e da eletrônica do último século, foi possível aumentar a estabilidade dos padrões de freqüência operados na região de microonda em duas ordens de grandeza. Uma nova geração de padrões de frequiência que operam em regime óptico promete estabilidades ainda maiores, uma vez que a freqüência de ressonância em operação é muito maior que as de microondas, $\frac{f_{\text {optico }}}{f_{\text {microonda }}} \cong$ $10^{5}$ (22). Atualmente, os padrões de freqüência atingem tal qualidade e tornam possíveis realidade testes de física fundamental, como em relatividade geral (23) e a variação de constantes fundamentais (24). Dessa forma, os relógios atômicos passam a ser essenciais não apenas para o desenvolvimento tecnológico mas também para superar as atuais 
fronteiras do conhecimento.

Em nosso país, esse tipo de pesquisa teve início há nove anos, com a construção do primeiro relógio atômico a feixe térmico de césio no Brasil (no CePOF - Instituto de física de São Carlos) (25-28), seguida pela construção de um padrão de freqüência tipo chafariz $(29,30)$ e o de expansão de uma nuvem de átomos frios $(31,32)$. Este último deu início à linha de padrões de frequiência atômicos compactos e de alto desempenho.

A proposta para este trabalho de doutorado é a concretização de um chafariz atômico operado como um padrão primário de freqüência. Este projeto teve início há seis anos $(30,33)$. Diversas mudanças foram implementadas no sistema experimental do chafariz atômio nesses últimos anos, como será descrito a seguir. Após a otimização do sistema experimental do chafariz atômico somos capazes de obter franjas de Ramsey com $1,4 \mathrm{~Hz}$ de largura e uma estabilidade a curto prazo de $\sigma_{y}(\tau)=6,97 \times 10^{-12} \tau^{-1 / 2}$. Com este desenvolvimento também deixamos o patamar inicial desta área e passamos a ter capacidade para experimentos mais ousados. 


\section{Princípios de Operação de um Padrão de Freqüiência Atômico}

\subsection{Introdução}

Os padrões de freqüência atômicos utilizam a freqüência de transição natural entre dois níveis de energia de um átomo de referência. Esses níveis são excitados coerentemente para gerar um sinal de saída periódico ao longo do tempo. Para gerar esse sinal de saída podemos utilizar dispositivos de medida ativos ou passivos. Os sistemas ativos baseiam-se na amplificação da radiação eletromagnética por emissão estimulada da frequiência natural dos átomos proposta por Albert Einstein em 1917. Nos padrões passivos, o meio atômico discrimina a freqüência do oscilador local através da medida da taxa de probabilidade de transição entre dois níveis de uma transição atômica (34), como ilustrado na figura 1 . Se a frequiência sintetizada estiver em ressonância com a frequiência de transição entre os dois níveis em questão, os átomos irão transitar para o estado $E_{2}$. A seguir um sistema de detecção é usado para medir a taxa de probabilidade de transição como função da frequiência. Por meio da resposta atômica, calcula-se um sinal de erro que realimenta o oscilador externo de modo a travar a sua freqüência sempre no máximo da freqüência de ressonância atômica. O processo é repetitivo e a cada nova interação o oscilador externo é corrigido e o erro minimizado. Dessa forma dizemos que num padrão passivo de freqüência, a freqüência $v$ de um oscilador externo é estabilizado na freqüência de ressonância de um átomo de referência. O sinal de ressonância medido num padrão de freqüência atômico não é exatamente igual à freqüência natural dos átomos, mas deslocada por diversos efeitos, sendo seu valor 
efetivo dado por

$$
v(t)=v_{0} \cdot(1+\epsilon+y(t)) .
$$

onde $v_{0}$ designa a freqüência de ressonância entre os dois níveis atômicos que estabelecem a transição relógio do átomo não perturbado. $O$ termo $\epsilon$ representa o desvio da freqüência de ressonância causado por fatores que afetam a característica natural do átomo não perturbado (campos magnéticos espúrios, radiação de corpo negro, colisões atômicas) ou que induzam perturbações durante o processo de excitação (campos de excitação não uniformes). A incerteza em $\epsilon$ representa os deslocamentos de frequiência do relógio atômico e mede o quão bem a freqüência atômica é medida frente aos efeitos que a perturbam. A outra grandeza $y(t)$ representa as flutuações de frequiência desse sinal e determina a estabilidade de freqüência do relógio. Experimentalmente, essas flutuações de frequiência são medidas na forma de uma variância e a estabilidade $y(t)$ tem uma dependência com os parâmetros

$$
\sigma_{y}(\tau) \propto \frac{1}{Q_{a t}} \cdot \frac{1}{\frac{S}{R}}
$$

onde $\frac{S}{R}$ é a razão sinal-ruído e $Q_{0}=\frac{v_{0}}{\Delta v}$ é o fator de qualidade da ressonância atômica. Na prática, um bom relógio deve reunir o melhor destes dois parâmetros. Em 1967, na Conferência Geral de Pesos e Medidas optou-se pelos átomos de ${ }^{133}$ Cs para definir o segundo como a duração de 9192631770 períodos da radiação correspondente à transição entre dois níveis hiperfinos do estado fundamental dos átomos de ${ }^{133}$ Cs (35). Esta transição envolve os seguintes estados: $6^{2} S_{\frac{1}{2}}\left|F=3, m_{F}=0\right\rangle \rightarrow 6^{2} S_{\frac{1}{2}} \mid F=4, m_{F}=$ $0\rangle$. Os estados hiperfinos são originados pela interação do dipolo do elétron de valência destes átomos com o seu núcleo $(9,36)$ e portanto seu tempo de vida é bastante alto, favorecendo o fator de qualidade atômico, $Q_{a t}$. Os átomos de ${ }^{133} C s$ têm spin nuclear $\frac{7}{2}$ e dois níveis hiperfinos de momento angular $F=3$ e $F=4$, com sete e nove subníveis magnéticos degenerados, respectivamente. O espectro Zeeman desse átomo tem sete transições $\sigma\left(\Delta m_{F}=0\right)$ e quatorze transições $\pi\left(\Delta m_{F}= \pm 1\right)$. A transição $6^{2} S_{\frac{1}{2}}\left|F=3, m_{F}=0\right\rangle \leftrightarrow 6^{2} S_{\frac{1}{2}}\left|F=4, m_{F}=0\right\rangle$, independe do campo magnético em 


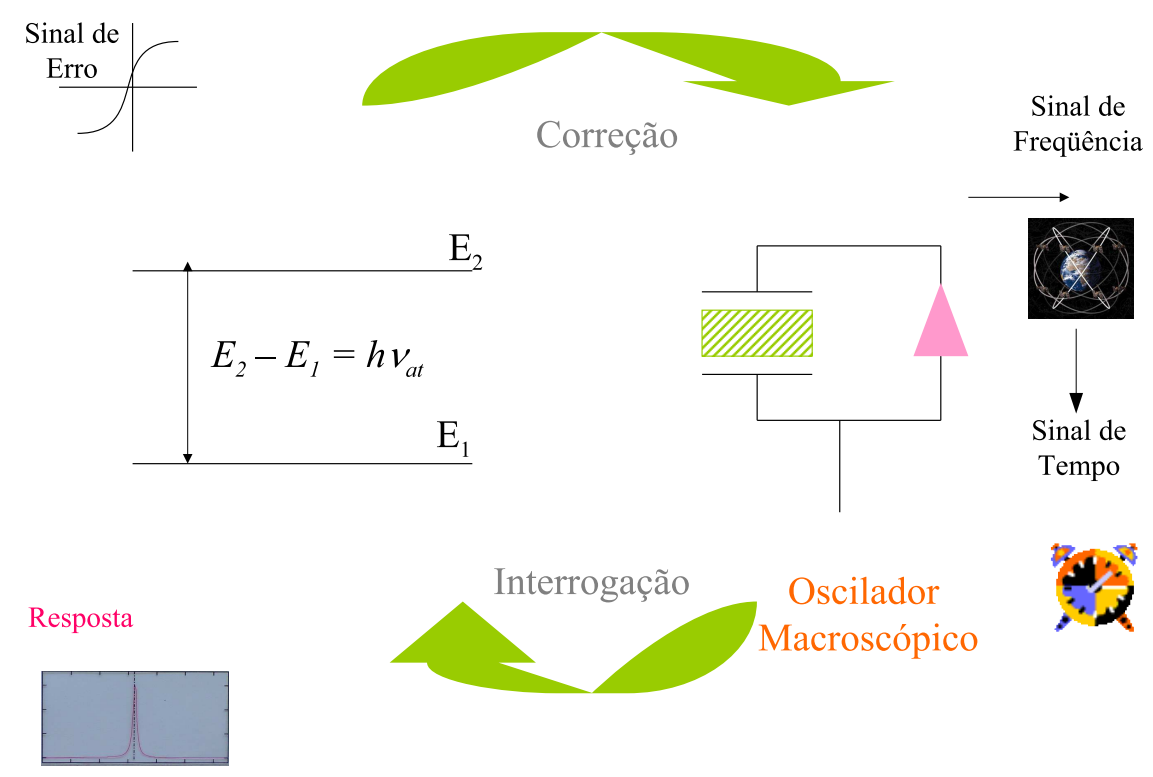

Figura 1: Princípio de funcionamento de um padrão de freqüência atômico passivo. A freqüência do oscilador macroscópico, $v$, é estabilizada na freqüência de ressonância através de um sistema de realimentação: o oscilador externo fornece um sinal de interrogação a um ensemble atômico e um sistema eletrônico coleta o sinal de resposta emitido pelo átomos e calcula um sinal de erro. Esse sinal de erro é usado para corrigir a frequiência do oscilador local. O processo é repetitivo e a freqüência do oscilador local é ajustada para um valor mais próximo da freqüência natural atômica.

primeira ordem e portanto foi estabelecida como a frequiência que define o segundo. Os níveis de energia mais relevantes no ${ }^{133}$ Cs são mostrados na figura 2. As transições ópticas utilizadas em nosso sistema de padrão de freqüência atômico de ${ }^{133} C s$ são $6^{2} S_{\frac{1}{2}}\left|F=4, m_{F}=0\right\rangle \leftrightarrow 6^{2} P_{\frac{3}{2}}\left|F=5, m_{F}=0\right\rangle$ e $6^{2} S_{\frac{1}{2}}\left|F=3, m_{F}=0\right\rangle \leftrightarrow 6^{2} P_{\frac{3}{2}} \mid F=$ $\left.4, m_{F}=0\right\rangle$, como indicadas na figura 2. A primeira delas é uma transição cíclica fechada e permite vários ciclos de absorção e emissão espontânea tornando-a uma transição atraente para ser utilizada no resfriamento Doppler e também para a detecção dos átomos. No entanto, durante o processo de aprisionamento magneto-óptico, os átomos podem decair para o estado $6^{2} S_{\frac{1}{2}}\left|F=3, m_{F}=0\right\rangle$ de forma que esses átomos não participam mais do processo de interrogação no chafariz. Para que esses átomos continuem participando do processo de resfriamento, e conseqüentemente das fases de interrogação e detecção, um feixe de rebombeio ressonante com a transição $6^{2} S_{\frac{1}{2}} F=$ $3 \leftrightarrow 6^{2} P_{\frac{3}{2}} F=4$ é utilizado. Esse processo será detalhado nos próximos capítulos. 


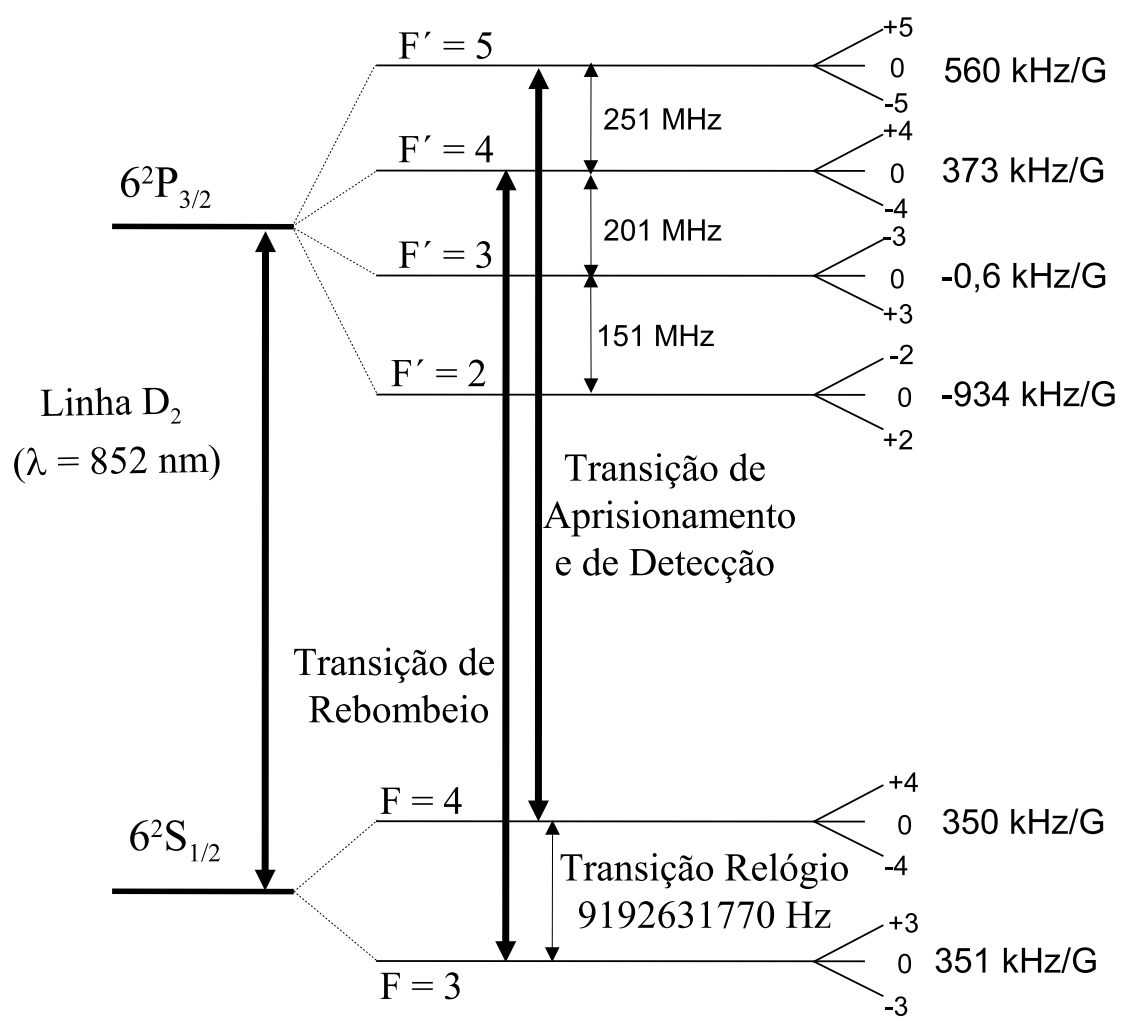

Figura 2: Diagrama dos níveis de energia dos átomos de ${ }^{133} C s$. A freqüência relógio corresponde à transição hiperfina $6^{2} S_{\frac{1}{2}}\left|F=3, m_{F}=0\right\rangle \leftrightarrow 6^{2} S_{\frac{1}{2}}\left|F=4, m_{F}=0\right\rangle$ do estado fundamental. Nela também estão esquematizadas as transições ópticas mais relevantes utilizadas em um chafariz atômico, como a transição utilizada no aprisionamento magnetico-óptico, na detecção e no rebombeio dos átomos.

\subsection{O método de Ramsey de campos separados de in- terrogação}

Como já mencionado, um padrão de freqüência atômico passivo é composto por três partes principais: um oscilador externo, um meio atômico que serve de discriminador e um sistema de realimentação que corrige a freqüência do oscilador local na referência atômica. De acordo com as normas internacionais, para a reprodução primária do segundo, o meio atômico é composto pelos átomos de ${ }^{133} C s$ e os níveis considerados para a transição relógio são $6^{2} S_{\frac{1}{2}}\left|F=3, m_{F}=0\right\rangle \leftrightarrow 6^{2} S_{\frac{1}{2}}\left|F=4, m_{F}=0\right\rangle$.

A radiação de microondas usada para interrogar os átomos aplicada por meio da interação de Ramsey de dois campos oscilatórios separados $(5,6)$, onde os átomos interagem duas vezes com a radiação eletromagnética separadas por uma região livre de 


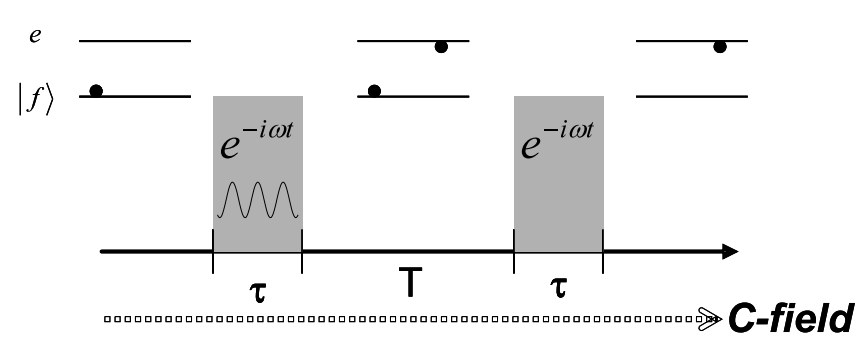

Figura 3: Método de Ramsey de campos separados de interrogação. O átomo interage com a primeira região de interação durante um tempo $\tau$, passa por uma região livre de microondas durante um intervalo de tempo $\mathrm{T}$ e finalmente, em $T+\tau$ os átomos interagem novamente com o campo de microondas. Ao longo de toda a região de interrogação os átomos sentem um campo magnético estático paralelo ao campo magnético oscilatório que define seu eixo de quantização.

qualquer perturbação oscilatória. Nesta configuração, o átomo interage com a primeira região de interação durante um tempo $\tau$, passa por uma região livre de microondas, onde o estado quântico interno evolui livremente durante um intervalo de tempo T e finalmente, em $T+\tau$, os átomos interagem novamente com o campo de microondas, de tal forma que a coerência de fase entre os dois campos oscilatórios é preservada.

Ao longo da região de interrogação, um campo magnético estático e de baixa amplitude é aplicado para separar os níveis de energia dos átomos por efeito Zeeman. A transição relógio dos átomos de césio acontece entre os níveis hiperfinos do estado fundamental que não dependem do campo magnético estático em primeira ordem $\left(m_{F}=0\right)$. Em segunda ordem, a dependência desses níveis com o campo magnético estático é dado pelo fórmula de Breit-Rabi:

$$
\Delta v=\frac{1}{2 v_{C s}} \frac{\left(g_{J}+g_{I}\right)^{2} \mu_{B}^{2}}{\hbar} B_{0}^{2}=427,45 H z T^{-2} \times 10^{8} B_{0}^{2}
$$

onde $B_{0}^{2}$ é a amplitude do campo magnético estático e é dado em unidades de $T^{2}, v_{C s}$ é a freqüência de ressonância do átomo de césio, $g_{J}$ e $g_{I}$ são o fator giromagnético eletrônico e nuclear, $\mu_{B}$ é o magneto de Bohr (ver tabela do Apêndice C) e $\hbar$ é a constante de Planck dividido por $2 \pi$ (tabela do Apêndice C).

A polarização do campo magnético oscilatório é paralelo à direção do campo magnético estático de forma que nessa configuração ele privilegia as transições $\Delta F=$ 
\pm 1 e $\Delta m_{F}=0$, respeitando as regras de seleção para as transições de dipolo magnético.

O sinal resultante desse método de interrogação é a superposição de uma ressonância estreita denominada de franja de Ramsey sobreposta a um pedestal alargado conhecido como pedestal de Rabi como mostrado na figura 4. O pedestal de Rabi responde pela probabilidade do átomo transitar do estado fundamental $|f\rangle$ para o estado excitado $|e\rangle$ na primeira zona de interrogação e não na segunda mais a probabilidade dele transitar na segunda região de interrogação e não na primeira. Já a oscilação mais estreita observada na figura 4 vem da região de vôo livre dos átomos. Os átomos entram na primeira região de interação sem qualquer coerência mas com uma diferença de população criada na fase de preparação, e saem para a região de vôo livre com uma coerência dada pela primeira interação do átomo com o campo oscilatório. Assim, a função de onda que descreve o átomo na saída dessa região está numa superposição coerente entre os dois níveis de energia do estado fundamental. Na região de vôo livre, os átomos não tem o seu estado perturbado por um campo magnético oscilatório, mas sentem um campo magnético estático de magnitude $B_{0}$ ao longo de todo o percurso. Devido a esse campo magnético estático, a fase dos átomos evolui de acordo com a freqüência inerente do átomo denominada de freqüência de Larmor. Dessa forma, a função de onda do átomo adquire um deslocamento de fase com relação ao campo de interrogação, e o número de oscilações observadas no sinal de ressonância do padrão de freqüência atômico dependerá do número de multiplos inteiros de $2 \pi$ de oscilações da fase, até o átomo entrar novamente na segunda região de interação. Nessa região, os átomos são novamente excitados coerentemente pelo campo magnético oscilatório.

A probabilidade dos átomos transitarem do estado fundamental $|f\rangle$ para o estado excitado $|e\rangle$ em função da frequiência é dada pela equação 2.4 (ver Apêndice A.1) $(4,37)$,

$$
P(\tau)=\frac{4 b^{2}}{\Omega^{2}} \sin ^{2} \frac{1}{2}(\Omega \tau)\left[\frac{\Omega_{0}}{\Omega} \sin \frac{1}{2}(\Omega \tau) \sin \frac{1}{2}\left(\Omega_{0} T+\phi\right)-\cos \frac{1}{2}(\Omega \tau) \cos \frac{1}{2}\left(\Omega_{0} T+\phi\right)\right]^{2}
$$

onde $b$ é a freqüência de Rabi, $T$ é o tempo entre as duas interações com o campo 
oscilatório, $\tau$ é o tempo de interação, $\Omega_{0}=\omega-\omega_{0}$ é a diferença entre a freqüência de interrogação e a freqüência angular de ressonância, $\phi$ é a diferença de fase entre os campos nas duas regiões e $\Omega^{2}=b^{2}+\Omega^{2}$. A freqüência de Rabi $b$ é dada por $b=\frac{\mu_{B} B}{\hbar}$, onde $\mu_{B}$ é o magneton de Bohr, e caracteriza a freqüência com que o campo oscilante faz evoluir o estado quântico dos átomos, sendo dado em unidades de freqüência angular. Vamos considerar a radiação eletromagnética em ressonância com a transição atômica, isto é, $\Omega_{0}=0$ e $\omega=\omega_{0}$, de forma que a probabilidade de transição, $P(\tau)$ será máxima. Assumindo os seguintes valores $\phi=0$ e $\Omega_{0}=0(3,6,38)$, na equação 2.4, obtemos

$$
P(\tau)=4 \sin ^{2} \frac{1}{2}(b \tau) \cos ^{2} \frac{1}{2}(b \tau)=2 \sin ^{2}(b \tau)
$$

e $P(\tau)$ é uma função simétrica com relação à posição da origem $\omega_{0}$. Da equação 2.5 vemos que a evolução dos estados atômicos na ressonância depende da amplitude de oscilação. A probabilidade de transição dada pela equação 2.5 é máxima quando,

$$
b \tau=\left(n+\frac{1}{2}\right) \pi
$$

Normalmente utilizamos o menor valor ótimo de $b$, logo $b \tau=\pi / 2$. Na figura 4 mostramos a probabilidade de transição como função da modulação de frequiência para $b \tau=\frac{\pi}{2}$. A largura à meia altura da franja é dada por,

$$
\Delta v \cong \frac{\pi}{T}=\frac{\pi v}{L}
$$

onde $v$ é a velocidade dos átomos, e $L$ é a distância percorrida pelos átomos na região livre de qualquer perturbação oscilatória.

Para travar a freqüência do oscilador macroscópico na freqüência de ressonância dos átomos aplica-se uma modulação quadrada em torno da freqüência de transição atômica, cuja freqüência de modulação é $\frac{1}{2 T_{c}}$, onde $T_{c}$ é o tempo de ciclo, e a amplitude de modulação $v_{m}$ é ajustada para obter um sinal à meia altura da ressonância atômica, $v_{m}=\frac{1}{T}$, com $\mathrm{T}$ sendo o tempo de trânsito dos átomos na região de vôo livre. A modulação da franja de Ramsey central à meia altura está esquematizada na 


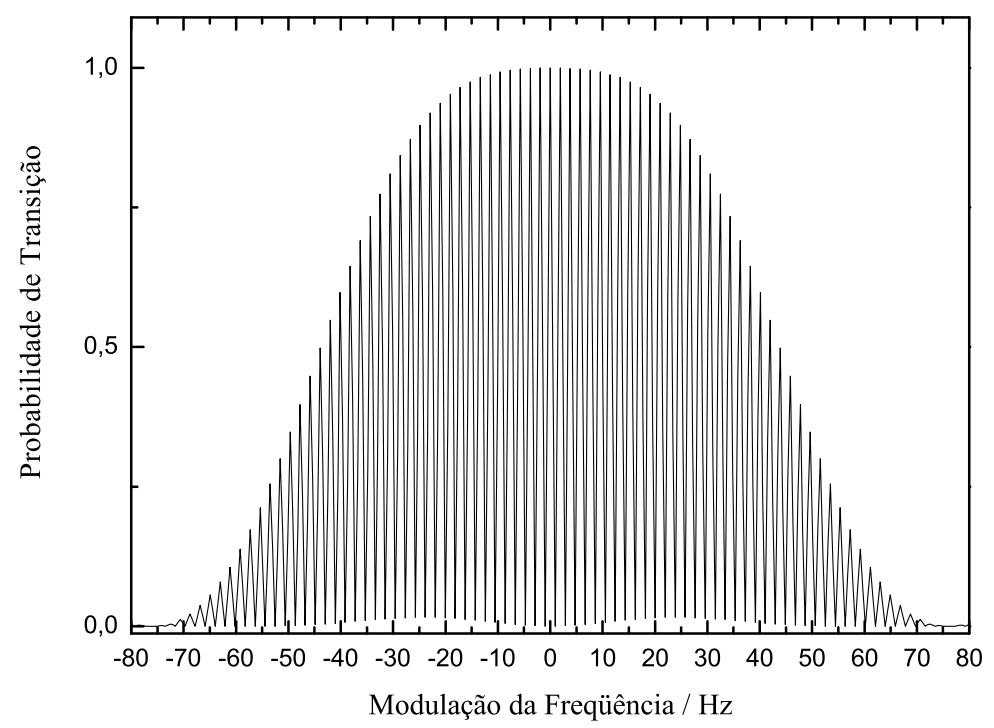

Figura 4: Franja de Ramsey típica obtida em um padrão de freqüência atômico tipo chafariz para um pulso $b=\frac{\pi}{2}$, quando $T=360 \mathrm{~ms}$ e $\tau=12 \mathrm{~ms}$.

figura 5. Por meio desta vemos que durante um ciclo de operação, a probabilidade de transição, $\delta P_{-}$, medida a esquerda de $v_{0}$ corresponde ao intervalo de freqüência $v_{-m}$ até $v_{0}$ e no próximo ciclo, medimos a probabilidade de transição, $\delta P_{+}$, a direita de $v_{0}$ correspondendo ao intervalo de freqüência $v_{0}$ até $v_{+m}$, de modo que é possivel analisar cuidadosamente cada um dos lados da franja de Ramsey central. Como $\delta P_{-}$e $\delta P_{+}$são medidas à meia altura da franja central correspondem ao igual balanço da população dos átomos nos estados $|f\rangle$ e $|e\rangle$ e, portanto, ela apresenta a maior sensibilidade a quaisquer flutuações de freqüência. Nas condições ideais de operação, temos

$$
P\left(\delta v_{0}+v_{m}\right)=P\left(\delta v_{0}-v_{m}\right)
$$

Procedendo de acordo com os cálculos mostrados no Apêndice A.2, o deslocamento de frequiência é dado por

$$
\delta v=\frac{\left(-\delta P_{+}-\delta P_{-}\right)}{\pi T}
$$

A partir da equação 2.9 gera-se um sinal de erro que será utilizado para corrigir a freqüência do oscilador local. Após vários ciclos de correção, o sinal de erro tende 
a se anular e a freqüência do sintetizador de microonda está travado no máximo da ressonância atômica.

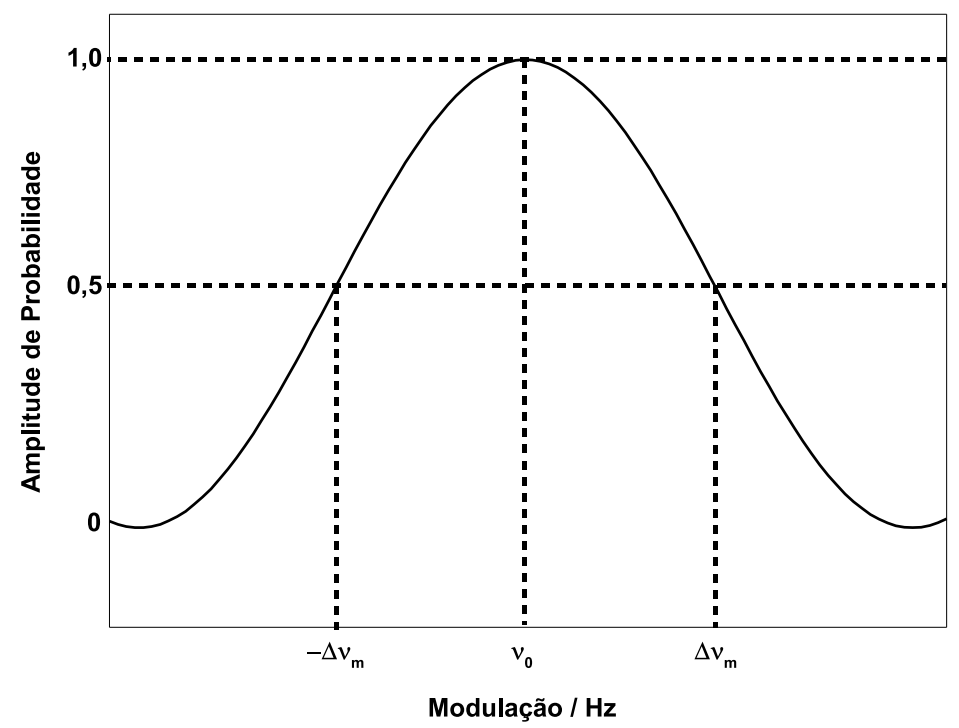

Figura 5: Franja central obtida com um padrão de freqüência atômico tipo chafariz. A freqüência relógio é obtida através da escravização da franja central ao efetuar uma modulação em torno da freqüência, $v_{0}$, a meia altura.

\subsection{Avaliação de um Padrão de Freqüência Atômico}

O segundo foi definido baseado na transição hiperfina entre os dois níveis do estado fundamental dos átomos de ${ }^{133} \mathrm{Cs}$ quando estes se encontram em repouso, isolados e no espaço livre $(39,40)$. Tais condições não são satisfeitas em um padrão de freqüência atômico real, onde ocorre a reprodução do segundo. Esta freqüência é deslocada por uma quantidade $\epsilon$, como mostrado na equação 2.1 e ela é caracterizada pela soma dos $\epsilon_{i}$ de cada um dos efeitos que deslocam a transição relógio. Cada um desses efeitos tem uma incerteza associada a sua medida, $\pm \sigma_{i}$.

Tais deslocamentos podem ser generalizados na forma de uma expressão, válida para os diversos deslocamentos de freqüência que afetam a transição relógio, como 
calculado em (40-42), e dada pela expressão 2.10

$$
v_{d}=\frac{\int g(\tau) A\left(\omega_{m}, b, \tau\right) f(\tau), \mathrm{d} \tau}{2 \pi \int A\left(\omega_{m}, b, \tau\right) f(\tau), \mathrm{d} \tau}
$$

onde $A\left(\omega_{m}, b, \tau\right)$ representa a probabilidade de transição não perturbada, $g(\tau)$ representa a quantidade de freqüência deslocada por cada efeito e $f(\tau)$ é a distribuição de velocidade. Os principais efeitos sistemáticos que deslocam a freqüência de transição relógio medida por um padrão de freqüência atômico estão listadas abaixo:

1. Efeito Zeeman de Segunda ordem. Ele é induzido por um campo magnético estático conhecido por $C$-field. O C-field tem a função de levantar a degenerescência dos níveis hiperfinos do estado fundamental e definir o eixo de quantização atômico de modo a privilegiar a transição relógio. A dependência da transição relógio com o campo magnético estático é quadrática e a incerteza de sua freqüência é determinada baseada nos dados experimentais da intensidade média do campo magnético estático, sua não homogeneidade e sua estabilidade temporal.

2. Radiação de Corpo Negro. Durante o vôo balístico, os átomos experimentam uma radiação em equilíbrio térmico com a temperatura $\mathrm{T}$ da região de interrogação e o sistema de vácuo. Essa radiação dá origem a uma densidade espectral de potência equivalente à radiação de corpo negro e induz um deslocamento de frequiência devido aos efeitos Stark e Zeeman AC não ressonantes.

3. Efeito Colisional. O deslocamento de freqüência colisional é devido à colisão entre átomos frios de ${ }^{133} C s$ na nuvem e com os átomos do vapor de fundo. Ela tem dependência linear com a densidade média dos átomos na nuvem entre as duas regiões de interação.

4. Efeito Gravitacional. Este efeito é devido à variação da energia potencial gravitacional terrestre para diferentes altitudes em que os padrões de freqüência atômicos se encontram. 
5. Rabi Pulling. Outras sete transições hiperfinas, $\Lambda F= \pm 1, \Delta m_{F}=0$, denominadas de transições $\pi$, são excitadas durante a interrogação dos átomos com a microondas, quando o campo magnético oscilatório é paralelo ao campo magnético estático. O Rabi Pulling é um deslocamento de freqüência sentido pela transição relógio devido à superposição dos pedestais entre transições adjacentes, $F=$ $3, m_{F}=-1 \leftrightarrow F=4, m_{F}=-1$ e $F=3, m_{F}=1 \leftrightarrow F=4, m_{F}=1$, ao pedestal da transição relógio e devido a presença de uma assimetria entre as raias vizinhas da transição relógio.

6. Efeito Doppler de primeira ordem. Como a cavidade de microondas possui uma condutividade finita, o cmapo de microondas sustentado pela cavidade perderá energia para as paredes da cavidade. Este efeito acarreterá em um gradiente de fase do campo sentido dentro da cavidade sentido pelos átomos e é uma função da caoordenada longitudinal z. Esse efeito é bastante reduzido num chafariz após as duas passagens dos átomos em sentidos invertidos pela mesma cavidade, uma vez que o campo de microondas é simétrico.

7. Cavity Pulling. Quando a cavidade de microondas não está exatamente sintonizada na freqüência de transição atômica, a amplitude do campo varia assimetricamente quando a freqüência for modulada em torno da freqüência de transição atômica, $v_{0}$, o que produzirá um deslocamento de freqüência na transição relógio. Esse deslocamento está associado à interferência entre o campo irradiado pela antena da cavidade e o campo emitido pelo dipolo magnético quando os átomos passam pela cavidade.

8. Deslocamento Luminoso. A incidência de luz laser durante a interação dos átomos com a microonda pode causar um deslocamento na freqüência de transição relógio. Devido ao caráter pulsado do relógio tipo chafariz, durante a passagem dos átomos pela cavidade a luz laser está desligada e, portanto este efeito é minimizado. 
9. Fuga de microondas. Se houver qualquer acoplamento da perturbação oscilatória com os átomos na região de vôo livre, a freqüência da transição relógio será deslocada.

\subsection{Estabilidade}

Outro parâmetro a ser estudado quando trabalhamos com padrões de freqüência atômicos é a estabilidade do relógio e caracteriza a capacidade do oscilador atômico em reproduzir a mesma frequiência média ao longo do tempo. A sua variância é determinada pelo fator de qualidade atômico, $Q_{a t}$, e pela relação sinal ruído. Qualquer medida de freqüência envolve uma janela de amostragem $\tau$, através do qual o oscilador é observado. Desta forma, o acontecimento real na determinação da freqüência $x(t)$, é o de uma medida de desvio temporal iniciada em $t$ e outra em $t+\tau$. A diferença entre esses dois desvios temporais, dividida pelo tempo de amostragem resulta na freqüência normalizada média, $y(t)$. Dispondo dos dados das flutuações temporais, calculamos as flutuações de frequiência média $y_{k}$ de um período de amostragem para outro em todo o conjunto de dados como dado pela equação 2.11 (43),

$$
y_{k}=\frac{1}{\tau} \int_{t_{k}}^{t_{k}+1} y(t) \mathrm{d} t
$$

Diversas técnicas foram desenvolvidas para tornar a caracterização independente do tamanho do conjunto de dados. A variância de Allan (44), também conhecida como a variância de duas amostras, é utilizada para expressar a estabilidade relativa no domínio temporal. A estabilidade de freqüência medida sobre um instante de tempo $\tau$ é feita sobre uma série temporal que resulta em $k=N-1$ medidas, dada pela equação $2.12(45)$

$$
\sigma_{y}^{2}(\tau)=\frac{1}{2(m-1)} \sum_{\substack{k=1 \\ m=1}}\left(\bar{y}_{k+1}-\bar{y}_{k}\right)^{2}
$$


onde $N$ é o número de amostras e $y_{k}$ foi definida anteriormente e corresponde o valor médio durante um intervalo de tempo $\tau$ na k-ésima medida. A equação 2.12 é conhecida por variância de Allan.

A variância de Allan calculada para as flutuações de freqüência que caracterizam a estabilidade do chafariz atômico é expressa como (46):

$$
\sigma_{y}(\tau)=\frac{1}{\pi Q_{a t}} \frac{\sigma_{p}}{P} \sqrt{\frac{T_{C}}{\tau}}
$$

onde $\tau$ é o tempo de interrogação e muito maior que o tempo de ciclo $T_{c}, \tau \gg T_{c}$, e o $\sigma_{P}$ é o desvio padrão da probabilidade de transição. Como $\tau^{-1 / 2}$ na equação 2.13 , o ruídos característico de um padrão de freqüência atômico é o ruído branco de freqüência.

As diferentes fontes de ruído que contribuem com o valor de $\sigma_{P}$ são dados por:

1. Ruído da detecção. Esse tipo de ruído é devido à flutuação da probabilidade de transição, ou seja, devido à flutuação no número de átomos medidos entre os estados $|F=3\rangle$ e $|F=4\rangle$.

2. Ruído de Projeção Quântica. Ela está relacionada às flutuações do sistema de dois níveis do átomo $(47,48)$. Após a interrogação de Ramsey, o átomo de ${ }^{133} \mathrm{Cs}$ encontra-se em uma superposição de duas auto-energias internas, $|F=3\rangle$ e $|F=4\rangle$. A incerteza na medida da população desses níveis de energia está relacionada com as propriedades quânticas do sistema bem como do tempo de relaxação e observação dos átomos. A não ser que a amplitude de uma das populações seja igual à zero, a variância na probabilidade de transição deverá ser um limitante para os padrões de freqüência a átomos frios.

3. Efeito Dick. Devido ao processo pulsado de interrogação atômica, o controle do oscilador de interrogação também será periódico e descontínuo. Dessa forma, a estabilidade de freqüência é degradada uma vez que o processo de interrogação torna-se sensível aos ruídos de freqüência do oscilador macroscópico para a 
interrogação atômica (49).

4. Ruídos diversos. Esse inclui os ruídos eletrônicos da detecção, ruídos devido a luz espalhada na região de detecção e as flutuações de intensidade e freqüência do feixe laser de detecção.

Nos próximos capítulos serão analisados alguns dos efeitos sistemáticos descritos anteriormente, além dos efeitos que podem degradar a estabilidade de freqüência. 


\section{Chafariz Atômico de ${ }^{133}$ Cs operado como um Padrão Primário de Tempo e Freqüência}

\subsection{Introdução}

Existem diversos tipos de padrões de freqüência em operação que distinguemse entre o tipo de átomos escolhido para servir de referência ou pelo mecanismo de operação utilizado para detectar a transição relógio escolhida. Dentre os padrões de freqüência passivos em operação destaca-se os padrões de freqüência tipo feixe térmico de ${ }^{133} \mathrm{Cs}(7,28,42)$, o chafariz atômico pulsado de ${ }^{133} \mathrm{Cs}$ e ${ }^{87} \mathrm{Rb}(30)$, o chafariz atômico contínuo de ${ }^{133} \mathrm{Cs}$, os padrões de frequiência baseados em armadilhas de um único íon como $\mathrm{Hg}^{+}, \mathrm{Sr}^{+}$e $\mathrm{Yb}^{+}$e os padrões de frequiência ópticos que utilizam uma nuvem de átomos neutros o que incluem os átomos de $\mathrm{Ca}, \mathrm{Sr}$ e $\mathrm{Mg}$ além de outros candidatos promissores como o $\mathrm{Yb}, \mathrm{Ag}$ e $\mathrm{H}$ (22). Além disso podemos citar também os padrões de freqüência atômicos baseados em células que contém vapor de Rb e Cs (50), que são simples, compactos e reprodutíveis, e os que utilizam um perfil de emissão do aprisionamento populacional coerente (CPT - coherent population trapping)(51). Dentre todos os padrões de freqüência atômicos citados, cada um deles apresenta diversas vantagens e desvantagens no que diz respeito aos parâmetros de funcionamento, como a duração do tempo de interação, a relação sinal ruido obtida, além do tamanho e da complexidade envolvida em sua operação. Não vamos aqui entrar no mérito de cada uma delas. 
A vantagem do chafariz atômico frente a um padrão de frequiência primário tipo feixe térmico de césio é que o primeiro utiliza técnicas de resfriamento e aprisionamento para produzir amostras de átomos frias cuja velocidade média na amostra é de alguns $\mathrm{ms}^{-1}(52)$. Como a largura da franja central é proporcional a $\frac{1}{T}$ ou $\frac{v}{L}$, a questão de aprimorar os padrões de frequiência atômicos tornou-se uma questão de aumentar o tempo de interação dos átomos com a radiação eletromagnética.

Tipicamente, em um feixe térmico a velocidade média dos átomos é $200 \mathrm{~ms}^{-1}$. O comprimento de interrogação é $10 \mathrm{~cm}$, de forma que os átomos levam em torno de $0,5 \mathrm{~ms}$ para percorrê-la. A largura de linha da franja central é de $915 \mathrm{~Hz}$ e o fator de qualidade atômico nessa configuração é $Q_{a t}=1,0 \times 10^{7}$. Em um chafariz atômico, o comprimento da região de vôo livre é em torno de $16 \mathrm{~cm}$ e a velocidade média dos átomos na temperaturas típicas de um MOT é de $1 \mathrm{cms}^{-1}$. Assim, o tempo de interação efetivo é $500 \mathrm{~ms}$ de forma que a largura de linha obtida é da ordem $\Delta v=1 \mathrm{~Hz}$ e o fator de qualidade atômico é aumentado em duas ordens de grandeza, $Q_{a t} \approx 10^{9}$. Conseqüentemente, todos os deslocamentos de freqüência que dependem de $Q_{a t}$ são reduzidos como é o caso do cavity pulling (40) que depende de $Q_{a t}^{-2}$. Além disso a estabilidade $\sigma_{y}(\tau)$ também é melhorada em pelo menos duas ordens de grandeza, uma vez que ela tem dependencia com $\frac{1}{Q_{a t}}$. Igualmente importante é a vantagem ganha com a baixa dispersão de velocidade dos átomos frios. Como exemplo, o efeito Doppler de segunda ordem tem dependência com $v^{2}$ e em um chafariz ele é reduzido por um fator $(100)^{2}$. Outra característica deste sistema experimental é que o método de Ramsey de dois campo oscilatórios separados é implementado em uma única cavidade de microondas. Para isso, os átomos são lançados para cima e passam uma vez pela cavidade de microondas, atingem o ápice de sua trajetória e, finalmente, pela ação da gravidade, os átomos caem passando novamente pela mesma cavidade. O uso de uma única cavidade de interrogação e a inversão da trajetória dos átomos previne de deslocamentos devido à diferença de fase entres as duas regiões de interrogação e a influência da distribuição de fase da cavidade causada por imperfeições do campo de 
microondas dentro da cavidade.

O sistema experimental tipo chafariz onde os átomos de ${ }^{133} C s$ são interrogados é mostrado na figura 6 .

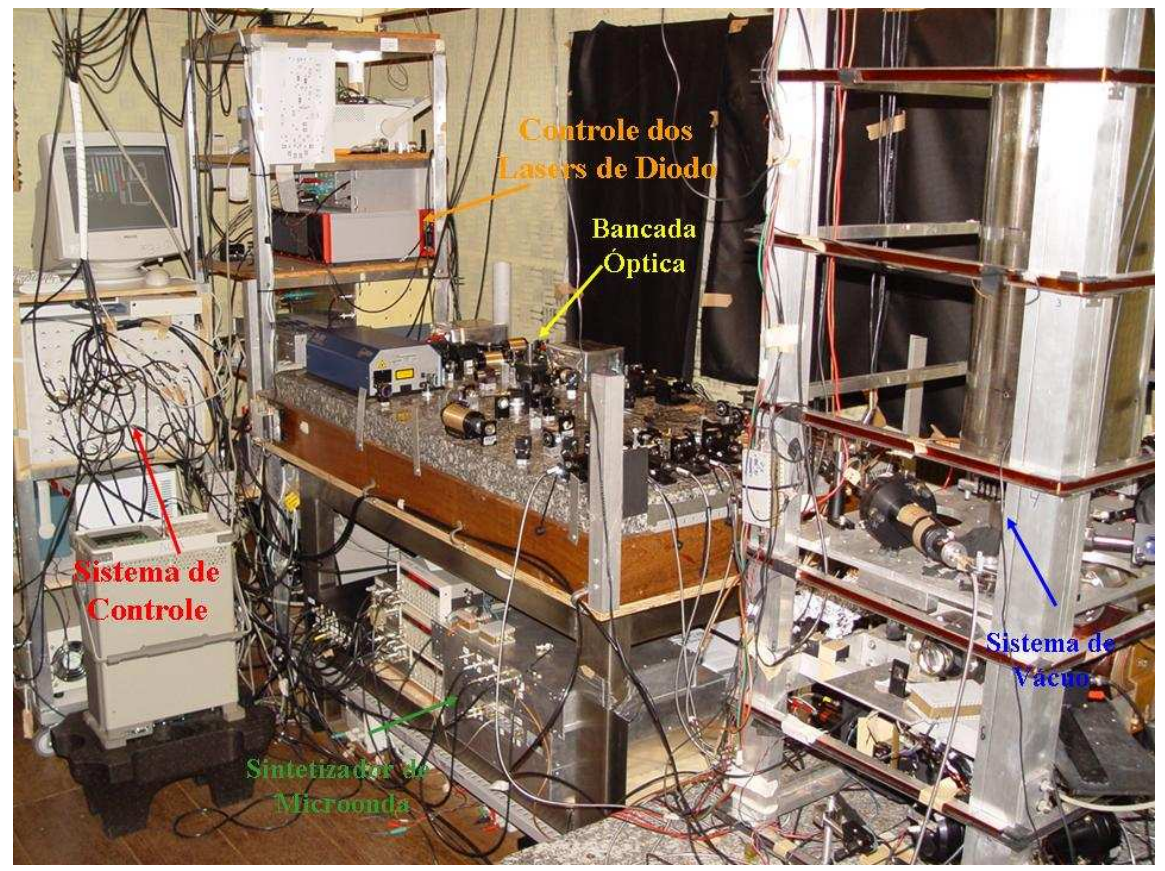

Figura 6: Vista geral do padrão de freqüência tipo chafariz do Instituto de Física de São Carlos da Universidade de São Paulo. Nela vemos as quatro partes principais da sua montagem experimental: a bancada óptica, o sistema de vácuo, a sintetização de microondas e o sistema de controle.

O chafariz atômico consiste de 4 partes principais:

1. o sistema de vácuo, composto pela câmara de aprisionamento e o tubo de vôo livre. No sistema de vácuo, os átomos de césio são manipulados, interrogados e detectados como mostrado na figura 7;

2. a mesa óptica, onde são produzidos todos os feixes ópticos para a manipulação dos átomos;

3. o sintetizador de microondas, que gera o sinal de interrogação necessário para os átomos executarem a transição relógio;

4. o sistema de controle eletrônico, onde se define todos os parâmetros de operação do relógio. Além disso, aquisiciona-se o sinal de detecção e estabelece a correção 
da freqüência de microondas injetada na cavidade.

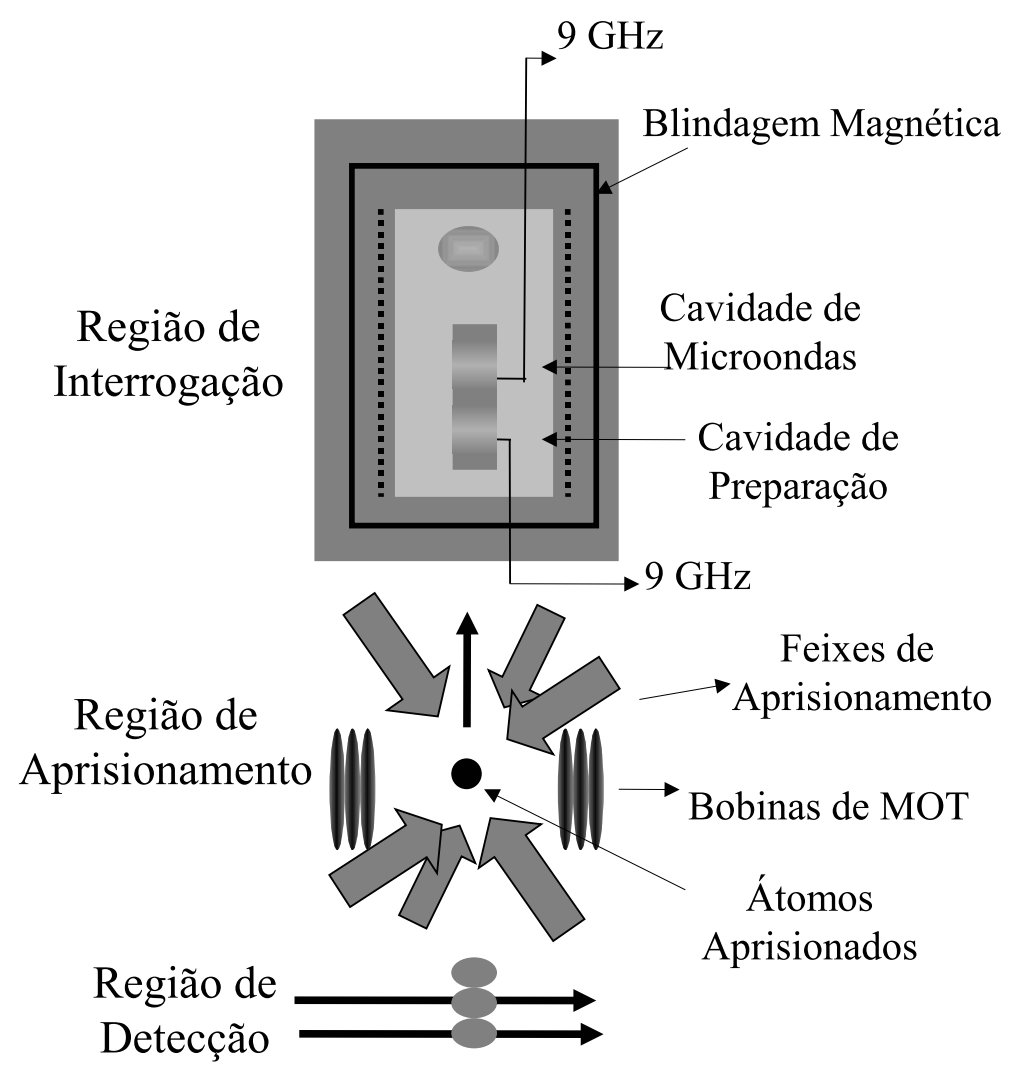

Figura 7: Esquema experimental do sistema de vácuo do Chafariz Atômico. O ciclo de funcionamento é formado por etapas distintas para realizar a interrogação dos átomos de ${ }^{133}$ Cs. Primeiro os átomos são aprisionados utilizando-se a técnica de armadilha magneto-óptico (MOT) e melado. Em seguida, arremessados na vertical por meio da técnica de melado em movimento, fazem um vôo balístico passando duas vezes pela mesma cavidade de microondas. Desse modo, os átomos são submetidos a dois campos oscilatórios separados por uma região livre de campo oscilatório. Por fim, a nuvem atinge a zona de detecção, que verifica as populações em cada um dos níveis de energia $6^{2} S_{1 / 2}(F=3)$ e $6^{2} S_{1 / 2}(F=4)$, estabelecendo a eficácia com que a transição foi estimulada.

\subsection{Processo Cíclico do Chafariz Atômico}

Resumidamente, as fases necessárias para operar um padrão de átomos frios são descritas abaixo:

1. Captura dos Átomos 
Os átomos são aprisionados por uma armadilha magneto óptica $\left(\sigma^{+}-\sigma^{-}\right)$. Nessa fase, tanto o laser de aprisionamento como o de rebombeio operam em máxima potência. A frequiência dos feixes de aprisionamento está deslocada em 1,7Г para o vermelho da transição atômica $F=4 \rightarrow F^{\prime}=5$. O tempo de captura dos átomos é de 1s. Optamos por operar nesse modo de captura por produzir nuvens já considerável número de átomos e otimizando a estabilidade de freqüência em curto prazo. Esta é a fase de carregamento e a temperatura dos átomos atingida é de $140 \mu \mathrm{K}$.

\section{Melado Óptico}

Entre o fim da fase de armadilha e o início da fase de lançamento aguardamos pelo menos 300ms. Durante esse intervalo de tempo os átomos passam por uma fase de melado óptico para homogeneizar a nuvem de átomos frios. Os feixes laser são deslocados em $-2 \Gamma$ para o vermelho da transição e a intensidade dos feixes é ligeiramente atenuada para manter a temperatura da nuvem atômica.

3. Lançamento dos átomos capturados

A nuvem de átomos frios é lançada pela técnica de melado em movimento, deslocando em freqüência os feixes superiores para o vermelho $\left(2 \Gamma+\Delta v_{L}\right)$ e os feixes inferiores para o azul $\left.\left(2 \Gamma+\Delta v_{L}\right)\right)$ da transição da linha $D_{2}$ dos átomos de ${ }^{133} C s$. A velocidade inicial dos átomos depende da diferença de freqüência entre os feixes superiores e inferiores dada pela equação $2 \lambda \Delta v$. A duração dessa fase é de aproximadamente $0,3 \mathrm{~ms}$ e os feixes estão na potência máxima para maior eficiência de lançamento dos átomos. O $\Delta v$ de operação do chafariz atualmente é de 4,6 MHz uma vez que operamos com a cavidade de preparação.

4. Resfriamento no referencial em movimento (sub-Doppler)

Durante a fase de lançamento, os átomos são ligeiramente aquecidos e uma fase suplementar de resfriamento é introduzida. A temperatura da nuvem é proporcional à intensidade do laser e inversamente proporcional à diferença 
de freqüência (efeito Sysiyphus). Assim, a fase de lançamento é seguida de uma fase de resfriamento sub-doppler suplementar de $3 \mathrm{~ms}$, onde os átomos são resfriados durante o referencial em movimento. Essa técnica é implementada deslocando-se a freqüência dos feixes de aprisionamento em $-8 \Gamma$ (limite ainda devido as limitações do nosso sistema Tóptica, mostrado no Capítulo 5) e em conjunto reduzimos linearmente a intensidade dos feixes laser para $2,67 \mathrm{mWcm}^{-2}$. Finalmente, os feixes laser são completamente desligados com obturadores mecânicos. Alguns ms depois, o feixe de rebombeio é desligado por um obturador mecânico.

5. Interrogação dos átomos

Após a fase de lançamento para a região de vôo livre, os átomos encontram a cavidade de microondas. Em um movimento balístico, os átomos passam pela cavidade de microondas, atingem o ápice e caem passando pela segunda vez através da mesma cavidade. Dessa forma, eles promovem uma interação de dupla zona de Ramsey, que devidamente travada, permite estabilizar a cadeia de osciladores de quartzo com a precisão da medida da ressonância atômica. O sinal de microondas permanece constantemente ligado durante todo o ciclo de funcionamento do chafariz atômico. Durante essa fase, os feixes laser de aprisionamento são bloqueados por obturadores para evitar qualquer deslocamento de frequiência luminoso. A duração dessa fase é em torno de 513 ms. Tanto a potência da microondas injetada, como a modulação, são pré-definidas no programa que faz o controle por meio da interface PCI-GPIB.

\section{Detecção}

Após a interação com a cavidade de microondas, os átomos encontram-se em um superposição coerente entre os estados $F=3$ e $F=4$ distribuídos ao longo de sete subníveis Zeeman. O sistema de detecção mede a população de cada um dos estados. Disparado pelo o sistema de controle uma seqüência de coleta dados, com um determinado número de pontos e uma taxa de aquisição estabelecida é 
executada. O sinal de fluorescência emitido pela nuvem de átomos, ao cruzar os feixes de detecção, é coletado pela janela de detecção. Por isso deve haver um sincronismo entre o tempo de lançamento dos átomos e o tempo de disparo. $\mathrm{O}$ sistema de controle calcula a eficiência na transição atômica interrogada através de alterações no sinal detectado e injeta um sinal de correção no sintetizador externo que modula o sinal interrogação em torno da freqüência de ressonância relógio. Para calcular as franjas de Ramsey através da equação 6.1 determina-se o número de átomos em cada um dos estados pela integral do ajuste do sinal de tempo de vôo por uma função gaussiana.

7. Correção do sinal de modulação da cadeia de síntese de microondas Através do sinal de erro medido na fase de detecção, uma correção é aplicada na freqüência central de modulação da cadeia de microondas fornecida através de um sintetizador digital externo configurado por meio de uma placa de interface PCI-GPIB.

A seguir apresentamos uma visão geral do princípio de funcionamento do chafariz atômico desenvolvido pelo nosso grupo, no Instituto de Física de São Carlos da Universidade de São Paulo. A descrição completa de cada uma das partes do sistema experimental será feita nos capítulos subseqüentes.

\subsection{Ciclo de funcionamento do chafariz atômico}

O processo cíclico do chafariz atômico começa com átomos de ${ }^{133} \mathrm{Cs}$ sendo capturados em uma armadilha magneto-óptica (MOT, ver apêndice B.2). Para acumular os átomos em um MOT usamos três pares de feixes laser colimados e contrapropagantes, de mesma intensidade e freqüência, na configuração tetraédrica $(1,1,1)$. Nessa configuração, os três feixes laser superiores e os três feixes laser inferiores fazem um ângulo de aproximadamente $35^{\circ}$ com o plano horizontal. As bobinas que geram o gradiente de campo magnético para o aprisionamento dos átomos de césio estão 
posicionadas de modo a gerar um campo magnético de quadrupolo, necessário para a operação do MOT. A vantagem dessa configuração de MOT é que para fazer o lançamento dos átomos na vertical, nenhum dos feixes laser tem que passar através da torre, onde os guia de corte das cavidades de microondas trariam sérias limitações ao diâmetro do feixe $(<10 \mathrm{~mm})$. O MOT é carregado a partir do vapor de césio e pelo menos $10^{8}$ átomos são resfriados em $1000 \mathrm{~ms}$. Para o aprisionamento de ${ }^{133} \mathrm{Cs}$, a frequiência dos feixes laser de aprisionamento é sintonizada para o vermelho da transição atômica $\left|6^{2} S_{\frac{1}{2}}, F=4\right\rangle \leftrightarrow\left|6^{2} P_{\frac{3}{2}}, F=5\right\rangle$ e circularmente polarizados, $\sigma^{+}-\sigma^{-}$. Apesar da transição $\left|6^{2} S_{\frac{1}{2}}, F=4\right\rangle \longrightarrow\left|6^{2} P_{\frac{3}{2}}, F=5\right\rangle$ ser uma transição cíclica (fechada), alguns átomos podem decair para o estado fundamental $\left|6^{2} S_{\frac{1}{2}}, F=3\right\rangle$. Dessa forma, sobrepomos a dois feixes superiores de aprisionamento, um feixe de rebombeio, ressonante com a transição $\left|6^{2} S_{\frac{1}{2}}, F=3\right\rangle \leftrightarrow\left|6^{2} P_{\frac{3}{2}}, F=4\right\rangle$, de modo a manter a população dos átomos no estado $\left|6^{2} S_{\frac{1}{2}}, F=4\right\rangle(53)$.

Para uniformizar a nuvem atômica e alcançar temperaturas mais baixas, o gradiente de campo magnético é desligado e por $150 \mathrm{~ms}$ os átomos passam por uma fase de melado óptico (ver Apêndice B.1). O próximo passo é lançar a nuvem de átomos para a região de interrogação por meio da técnica de melado em movimento (13). Por essa técnica introduz-se um deslocamento de freqüência para o vermelho nos feixes superiores e para o azul da ressonância nos três feixes inferiores. Dessa forma cria-se uma onda propagante que lança verticalmente os átomos para cima com velocidade $v_{z}=\frac{\sqrt{3} \lambda \Delta v_{L}}{2}$ determinada pelo deslocamento de freqüência $\Delta v_{L}$ entre os feixes de aprisionamento superiores e inferiores. Durante o processo de lançamento os átomos são aquecidos, enquanto seguem adiabaticamente a temperatura do referencial em movimento. Dessa forma torna-se necessário aplicar uma fase de resfriamento adicional, onde a freqüência dos feixes de aprisionamento é dessintonizada adiabaticamente para longe da ressonância atômica e a intensidade é reduzida até zero, intoduzindo-se uma fase chamada de resfriamento sub-Doppler (13)(ver Apêndice B.3). Desse modo, após 1,4 ms do lançamento, a freqüência dos feixes de aprisionamento é deslocada de $-2 \Gamma$ 
até $-8 \Gamma$, onde $\Gamma \cong 5,3 \mathrm{MHz}$ é a largura de linha natural dos átomos de ${ }^{133} \mathrm{Cs}$, e a intensidade do laser é reduzida em 3, 0 ms. O resfriamento sub-Doppler é aplicado somente após o lançamento dos átomos, uma vez que a aceleração obtida é maior para altas intensidades do laser e pequenos deslocamentos. Por fim, os feixes de aprisionamento são desligados e alguns $m s$ depois o rebombeio também é desligado para introduzir uma seleção de estado nos átomos lançados. Por fim todos os feixes são completamente desligados com a utilização de obturadores eletromecânicos. Aplicando-se a técnica de resfriamento sub-Doppler é possível lançar os átomos até $80 \mathrm{~cm}$ acima da região de MOT e a temperatura dos átomos medida na região de detecção, que se encontra $19 \mathrm{~cm}$ abaixo da região de MOT, é de $15 \mu K$.

Em torno de $42 \mathrm{~cm}$ acima da região de captura, uma cavidade retangular de cobre (modo $\mathrm{TE}_{102}$ ) é usada para interrogar a transição hiperfina no método de interrogação de Ramsey. Em um movimento balístico, os átomos passam uma vez pela cavidade de interrogação, atingem o ápice e, devido ao efeito da gravidade, caem passando pela segunda vez através da mesma cavidade de microonda. A cavidade de interrogação é alimentada com o sinal sintetizado por uma cadeia de osciladores construída pelo nosso grupo (54) ressonante com a transição entre os dois níveis hiperfinos do estado fundamental dos átomos de ${ }^{133} \mathrm{Cs}, 9,192631770 \mathrm{GHz}$. A escolha do modo foi feita para que os átomos experimentem um mínimo de variações de fase enquanto passam através do eixo da cavidade, o que introduz um deslocamento de freqüência devido ao efeito Doppler de primeira ordem.

Ao longo do trajeto de interrogação, os átomos sentem um campo magnético estático que levanta a degenerescência dos subníveis Zeeman do césio e define o eixo de quantização atômico. Esse campo magnético estático é denominado de C-field. O campo eletromagnético no interior da cavidade é paralelo ao C-field para selecionar as transições que independem de $\vec{B}_{0}$ em primeira ordem. Para prevenir que os átomos sintam qualquer componente de campo magnético que não do $C$-field durante o processo de interrogação, blindagens magnéticas de $\mu$-metal são colocadas a região de 
interrogação.

Ao final da trajetória parabólica, os átomos atingem a região de detecção. A população dos átomos nos dois níveis hiperfinos do estado fundamental, $16^{2} S_{\frac{1}{2}}, F=$ 3) e $\left|6^{2} S_{\frac{1}{2}}, F=4\right\rangle$, é medida através do sinal de tempo de vôo (TOF) pela fluorescência produzida quando os átomos atravessam perpendicularmente dois feixes laser. O primeiro feixe é sintonizado com a transição cíclica do estado fundamental para o estado excitado $\left|6^{2} S_{\frac{1}{2}}, F=4\right\rangle \leftrightarrow\left|6^{2} P_{\frac{3}{2}}, F=5\right\rangle$ e permite a detecção por fluorescência apenas dos átomos em $\left|6^{2} S_{\frac{1}{2}}, F=4\right\rangle$. O segundo feixe é uma composição de um feixe de rebombeio, para bombear os átomos remanescentes em $\left|6^{2} S_{\frac{1}{2}}, F=3\right\rangle$, que não sofreram a transição relógio na passagem pela cavidade, e o feixe de detecção $\left|6^{2} S_{\frac{1}{2}}, F=4\right\rangle \leftrightarrow\left|6^{2} P_{\frac{3}{2}}, F=5\right\rangle$ tal que ele interage com todos os átomos da nuvem. A fluorescência induzida pelo segundo feixe é detectada por um outro detector. A probabilidade de transição entre dois níveis do estado fundamental como função da modulação de freqüência do sintetizador de microonda é $P=\frac{N_{|F=4\rangle}}{N_{|F=4\rangle}+N_{|F=3\rangle}}$, onde $\mathrm{N}_{|4\rangle}$ e $\mathrm{N}_{|3\rangle}$ são obtidos a partir do sinal medido em cada fotodetetor e corresponde a população nos estados $F=4$ e $F=3$ respectivamente.

Para travar o oscilador externo na freqüência de ressonância atômica medimos a probabilidade de transição à esquerda e a direita à meia altura da franja central e o sinal de diferença da frequiência entre as duas medidas é utilizado como sinal de erro. O sinal de erro é usado para realimentar o gerador de microonda de modo a mantê-lo sempre no máximo da ressonância atômica. A cada nova interação, o gerador é corrigido e esse erro é minimizado. A seqüiência temporal do chafariz de átomos é mostrado na figura 8 .

O sistema experimental foi minunciosamente descrito em (33), de modo que, nos próximos capítulos, nos deteremos apenas nas partes que sofreram algum tipo de alteração. Como será descrito adiante, diversas mudanças foram implementadas no sistema experimental do chafariz de átomos. Na câmara de aprisionamento atômico, uma das direções do feixe de aprisionamento foi corrigida. O tubo de vôo livre em 


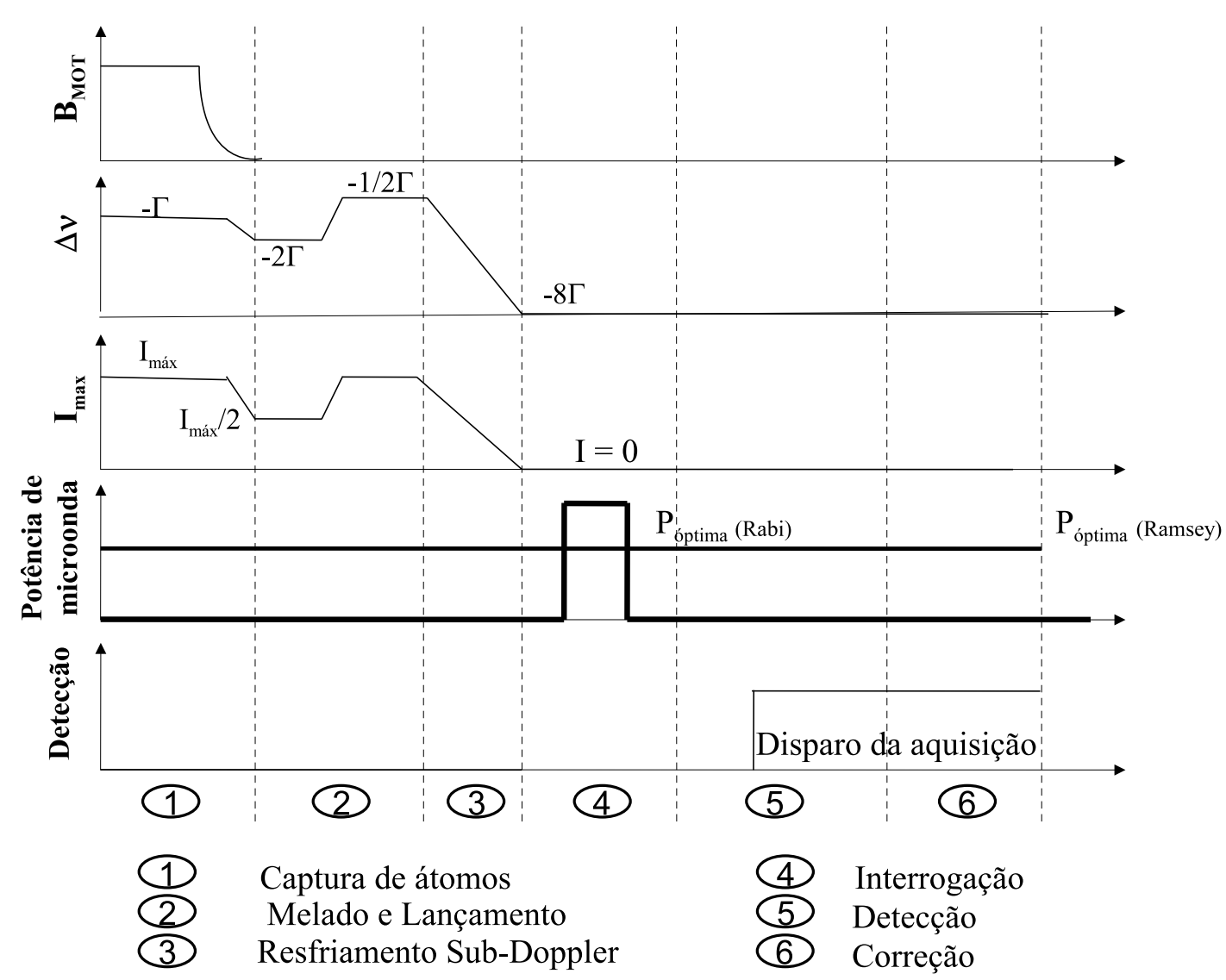

Figura 8: Sequiência temporal do padrão de freqüência tipo chafariz do CePOF.

cobre, antes confeccionado em alumínio, bem como as cavidades de preparação e de interrogação foram substituídas. Atualmente, as cavidades formam uma estrutura rígida junto com o tubo de vôo livre e o sistema de detecção foi otimizado. Após essas mudanças foi possível lançar os átomos a altitudes maiores, de modo que mesmo após passarem duas vezes pela cavidade de Ramsey, o sinal de detecção foi aumentado, e, conseqüentemente, é possível observar as franjas de Ramsey, assinatura característica de um relógio atômico. 


\section{$4 \quad$ Sistema de Vácuo do Chafariz. Atômico de ${ }^{133}$ Cs}

A partir deste capítulo descreveremos o sistema experimental do chafariz atômico de ${ }^{133}$ Cs: desde a utilização de equipamentos comerciais, construção do sistema de vácuo, construção da cadeia de síntese de microondas até a estabilização dos lasers de diodo. O processo todo descrito aqui foi realizado num período de 7 anos. Desta forma, teses anteriores do grupo foram importantes para a configuração atual e os resultados apresentados até aqui (33). Diversas mudanças foram implementadas no sistema experimental do chafariz de átomos para operá-lo como um padrão de freqüência atômico. O tubo de vôo livre em cobre, antes confeccionado em alumínio, bem como as cavidades de preparação e de interrogação antes de cobre e de formato cilíndrico, foram trocadas por cavidades de cobre de formato retangular. Atualmente, as cavidades formam uma estrutura rígida junto com o tubo de vôo livre. Um solenóide C-field e duas blindagens magnéticas cilíndricas são posicionadas ao longo do tubo de vôo livre. Com relação ao sistema óptico do chafariz atômico trabalhamos para ajustar melhor o lançamento da nuvem fria de átomos, conseguido através da técnica de melado em movimento, e o sistema de detecção óptico através de um sinal de tempo de vôo de qualidade e com baixo nível de ruído. Após essas mudanças foi possível lançar os átomos a altitudes maiores de modo que após passarem duas vezes pela cavidade de Ramsey, o sinal de detecção foi aumentado, e, conseqüentemente, foi possível obter franjas de Ramsey, sinal característico de um relógio atômico desse tipo.

Neste capítulo descrevemos o sistema de vácuo do chafariz atômico. Ela é for- 
mada por três regiões principais: a câmara de aprisionamento magneto-óptico, onde os átomos são resfriados e confinados; a região de vôo livre, onde os átomos encontram a cavidade de preparação e de interrogação; e a região de detecção, onde o sinal de tempo de vôo (TOF) é detectado. A figura 9 ilustra a estrutura de vácuo do chafariz atômico.

\subsection{Sistema de Vácuo do Chafariz Atômico}

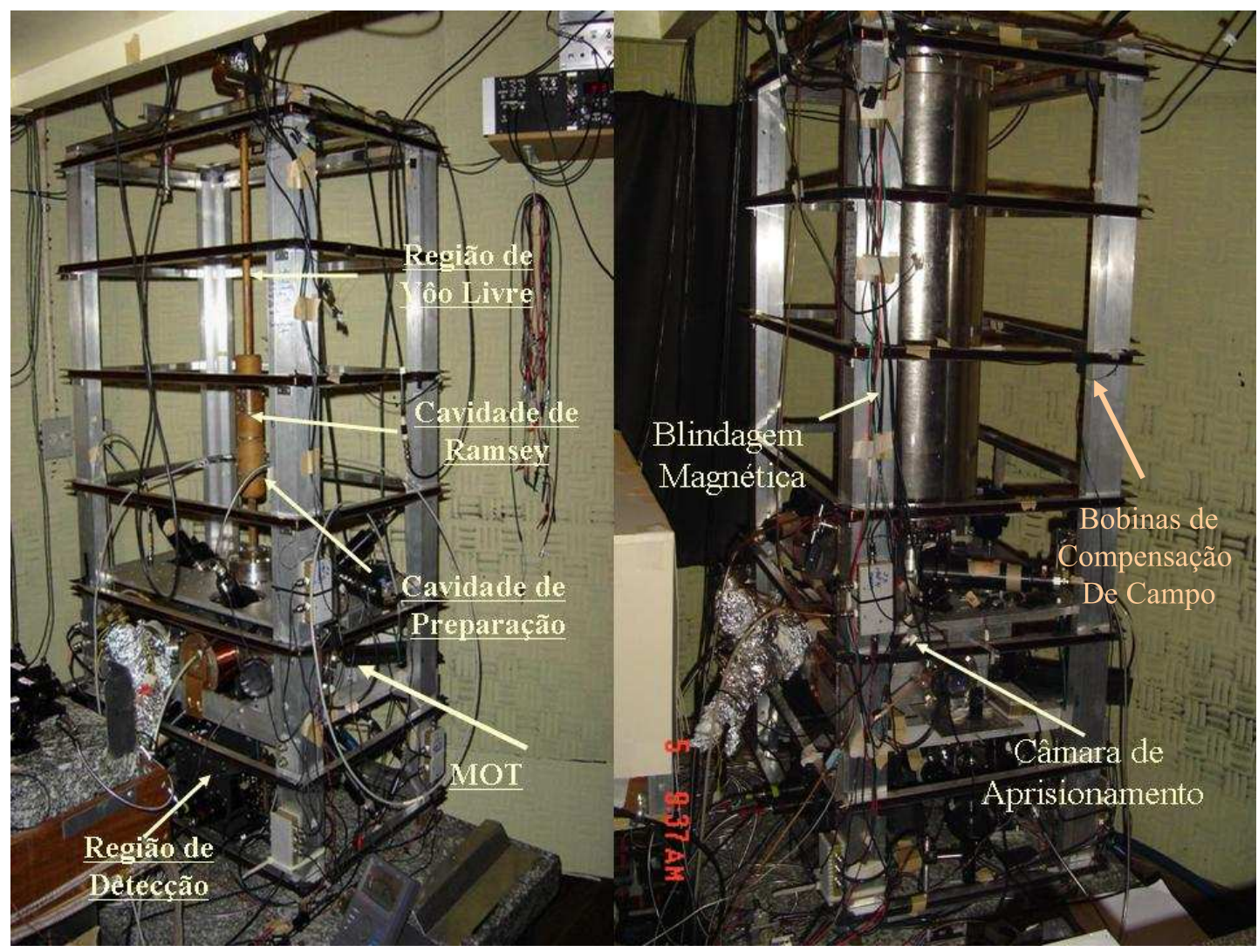

Figura 9: Imagens do sistema de vácuo do chafariz atômico. Ela é constituída pela câmara de aprisionamento e pela região de vôo livre. A região de vôo livre está situada acima da câmara de aprisionamento. Nela observamos a disposição das cavidades de preparação e interrogação, a blindagem magnética e o conjunto de bobinas de compensação do campo magnético. O sistema de detecção encontra-se a $19 \mathrm{~cm}$ abaixo da câmara de aprisionamento.

Tanto a câmara de aprisionamento como a região de detecção estão contidas em uma célula construída em aço inox (304L). A câmara de aprisionamento tem $35 \mathrm{~cm}$ de comprimento e $18 \mathrm{~cm}$ de diâmetro. A região de detecção está situada a $19 \mathrm{~cm}$ abaixo 
da câmara de aprisionamento. A região de captura dos átomos contém onze janelas das quais seis são utilizadas para passar os feixes de aprisionamento e as outra servem de conexão de bombeamento de vácuo, observação e detecção de fluorescência. A região de detecção possui cinco janelas de vidro, quatro para o sistema de detecção e uma na extremidade inferior do sistema de vácuo, como ilustra a figura 10 . Todas as janelas possuem cobertura anti-refletora para infra-vermelho $(852 \mathrm{~nm})$ de modo a minimizar reflexões parasitas. O cilindro de vôo livre foi gentilmente cedido pelo

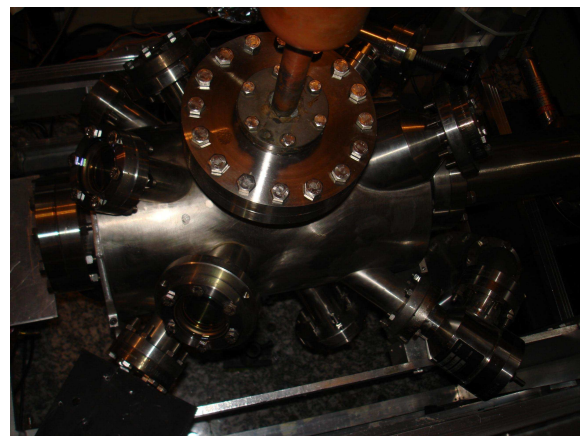

(a) Câmara de Aprisionamento

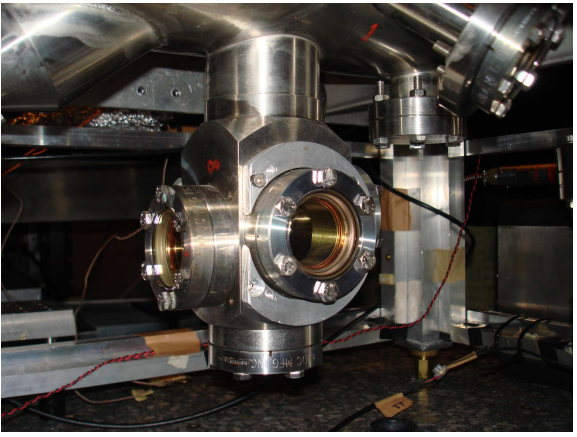

(b) Deteção

Figura 10: Imagem da região de captura e da região de detecção. A região de aprisionamento contém 11 janelas e a região de detecção contém 5 janelas soldadas em tubos sobre a câmara de aprisionamento. Todas as janelas possuem cobertura anti-refletora para infra-vermelho.

NIST-Gaithsburg e detalhado em (55). O tubo tem $90 \mathrm{~cm}$ de altura e 1,5 cm de de diâmetro externo. As cavidade de interrogação e de preparação foram soldadas por brasagem ao cilindro de vôo livre formando uma estrutura rígida que é parte de todo o reservatório de vácuo, como pode ser visto na figura 11. Tanto o tubo como as cavidades foram confeccionadas em cobre OFHC (oxygen-free high conductivity copper), um material não magnético e com excelente condutividade térmica. Dessa forma evitase o confinamento das linhas de campo magnético e gradientes de temperatura que induzem um deslocamento na frequiência de transição produzido pelo deslocamento Zeeman quadrático durante o vôo livre dos átomos $(38,46,56)$ e um deslocamento de frequiência devido à radiação de corpo negro respectivamente. É fundamental que o cilindro de vôo livre seja confeccionado de um material não magnético, de modo a minimizar perturbações da referência atômica durante o vôo balístico. Na extremidade in- 


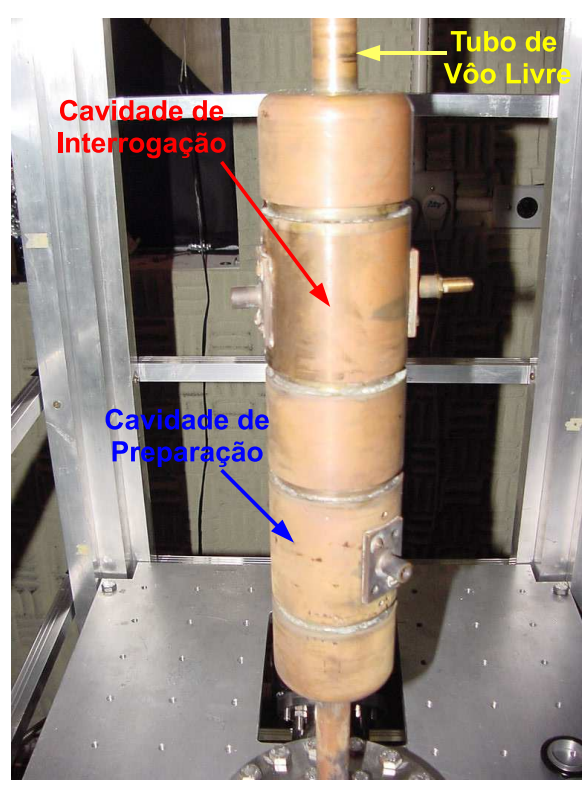

(a)

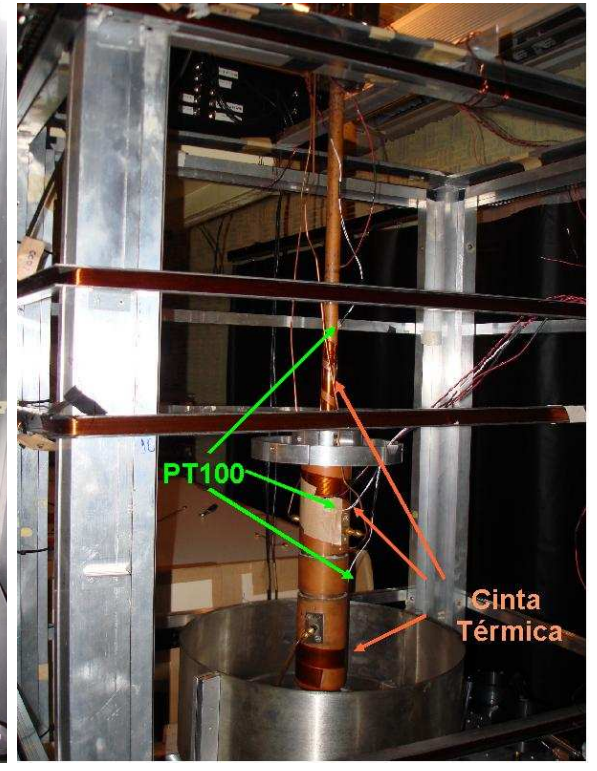

(b)

Figura 11: Disposição das cavidades de interrogação e de preparação soldadas por brasagem ao tubo de vôo livre, formando uma única estrutura rígida do sistema de vácuo. Ao longo do tubo de vôo livre foram posicionadas três cintas térmicas para manter a uniformidade térmica do tubo e três sondas PT100 para medir a temperatura.

ferior do tubo de vôo livre foi soldada uma flange de inox que permite sua conexão com a câmara de aprisionamento e a extremidade superior do tubo de vôo livre é fechada por uma janela de vidro, o que permitirá, num futuro próximo, introduzir um feixe de laser para seleção de estado dos átomos antes de entrarem na cavidade de Ramsey. Três fitas térmicas de até $25 \mathrm{~W}$ de potência foram posicionadas na extremidade inferior da cavidade de preparação, na extremidade superior do cavidade de Ramsey e na extremidade inferior do tubo de vôo livre para manter a homogeneidade térmica e a cavidade ressonante com a freqüência de transição relógio. Para medir a temperatura, foram posicionados três termistores PT100 ao longo do tubo de vôo livre como mostra a figura 11.

Ao longo da região de interação, os átomos sentem um campo magnético estático produzido por um solenóide de $80 \mathrm{~cm}$ de comprimento que levanta a degenerescência dos subníveis Zeeman para criar o eixo de quantização e favorecer a transição relógio. Esse campo magnético estático é conhecido como $C$-field. Com o intuito de blindar magneticamente toda a vizinhança do cilindro de vôo livre e minimizar perturbações 
de campo magnético, em especial na cavidade de preparação e de interrogação, dois cilindros em $\mu$-metal foram posicionados concêntricos ao longo do eixo do tubo de vôo livre. Além disso, em torno do sistema de vácuo, onze bobinas de compensação de campo magnético foram implementadas com a finalidade de minimizar campos espúrios na região de vácuo. Tanto a blindagem magnética como as bobinas de compensação de campo podem ser vistas na figura 12. A pressão de vácuo atingida na

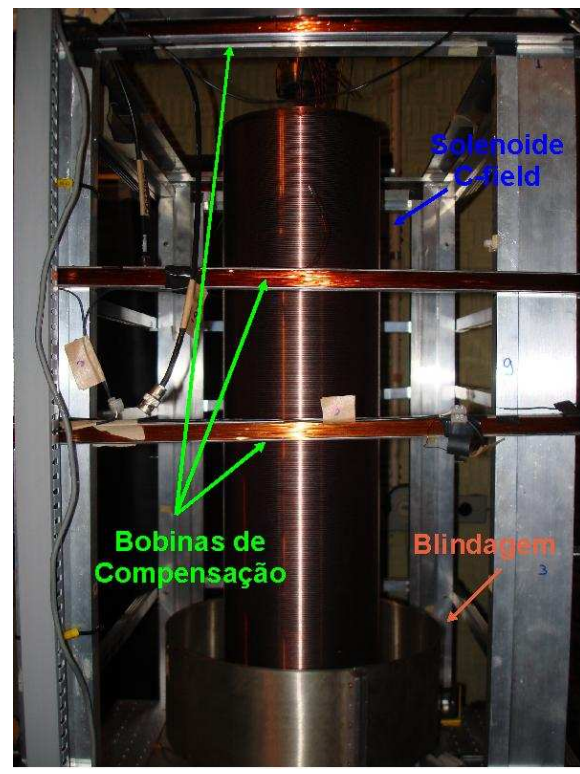

(a)

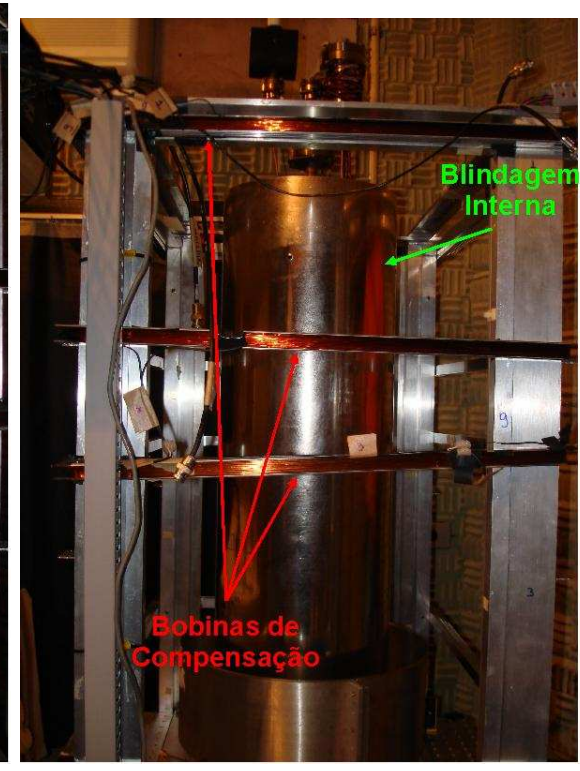

(b)

Figura 12: Disposição da bobina $C$-field, da blindagem magnética e das bobinas de compensação para definir o eixo de quantização dos átomos e evitar que campos magnéticos espúrios mascarem a frequiência da transição relógio.

câmara de aprisionamento, após um processo de desgaseificação, é de $2 \times 10^{-9}$ Torr e na região de vôo livre é melhor do que $10^{-10}$ Torr. Em operação normal do nosso sistema, o vácuo é mantido por meio de duas bombas iônicas, uma de 601/s conectada na câmara de aprisionamento e outra de $81 / \mathrm{s}$ conectada na extremidade superior do tubo de vôo livre. Blindagens magnéticas foram colocadas em torno da bomba iônica de 601/s para minimizar as perturbações provocadas pelo forte campo magnético gerado pela mesma. Para reduzir a pressão de fundo dentro das zonas de interrogação e da zona de detecção, introduzimos tubos de grafite nas junções com a câmara de aprisionamento. Dessa forma, os efeitos de colisão e de fluorescência parasita na zona de detecção são reduzidos. 


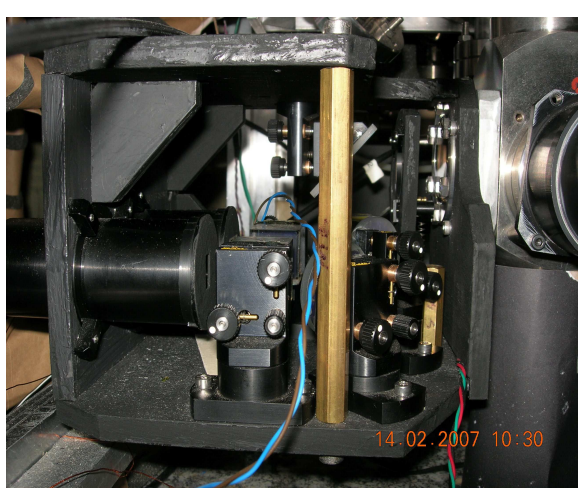

Figura 13: Imagem do sistema de detecção rigidamente acoplada à estrutura de vácuo. Os feixes são produzidos na parte externa da estrutura e a seguir introduzidos por meio de uma das janelas dessa região.

O sistema de detecção fica na extremidade inferior da câmara de vácuo, rigidamente acoplado à estrutura de vácuo, como mostrado na figura 13. Atenção especial foi dada à região de detecção com o intuito de aumentar a sua estabilidade e ela será descrita detalhadamente nos próximos capítulos.

\subsection{Controle de Campo Magnético}

Para investigar a transição relógio, é necessário aplicar um campo magnético estático paralelo à direção do campo magnético oscilatório (6). Esse campo magnético estático, denominado de $C$-field, levanta a degenerescência das diferentes transições $\Delta m_{F}=0$ dos níveis hiperfinos e mantém o eixo de quantização dos átomos. Quando um campo magnético estático, fraco e uniforme, é aplicado na zona de interrogação, o efeito Zeeman de segunda ordem induzido desloca a frequiência da transição relógio (2):

$$
\Delta v_{z}=427,45 \times 10^{10}\left(\frac{H z}{T^{2}}\right)\left\langle B_{0}^{2}\right\rangle
$$

onde \langle\rangle dá o valor médio do campo sobre a região de interrogação. Esse valor, no chafariz atômico é da ordem $(800 \pm 0,1)$ nT. Para produzir o campo magnético estático foi construído um solenóide feito em fio de cobre, espiralmente enrolada em torno de um cilindro de alumínio de $80 \mathrm{~cm}$ de comprimento com 3,41 voltas/cm como mostra a figura 14(a). A bobina $C$-field foi caracterizada utilizando-se uma sonda 


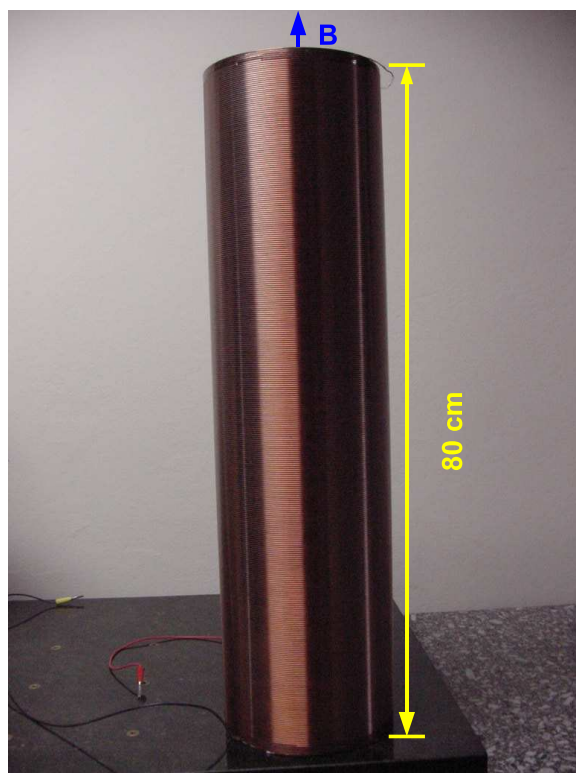

(a)

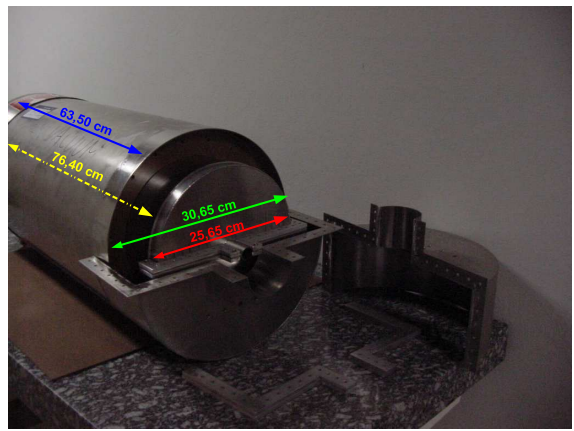

(b)

Figura 14: O solenóide $C$-field e a blindagem magnética. O solenóide é espiralmente enrolado com fio de cobre em torno de um cilindro de aluminio com 3,41 voltas $/ \mathrm{cm}$. A blindagem magnética da Fountain é composta por dois cilindros concêntricos separados por uma distância de $5 \mathrm{~cm}$.

Hall Mag 01H, com resolução de 0,1 nT. Na figura 15 observamos a variação da amplitude do campo magnético como função da intensidade de corrente aplicada ao C-field. Duas blindagens magnéticas cilíndricas em $\mu$-metal e de formato cilíndrico envolvendo concentricamente o solenóide, para homogeneizar o campo magnético local nas vizinhanças do tubo de vôo livre. O cilindro mais externo tem 63,50 cm de comprimento e 30,65 cm de diâmetro. O cilindro interno tem 76,40 $\mathrm{cm}$ de comprimento e 25,65 de diâmetro. A caracterização destas blindagens foi feita com a mesma sonda utilizada para caracterizar a bobina C-field e observou-se que as blindagens magnéticas atenuam o campo externo em até $10^{6} \mathrm{~T}$, como ilustra a figura 16. Para alimentar o solenóide construímos uma fonte de corrente de mA (56). O diagrama da fonte de corrente está esquematizado na figura 17. A referência de tensão, a resistência em série e o potenciômetro foram escolhidos para assegurar a estabilidade na corrente para variações na resistência da bobina devido à temperatura, por exemplo. Para evitar variações rápidas do campo magnético na região de vôo livre, que podem induzir as transições majoranas, construiu-se uma estrutura de bobinas contendo sete bobinas 


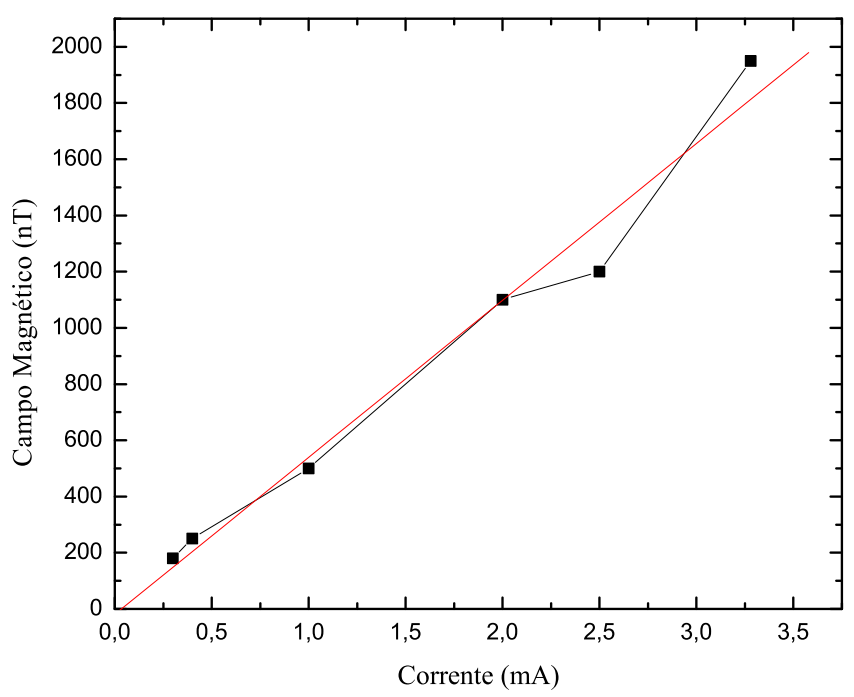

Figura 15: Caracterização da bobina C-field.

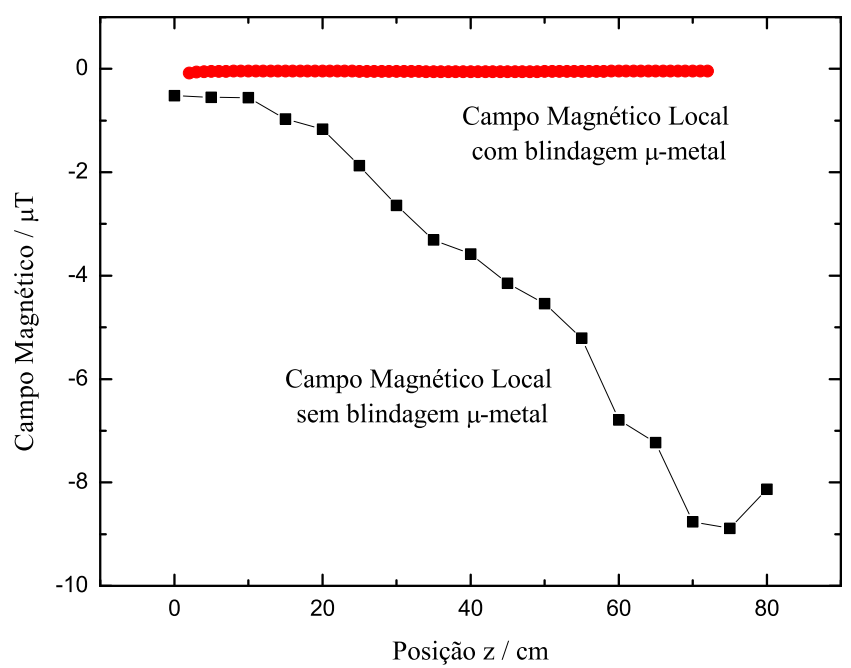

Figura 16: Efeito da blindagem magnética sobre o campo magnético local.

horizontais alinhadas com a direção de lançamento dos átomos, e quatro verticais em uma armação de alumínio como ilustrado na figura 18(a). Esta estrutura de bobinas tem a finalidade de eliminar o campo magnético nas vizinhanças do relógio tipo chafariz. O número de voltas em cada uma das bobinas foi estimado de tal modo que, passando-se uma corrente de $200 \mathrm{~mA}$, seja possível compensar um campo de 600 mG. 


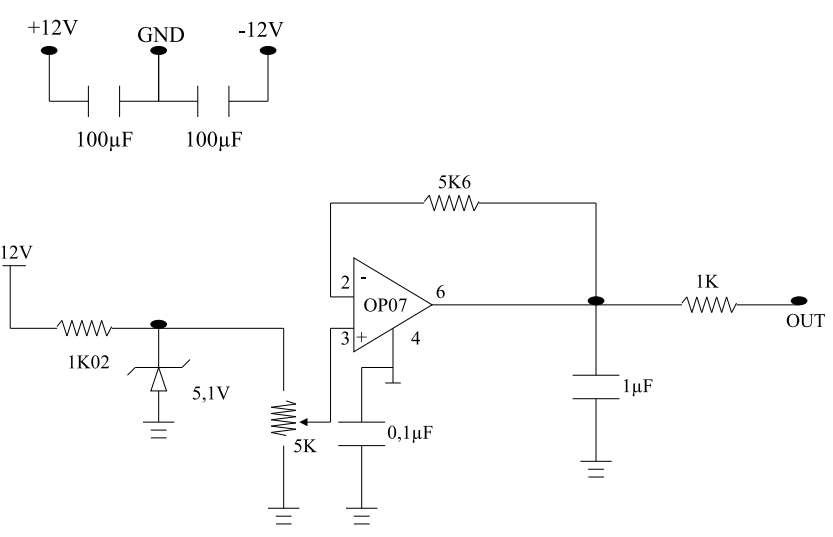

Figura 17: Fonte de corrente para alimentar a bobina do C-field.

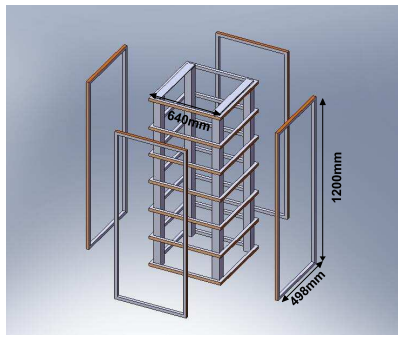

(a) Estrutura das Bobinas de (b) Vista superior da estrutura de bobinas compensação de campo (as bobinas verticais estão fora para melhor visuallização).

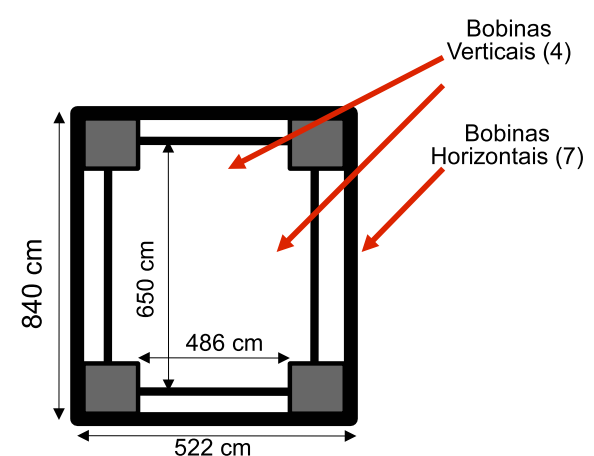




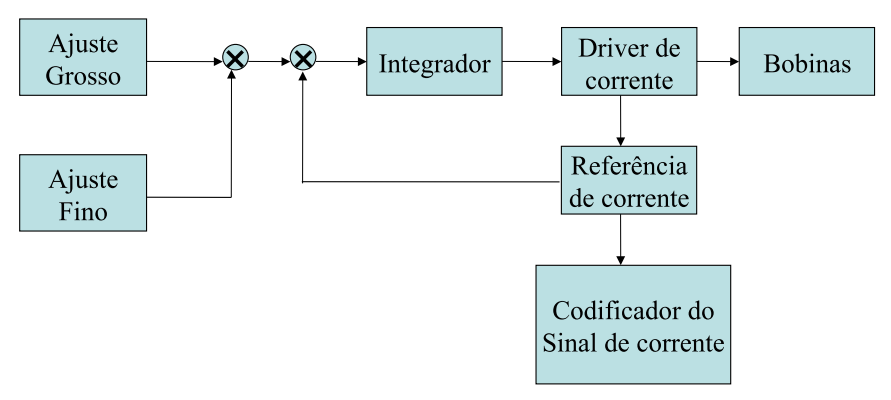

Figura 18: Diagrama de blocos da fonte de corrente.

da sonda Hall. Na figura 19(a) vemos o perfil do campo magnético obtido antes de ligar as bobinas de compensação e após a pré-regulagem ao redor da blindagem magnética. As medidas foram tomadas em torno de $360^{\circ}$ da circunferência do cilindro de $\mu$-metal dividido em cinco linhas verticais separadas de aproximadamente $60^{\circ}$. As diferentes correntes que passam pela bobina são inicialmente ajustadas grosseiramente com uma sonda Hall medindo o campo axial e as componentes transversais em função de suas orientações supracitadas. Comparando os dois gráficos da figura 19, vemos que há redução considerável da amplitude do campo magnético nas vizinhanças da blindagem de $\mu$-metal, além da homogeneidade do campo na região das cavidades de preparação e de interrogação que ficam a $21,5 \mathrm{~cm}$ e $33,6 \mathrm{~cm}$ respectivamente. As medidas finais do campo magnético serão efetuadas in situ, utilizando-se os átomos frios. A estabilidade temporal do campo magnético local fora da blindagem magnética e dentro da estrutura de bobinas também foi medida como mostra o gráfico da figura 20. A sonda Hall foi posicionada entre as cavidades de preparação e interrogação e o campo magnético medido durante $24 \mathrm{~h}, 3$ dias consecutivos para verificar a sua flutuação local nas condições normais de operação do chafariz atômico. O valor médio do campo obtido através do gráfico é de $(-0,30 \pm 0,01) \mu T$.

\subsection{Cavidade de Microondas}

Os átomos são interrogados segundo o método de Ramsey de campos oscilantes separados. Em um chafariz atômico, os átomos passam duas vezes pela mesma cavidade durante o seu vôo balístico, uma vez na subida e outra na descida da trajetória 


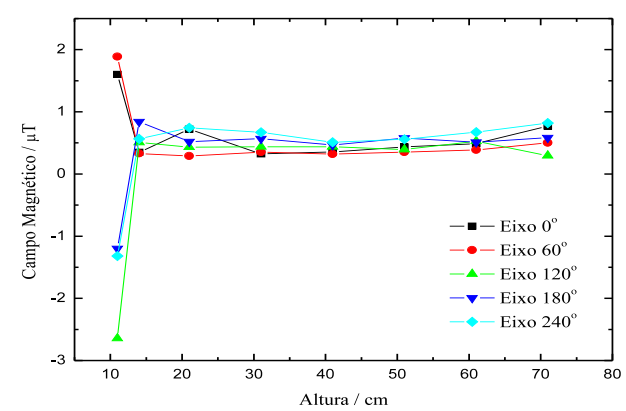

(a) sem bobinas de compensação

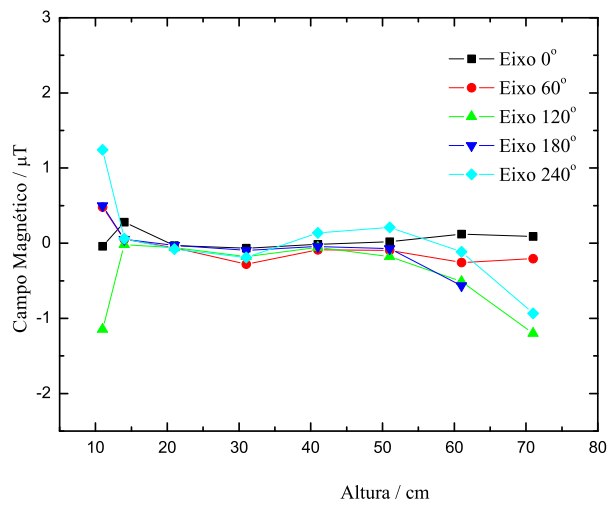

(b) com bobinas de compensação

Figura 19: Perfil do campo magnético nas vizinhanças da blindagem magnética.

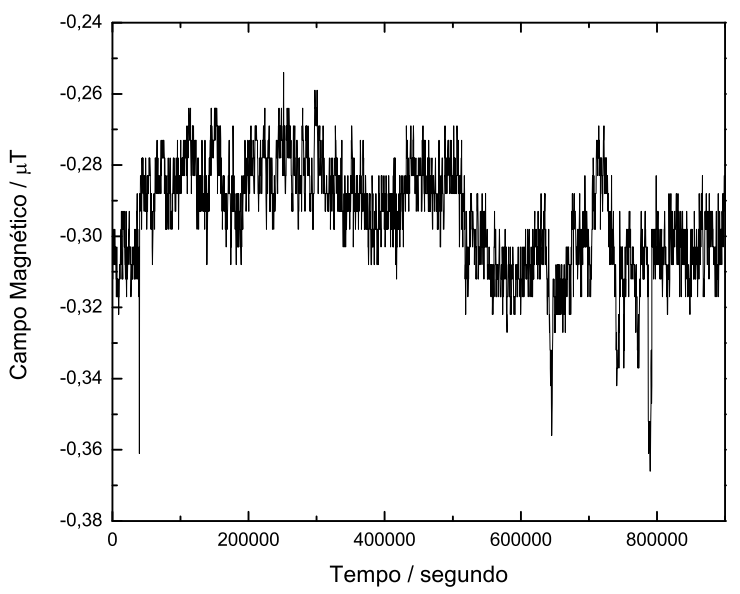

Figura 20: Estabilidade temporal do campo magnético local nas vizinhanças da cavidade após a pré-regulagem das bobinas de compensação. 
atômica. A cavidade de interrogação da transição hiperfina para os átomos de ${ }^{133} \mathrm{Cs}$ tem formato retangular, figura 21(a), construída em cobre com dimensões que visam acoplar o modo $\mathrm{TE}_{102}$ do sinal de microondas, que também é o modo dominante desse tipo de cavidade. A escolha desse modo é feita para que os átomos, ao passarem através do eixo da cavidade, não experimentem uma variação de fase na direção do movimento, o que provocaria um deslocamento de freqüência causado por efeito Doppler de primeira ordem $(46,56)$. As aberturas da cavidade de microondas são as maiores fontes de perdas de átomos em um chafariz atômico durante a passagem destes na cavidade (57). As aberturas de entrada e saída da cavidade tem $1 \mathrm{~cm}$ de diâmetro centrado sobre o eixo da cavidade e $10 \mathrm{~cm}$ de comprimento. Elas foram construídas com o maior diâmetro possível para minimizar as perdas atômicas sem que haja vazamento de microondas para o interior desta região. O comprimento de onda de corte dentro do guia é $\lambda_{c}=0,819 \mathrm{~cm}$ o que é bem menor do que o comprimento de onda usado para excitar os átomos de ${ }^{133} \mathrm{Cs}, \lambda_{C s}=3,26 \mathrm{~cm}$. A atenuação do campo de microondas dentro dos guias de corte é de $66,57 \mathrm{~dB} / \mathrm{cm}$, resultando em uma atenuação superior a $120 \mathrm{~dB}$ ao longo desses guias. O tubo de vôo livre tem espessura inferior ao do comprimento de onda de corte dos 9,2 GHz assegurando que não haja nenhuma interação da microondas com os átomos durante a fase de vôo livre. Na figura 21(b) vemos a configuração do campo magnético transversal dentro de uma cavidade retangular no modo $\mathrm{TE}_{102}$ bem como a propagação do campo dentro dos guias de corte. As componentes dos campos elétrico e magnético do modo dominante são dadas por:

$$
\begin{array}{r}
E_{x}(t)=0 \\
E_{y}(t)=-\imath H_{0} \frac{4 a}{\lambda_{g}} Z_{H} \sin \frac{\pi x}{a} \cos \frac{2 \pi z}{\lambda_{g}} \exp (\imath \omega t) \\
E_{z}(t)=0
\end{array}
$$




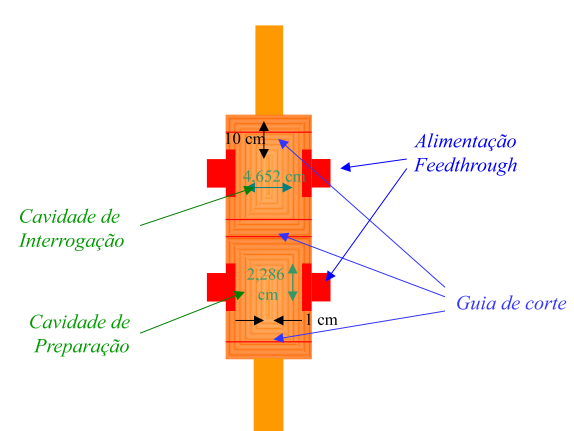

(a)

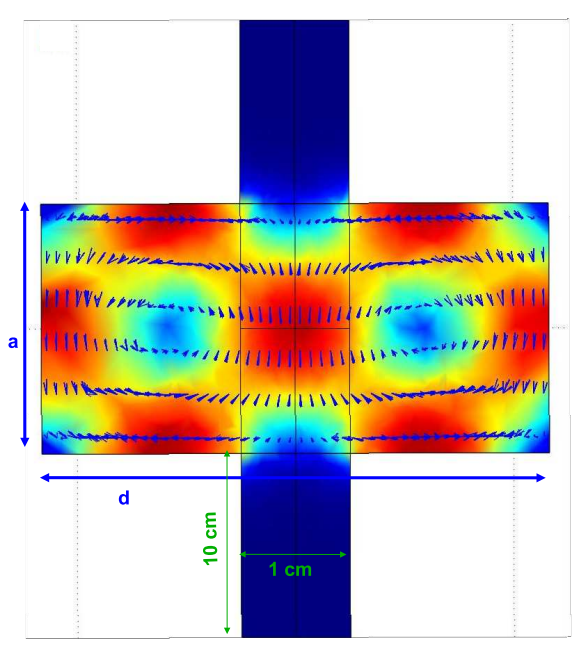

(b)

Figura 21: (a) Esquema da disposição das cavidades no tubo da estrutura de vácuo. A cavidade tem geometria retangular com dimensões a na direção $x$ e $b\langle a$ na direção $y$. A onda eletromagnética propaga-se na direção $z$ cuja dimensão d é múltiplo inteiro de $\frac{\lambda}{2}$. (b) Configuração do campo magnético dentro da cavidade para o modo $T E_{102}$.

$$
\begin{array}{r}
H_{x}(t)=H_{0} \frac{4 a}{\lambda_{g}} \sin \frac{\pi x}{a} \sin 2 \pi z \lambda_{g} \exp (l \omega t) \\
H_{y}(t)=0 \\
H_{z}(t)=2 H_{0} \frac{4 a}{\lambda_{g}} \cos \frac{\pi x}{a} \cos 2 \pi z \lambda_{g} \exp (l \omega t)
\end{array}
$$

Estes campos correspondem ao de uma onda estacionária e mostram que os campos magnético e elétrico variam em quadratura ao longo do eixo $z$. Nestas equações $\lambda_{g}$ corresponde ao comprimento de onda guiado dentro da cavidade, dado por

$$
\frac{1}{\lambda_{g}^{2}}=\frac{1}{\lambda^{2}}-\frac{1}{\lambda_{c}^{2}}
$$

onde $\lambda_{c}$ é o comprimento de onda de corte e $Z_{H}$ define a impedância da onda TE, dada por

$$
Z_{H}=\left(\frac{\lambda_{g}}{\lambda}\right) Z_{v}
$$

e $Z_{v}=\left(\mu_{0} / \epsilon_{0}\right)^{1 / 2}$ é a impedância da onda no vácuo. Para propagar apenas o modo dominante $T E_{102}$ na freqüência de transição hiperfina do átomos de ${ }^{133} \mathrm{Cs}$, as dimensões da cavidade são $a=2,286 \mathrm{~cm}$ e $b=1,016$. Nesse caso, o comprimento de onda de corte é $\lambda_{c}=4,572 \mathrm{~cm}$ e o comprimento de onda guiado é $\lambda_{g}=4,654 \mathrm{~cm}$. Nessas condições 
$Z_{H}=538 \Omega$. Das equações 4.4 e 4.6 , vemos que para $\mathbf{p}$ inteiro, o campo magnético é tangente aos planos

$$
z_{g}=\left(\frac{1}{2} p+\frac{1}{4}\right) \lambda_{g}
$$

enquanto o campo elétrico é zero nesses planos. Um padrão estacionário se estabelece ao longo da direção de propagação se a distância entre as paredes transversais for igual a múltiplos de $\frac{\lambda}{2}$ de excitação, ou seja, $d=n \frac{\lambda_{g}}{2}$, onde $\mathrm{n}$ é um número inteiro positivo. A nossa cavidade tem $d=4,65 \mathrm{~cm}$ de modo que duas regiões antinodais, $n=2$, são formadas, como mostra a figura 21(b). As linhas de força magnéticas são paralelas ao plano- $x z$ e sua equação é dada por

$$
\sin \frac{\pi x_{g}}{a} \cos \frac{2 \pi z_{g}}{\lambda_{g}}=C_{1}
$$

como mostrado na figura 21(b). Em torno do ponto antinodal P do campo magnético estacionário, as linhas de força magnéticas são quase paralelas. Por esta razão, a região em torno do ponto $\mathrm{P}$ é escolhido como região de interação e o campo magnético transversal $H_{x}(t)$ é aquele que induz as transições hiperfinas $\Delta F= \pm 1$ e $\Delta m_{F}=0$.

Tanto a cavidade de preparação como a de interrogação foram consrtuídas com dimensões que visam acoplar uma freqüência ligeiramente diferente da freqüência de transição do relógio. Para sintonizar a cavidade de microondas na frequiência de transição relógio aquecemo-na a uma temperatura ligeiramente superior à temperatura ambiente. A cavidade de interrogação torna-se ressonante a $38,87^{\circ} C$. A variação da freqüência de ressonância da cavidade como função da temperatura é dada pelo gráfico da figura 22. A medida foi feita através da transmissão do sinal de microonda por meio dos dois acopladores simétricos que alimentam a cavidade. Para isso utilizamos um analisador de espectro (HP8563E) e um gerador de microonda Gigatronics como ilustra a figura 23. A variação da frequiência de ressonância da cavidade como função da temperatura é de $161,96 \mathrm{kHz} /{ }^{\circ} \mathrm{C}$. Utilizando-se a mesma montagem experimental medimos o fator de qualidade carregado da cavidade de preparação e de interrogação. 


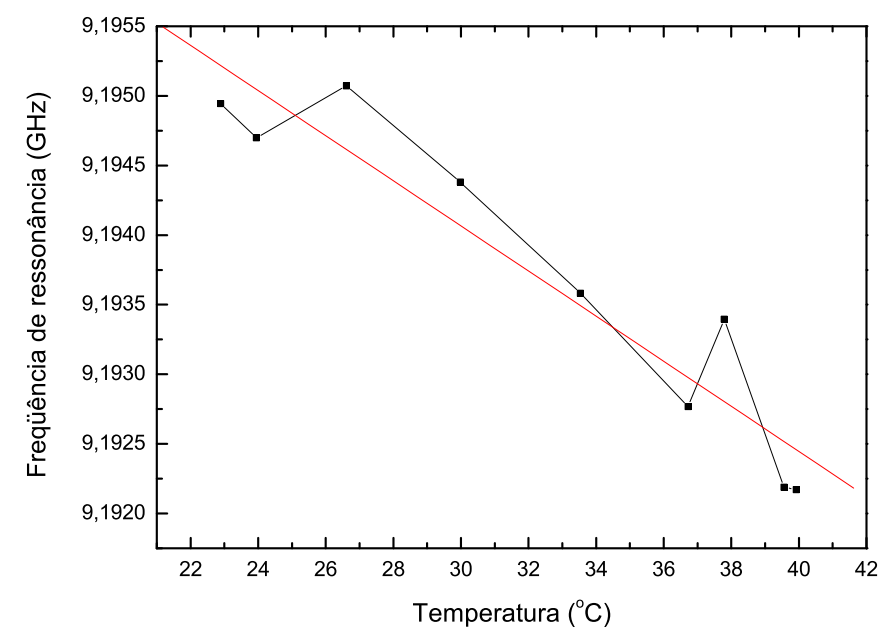

Figura 22: Sintonia da freqüência de ressonância da cavidade como função da temperatura.

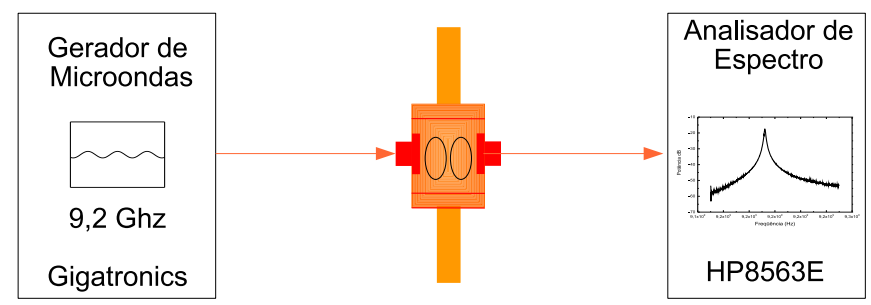

Figura 23: Esquema utilizado para medir a sintonia da cavidade como função da temperatura.

O fator de qualidade está relacionado com a largura da faixa de passagem através da seguinte relação

$$
Q=\frac{f_{r}}{\Delta f}
$$

e $\Delta f$ corresponde a faixa de freqüência cuja atenuação é menor ou igual a $3 \mathrm{~dB}$. A $38,87^{\circ} \mathrm{C}$ a cavidade de interrogação está ressonante com $v_{I}=9,192767130 \mathrm{GHz}$ e o fator de qualidade carregado medido é $Q=8358$. O próximo passo será o de implementar um controle ativo da temperatura en situ para minimizar quaisquer efeitos perturbativos sobre a freqüência de transição devido a esta variação. A essa temperatura, a cavidade de preparação está ressonante com $v_{P}=9,199966340 G \mathrm{~Hz}$ e seu fator de qualidade efetivo é $Q=1128$. 
O fator de qualidade da cavidade também é definido como sendo o produto da energia máxima armazenada num volume $\mathrm{V}$ pela freqüência angular de ressonância e dividido pela potência dissipada, ou seja,

$$
Q=\frac{\omega E_{\max }}{P_{d}}
$$

onde a energia máxima armazenada é dada por

$$
E_{\text {max }}=E_{m}=\iiint_{V} U_{m} d v=\frac{\mu}{4} \iiint_{V} \vec{H} \cdot \vec{H} d V
$$

e a potência dissipada é dada por

$$
P_{d} \equiv \frac{\operatorname{Re}\left\{\eta_{c}\right\}}{2} \iint_{S}\left|H_{t}\right|^{2} d S
$$

Aqui $H_{t}$ representa a componente de campo magnético tangencial à superfície interna das paredes condutoras, S é a área interna total, $\mathrm{V}$ o volume da cavidade e $U_{\max }$ a densidade volumétrica máxima de energia. Lembrando que a freqüência de ressonância de uma cavidade retangular é dada por:

$$
\omega_{r}=\frac{2 \pi c}{2 \sqrt{\epsilon_{r}}} \sqrt{\left(\frac{m}{a}\right)^{2}+\left(\frac{n}{b}\right)^{2}+\left(\frac{l}{d}\right)^{2}}
$$

onde $m, n, l$ são inteiros positivos que representam múltiplos de $\lambda / 2$ possíveis de existir em cada uma das direções e $a, b, d$ são as dimensões da cavidade nas direções $x, y$ e $z$, respectivamente. Usando as equações 4.6, 4.14 e 4.15, escreve-se a densidade volumétrica máxima de energia como,

$$
E_{\text {max }}=\mu \frac{H_{0}^{2} a b d}{2}\left[\left(\frac{l a}{m d}\right)^{2}+1\right]
$$

e finalmente,

$$
Q_{T}=\frac{\pi Z_{H}}{4 R_{s}}\left[\frac{2 b\left(a^{2}+d^{2}\right)^{\frac{3}{2}}}{a d\left(a^{2}+d^{2}\right)+2 b\left(a^{3}+d^{3}\right)}\right]
$$

onde $R_{s}$ é a resistividade da superfícia dada por $R_{s}=\sqrt{\frac{\omega \mu}{2 \sigma}} \cong 0,048 \Omega$. Para as dimensões da nossa cavidade, e utilizando os valores calculados para $R_{s}$ e $Z_{H}$, o fator 
de qualidade teórico é $Q=9352,84$. A relação entre o fator de qualidade teórico e o efetivo é dada pela equação abaixo,

$$
Q=\frac{Q_{T}}{1+\beta}
$$

onde $\beta$ representa o fator de acoplamento da cavidade e seu valor é $\beta=0,11$. Esses valores são de grande importância uma vez que são utilizados para determinar a potência a ser fornecida pela cadeia de síntese de freqüência de modo a obter um pulso $\frac{\pi}{2}$ para o método de Ramsey. Num lançamento balístico normal, o tempo de transito dos átomos passando através da cavidade é da ordem de ms. A amplitude do campo magnético oscilante é obtida a partir de

$$
B=\frac{b \hbar}{\mu_{B}}
$$

onde $b=\frac{\pi}{2 \tau}$ é a freqüência de Rabi definida anteriormente. Considerando-se a velocidade inicial de lançamento dos átomos é $3,54 \mathrm{~m} / \mathrm{s}$ e $64 \mathrm{~cm}$ a distância percorrida pelos átomos acima do plano de captura, o tempo de transito dos átomos no interior da cavidade é $24 \mathrm{~ms}$. Com isso determina-se $B=0,27 n T$. A energia armazenada para o modo $T E_{102}$ é obtida a partir

$$
E_{\text {modo }}=\frac{B^{2}(\omega)}{2 \mu_{0}} V_{\text {modo }}
$$

Outro fator importante é o tempo de relaxação do modo, ligando o fator de qualidade da forma

$$
\tau_{\text {rel }}=\frac{Q}{\omega_{r}}
$$

Com os dados obtidos até agora, pode-se estimar a potência a ser injetada na cavidade por meio de

$$
P_{i n j}=\frac{E_{\text {modo }}}{\tau_{\text {rel }}}
$$

A relação entre as oscilações de Rabi entre os dois niveis hiperfinos do estado fundamental do ${ }^{133} C s$ e a potência de microonda injetada na cavidade é mostrada na figura 
24. Há diversas oscilações de Rabi entre os dois níveis hiperfinos do estado fundamental quando varremos o intervalo de potência de $-15 \mathrm{dBm}$ ate $-75 \mathrm{dBm}$. A amplitude máxima corresponde à potência necessária para submeter os átomos a dois pulsos $\frac{\pi}{2}$.

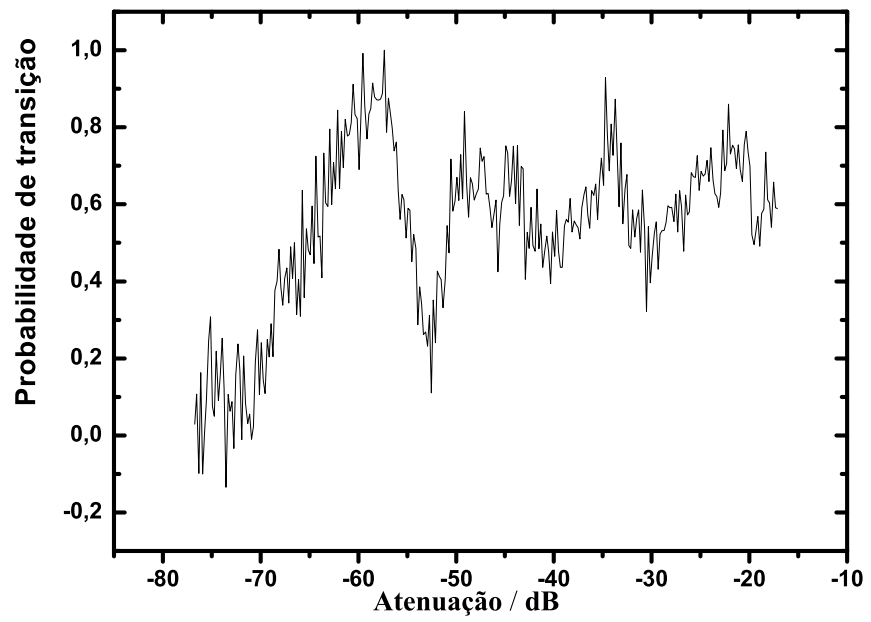

Figura 24: Variação da amplitude da probabilidade de transição como função da potência injetada na cavidade de microondas. Vemos que há diversas oscilações de Rabi entre os dois níveis hiperfinos do estado fundamental. A amplitude máxima corresponde à potência que é necessária para submeter os átomos a dois pulsos $\frac{\pi}{2}$.

\subsection{Controle de Temperatura}

Em 1967, o segundo foi definido baseado sobre o átomo de ${ }^{133} C s$ livre de qualquer perturbação. Em 1997 afirmou-se que o segundo é definido com relação aos átomos de ${ }^{133} \mathrm{Cs}$ em repouso e à temperatura termodinâmica de $0 \mathrm{~K}$. Logo, a frequiência de todos os padrões de freqüência devem ser corrigidas para o deslocamento da radiação de corpo negro devido à radiação ambiente. A radiação de corpo negro foi considerada relevante nos padrões de freqüência atômicos dos átomos de ${ }^{133} C s$ no início de 1980 por Itano et al (58). A expressão descrita por ele para o deslocamento de freqüência relativo da transição relógio do ${ }^{133} C s$ é,

$$
\frac{\Delta v}{v_{0}}=\beta\left(\frac{T}{T_{0}}\right)^{4}\left[1+\epsilon\left(\frac{T}{T_{0}}\right)^{2}\right]
$$


onde $\mathrm{T}$ é a temperatura termodinâmica expressa em Kelvin, $T_{0}=300 \mathrm{~K}$, e $v_{0}$ é a freqüência de transição relógio, $v_{0}=9,192631770 \mathrm{GHz}$. Os coeficientes $\beta$ e $\epsilon$ dependem do átomo e da transição considerada. Para átomos de césio a $T=300 \mathrm{~K}$, $\beta=-1,69(4) \times 10^{-14}$ e $\epsilon=1,4 \times 10^{-2}$. Essa expressão é adotada para corrigir a freqüência medida em todos os padrões de freqüência primários para o deslocamento devido à radiação de corpo negro. O Bureau International de Poids et Mesures (BIPM) recomendou em 1996 aplicar a correção devido a radiação de corpo negro em todos os padrões de freqüência primários reportando o valor $-1,64(4) \times 10^{-14}$ como o deslocamento à temperatura ambiente, $T=300 \mathrm{~K}$. Durante o vôo balístico dos átomos na região de interação, os átomos sentem um campo eletromagnético em equilíbrio termodinâmico com as paredes da zona de interrogação a uma temperatura T. Esta radiação térmica sentida pelos átomos é devida à radiação de corpo negro, e induz flutuações do campo elétrico e magnético e é dada pela lei de Planck (59). Assim, um corpo negro aquecido a uma temperatura $\mathrm{T}$, emite radiação térmica com uma distribuição espectral dada por

$$
\rho(v)=\frac{8 \pi v^{3}}{c^{3}} \frac{1}{\exp \left(\frac{h v}{k_{B} T}\right)-1}
$$

onde $h$ é a constante de Planck, c é a velocidade da luz e $k_{B}$ é a constante da Boltzmann. Estas flutuações do campo eletromagnético acoplam-se aos átomos e induzem a um deslocamento em seus níveis de energia. O efeito Stark é devido à deformação na nuvem eletrônica, o que implica numa alteração de funções de onda do estado fundamental ${ }^{2} S_{\frac{1}{2}}$ com relação aos estados excitados. O campo elétrico da radiação de corpo negro tem componentes significativas a frequiências que são muito menores do que as correspondentes à separação entre os estado fundamental e o excitado. O efeito dominante é proveniente das flutuações do campo elétrico oscilatório que induz um deslocamento de frequiência devido ao efeito Stark AC. No gráfico da figura 25 observamos o comportamento da densidade espectral $\rho(v)$ como função da freqüência para quatro valores diferentes da temperatura de corpo negro. À temperatura ambiente, a radiação de corpo negro mostra um espectro alargado, cuja largura a meia altura é 
aproximadamente $30 \mathrm{THz}$. Para o césio, o volume da distribuição espectral da figura 25 é muito pequeno para a freqüência do desdobramento hiperfino $v_{0}$ do estado fundamental e para a transição de dipolo elétrico mais baixa permitida, $v_{d}$. Comparando

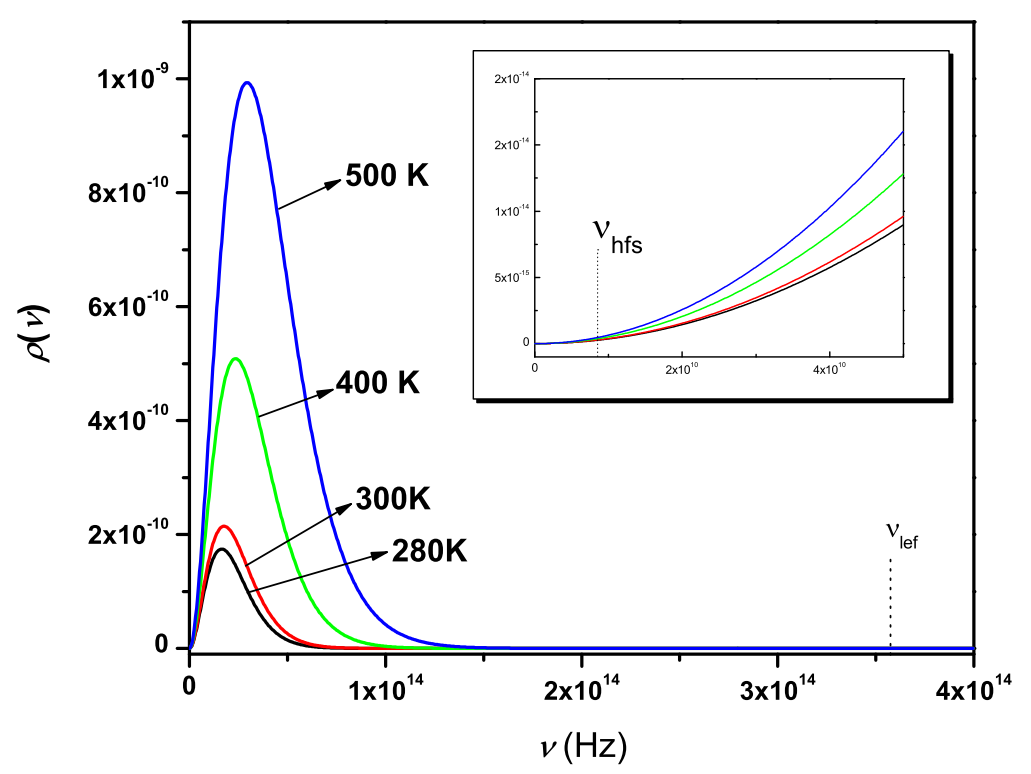

Figura 25: Densidade espectral da radiação de corpo negro para quatro temperaturas diferentes. Para o césio, a freqüência do desdobramento hiperfino no estado fundamental, $v_{0}$, e a transição de dipolo elétrico mais baixa permitida, $v_{d}$, estão indicadas.

o valor dos comprimentos de onda da transição hiperfina do ${ }^{133} \mathrm{Cs}, \lambda_{0}=32 \mathrm{~mm}$, aos comprimentos de onda de pico para as quatro temperaturas diferentes, podemos aproximar o efeito da radiação de corpo negro como sendo um efeito fraco proveniente de um campo AC não ressonante.

A partir da expressão 4.23 vemos que para se obter uma precisão melhor que $10^{-16}$ na medida da frequiência de ressonância do ${ }^{133} \mathrm{Cs}$ é preciso controlar a temperatura em até $0,5^{0} \mathrm{C}$. Por isso é necessário determinar precisamente a temperatura ao longo de todo o tubo de vôo livre para estimar a magnitude desse deslocamento. A temperatura de operação do tubo de vôo livre é de $38,8^{\circ} C$, que é a temperatura para sintonizar a cavidade de interrogação na freqüência de ressonância hiperfina do átomo de ${ }^{133}$ Cs. O tubo de vôo livre é aquecido por meio de três cintas térmicas e controlar 
a temperatura ao longo do tubo evita que o átomo sinta um gradiente de temperatura na região de interação, resultando flutuações na frequiência do espectro medido. No tubo de vôo livre, a temperatura é controlada por três resistências de Platina, PT100, estrategicamente posicionada sobre o tubo como mostra a figura 26. Um multímetro

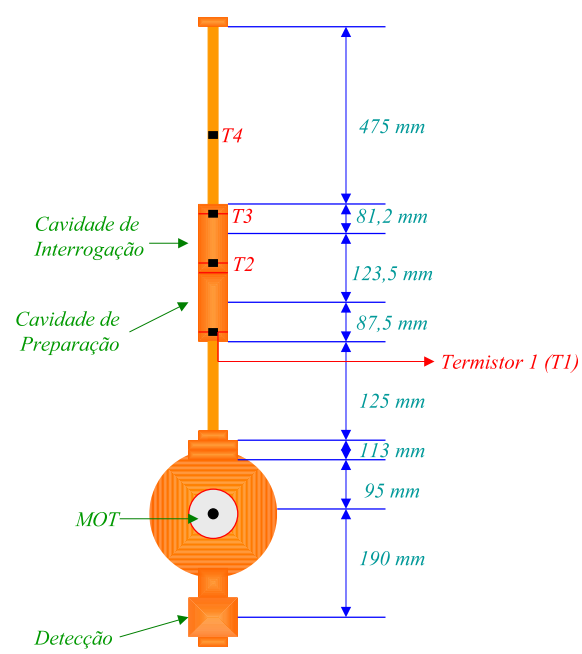

Figura 26: Esquema do sistema de vácuo do chafariz atômico com a posição dos termistores na região de vôo livre.

digital Keithley 195A é programado para medir diretamente a temperatura do PT100 por meio do método de 3 fios. A leitura é feita diretamente em ${ }^{\circ} C$.Ela é conectada a um microcomputador e uma medida de temperatura a cada 30 segundos foi programada para determinar a dispersão térmica em um dia, como mostra o gráfico da figura 27. O valor médio da temperatura é $(41,06 \pm 0,14)^{\circ} C$. Com esta precisão, a freqüência de ressonância medida é melhor que $\frac{\Delta v_{B B R}}{v_{0}}=1,17 \times 10^{-14}$.

\subsection{Sintetizador de Microondas}

Nesta seção descreveremos brevemente a cadeia de síntese de microondas. A montagem da cadeia bem como suas características de ruído foram objeto de estudo na tese de doutorado de Daniel Magalhães (33). Tanto a cavidade de preparação como a de 


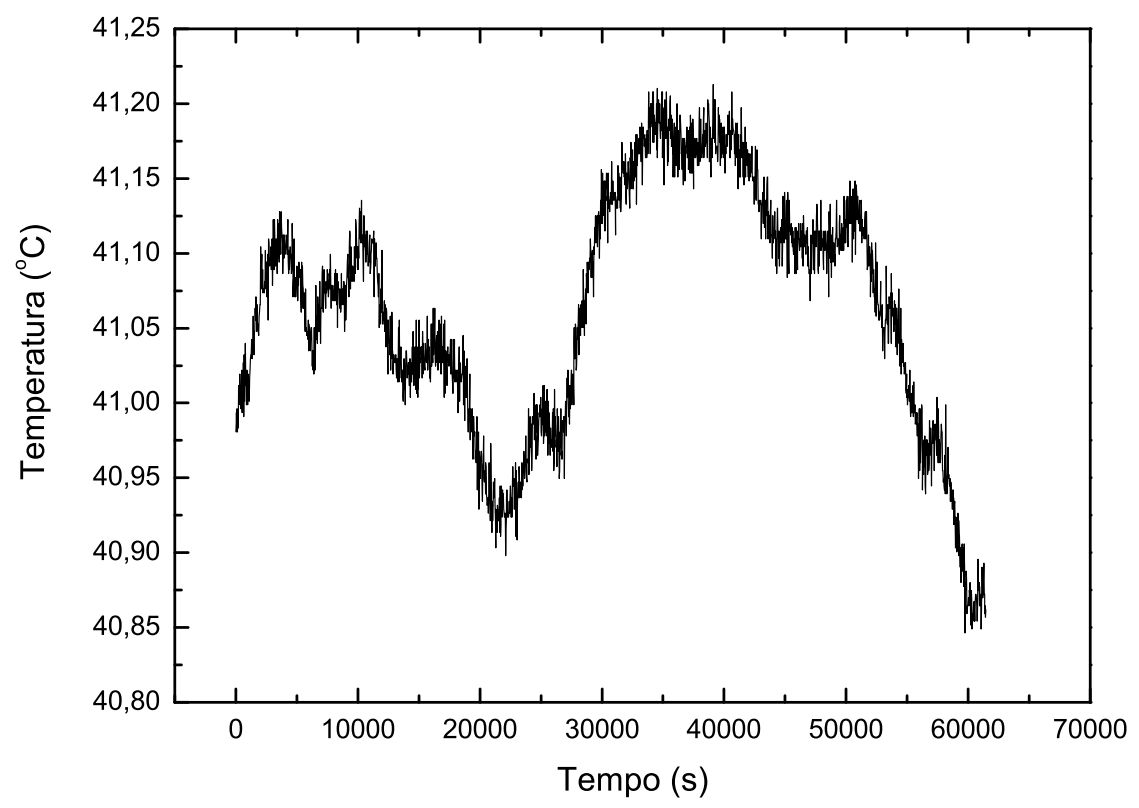

Figura 27: Variação da temperatura durante o dia medida através de um dos PT100 sobre o tubo de vôo livre.

interrogação são alimentadas por sintetizadores de microondas de alta qualidade espectral construídos pelo nosso grupo, com a colaboração da equipe francesa de tempo e freqüência do LNE-SYRTE. A cadeia foi explicada em $(33,54,60)$ e aqui apontaremos algumas de suas características.

O sinal gerado é idealizado como possuindo raias parasitas simétricas e de baixa amplitude, uma vez que a resposta atômica de um padrão de freqüência é simétrica em torno da frequiência de ressonância, bom nível de ruído próximo à portadora e boa estabilidade de freqüência a curto prazo. Além disso, a estabilidade de longo período do sinal sintetizado é da ordem de $\frac{p s}{d}$, pois o ciclo de funcionamento do padrão de átomos frios é razoavelmente longo e o tempo de escravização do oscilador de interrogação com base nos átomos é elevada. A cadeia de interrogação tem como base três osciladores ultra-estáveis: 4, $596 \mathrm{GHz}, 10 \mathrm{MHz}$ e $100 \mathrm{MHz}$. As características de ruído desses osciladores são tão boas que mesmo quando sua freqüência é multiplicada para a faixa de $\mathrm{GHz}$ o sinal ainda apresenta características melhores que os osciladores 
disponíveis comercialmente nessa faixa de operação. O oscilador de referência é o de 10 MHz OCXO 8600, Osciloquartz - Suíça, chamado de BVA (Boitier a Viellisement Amelloré). O oscilador de $100 \mathrm{MHz}$ é um OCXO 500-07542A Wenzel - USA e o oscilador de 4,596 GHz é um ressonador dielétrico DRO 4R596-10SF da Omega Technologies que possui uma raia principal em 4,596 GHz com $10 \mathrm{dBm}$ de potência e uma outra raia em 9,192 GHz, correspondente ao segundo harmônico, com -15dBm de potência.

Na cadeia, o sinal de $100 \mathrm{MHz}$ é multiplicado por 2, depois dividido por 10 e comparado ao sinal do BVA de $20 \mathrm{MHz}$ (o sinal de 10MHz multiplicado por 2). Eles estão travados em fase entre si via um circuito eletrônico de travamento, PLL (Phase Locked Loop). A diferença de fase entre eles é o sinal de erro que é injetado no oscilador de $100 \mathrm{MHz}$.

A freqüência do sinal de interrogação, $9192631770 \mathrm{~Hz}$, é obtida a partir do oscilador otimizado de $4,6 \mathrm{GHz}$ travado em fase com o oscilador de $100 \mathrm{MHz}$. Nessa configuração, a estabilidade do BVA de $10 \mathrm{MHz}$ é transferida ao DRO de 4,596 GHz através do VCXO de $100 \mathrm{MHz}$. A freqüência dobrada do oscilador de $100 \mathrm{MHz}$ e o sinal de 4,596 GHz são enviados a um Sampling Mixer. Dessa forma, utilizando o $23^{\circ}$ harmônico do sinal de $200 \mathrm{MHz}$, a diferença entre os dois sinais é de 3,684115 MHz. Essa diferença é comparada a um sintetizador externo Direct Digital Synthesis DS 345 (Stanford) que permite modular o sinal de microondas injetado na cavidade em torno da linha de transição do ${ }^{133}$ Cs. O sinal de modulação fornecido ao sintetizador digital direto é controlado por um microcomputador através de uma interface GPIB.

Um diagrama esquemático da cadeia de interrogação é mostrado na figura $28 . \mathrm{Na}$ saída da cadeia de síntese de microonda foram conectados um filtro de banda 8,5 a $11 \mathrm{GHz}$ para eliminar o sinal fundamental do DRO de $4,6 \mathrm{GHz}$, a atenuação para o sinal de 4,5 GHz é de $100 \mathrm{~dB}$. Um isolador, que minimiza os problemas de reflexão provenientes do acoplamento com a cavidade de microondas, e um atenuador variável, para controlar o nível de potência necessário para alimentar a cavidade (reduz o sinal de 


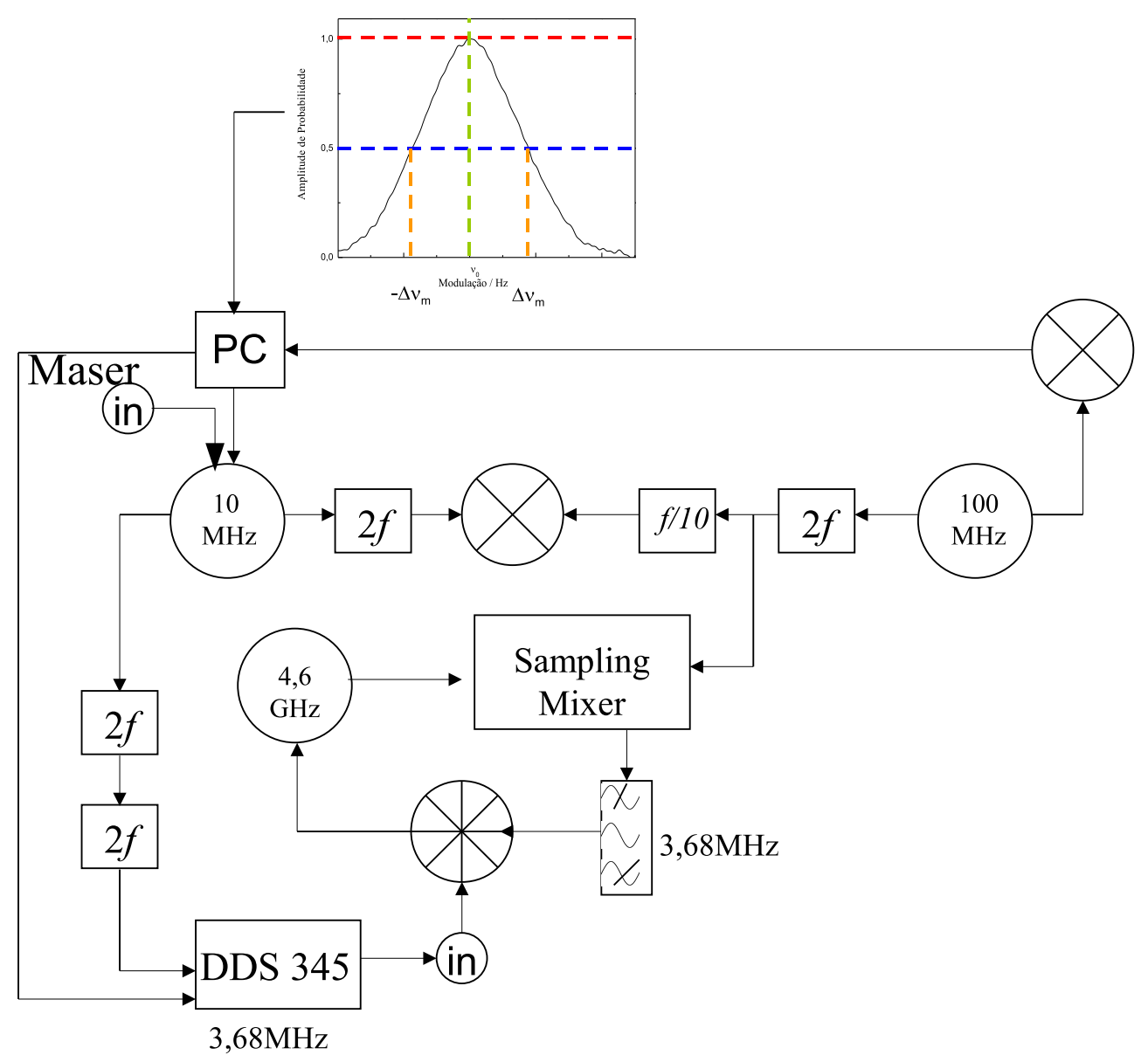

Figura 28: Diagrama esquemático da cadeia de síntese de 9192631770 Hz para a interrogação dos átomos de ${ }^{133} C s$.

saída em até $60 \mathrm{~dB}$ ) também são colocados na saída. Este sintetizador foi comparado com outro similar e a estabilidade em curto prazo da cadeia é de $9,7 \times 10^{-14} \tau^{-1 / 2}$.

Uma segunda cadeia é usada para alimentar a cavidade de preparação, onde um pulso $\pi$ pode ser usado para inverter a população dos átomos no estado ${ }^{6} S_{1 / 2} F=$ $4, m_{F}=0 \longleftrightarrow^{6} S_{1 / 2} F=3, m_{F}=0$, a fim de aumentar a relação sinal-ruído e, conseqüentemente, a estabilidade do relógio. Como a cavidade de preparação está mais longe da região de vôo livre, a potência do sinal injetado não desempenha um papel fundamental. Nessa cadeia foi utilizada um DRO de 9,192 GHz de 10,84 dBm ao invés de um de 4,596 GHz. A parte de baixa freqüência dessa cadeia é a mesma da cadeia de interrogação. A freqüência do DRO é travada em fase ao $46^{\circ}$ harmônico do oscilador de $100 \mathrm{MHz}$ e a frequiência de saída é de 7,3 MHz. Esse sinal é comparado 
com o sinal gerado por um sintetizador externo e gera um sinal de erro que corrigirá o DRO de 9,1 GHz. Após a passagem dos átomos através da cavidade de preparação, o sinal de microondas deve ser desligado até o próximo ciclo do relógio. Isso é feito por meio de um switch (F192A, General Microwave) na saída da cadeia, que corta a alimentação da cadeia com $80 \mathrm{~dB}$ de isolamento ao receber um pulso de comando. 


\section{Sistema Óptico do Chafariz Atômico}

\subsection{Introdução}

Um chafariz de átomos utiliza técnicas de aprisionamento e resfriamento para interrogar os átomos segundo o método de Ramsey de dois campos oscilatórios separados. Para a realização desse sistema experimental, diversos estudos com relação às técnicas de manipulação e resfriamento atômicos, desenvolvidas no início da década de 90 através de luz laser, permitiram obter tempos de medida significativamente mais longos e permitiram a realização de um chafariz atômico operado com átomos frios.

Essas técnicas consistem em capturar átomos a partir de vapor térmico, por exemplo, e resfriá-los a temperaturas de alguns $\mu K$ acima do zero absoluto. Em um chafariz atômico, essa amostra fria de átomos é lançada de forma que eles passem duas vezes através da mesma cavidade de microondas durante seu vôo balístico. Assim, ressonâncias da ordem de $1 \mathrm{~Hz}$ de largura são obtidas e aumentam consideravelmente a resolução das medidas.

Em nosso chafriz empregamos a técnica de aprisionamento magneto-óptico (MOT) para acumular átomos de ${ }^{133}$ Cs. No MOT, os átomos são confinados na região de interseção dos seis feixes de luz laser de resfriamento circularmente polarizados, combinado sobre o centro de um gradiente de campo magnético gerado por um quadrupolo magnético. Quando um número suficiente de átomos é coletado, o campo do quadrupolo é desligado e uma fase de melado óptico é iniciada. O passo seguinte é lançar os 
átomos pela técnica de melado em movimento $(13,14)$ a altitudes de até $75 \mathrm{~cm}$ no caso do nosso sistema. O último estágio do refriamento consiste no resfriamento subDoppler da nuvem. Essa fase é essencial para a operação do chafariz atômico, uma vez que sem ela a temperatura da amostra atômica seria limitada no limite Doppler, $127 \mu K$. A baixa temperatura é essencial para minimizar a expansão da nuvem durante a trajetória, comprometendo a relação sinal ruído na região de detecção. Ao final dessa fase, todos os feixes de resfriamento são desligados, com o laser de rebombeio sendo desligado ligeiramente após o laser de resfriamento. Os átomos terminam distribuídos ao longo dos subníveis atômicos $\left|4, m_{F}\right\rangle$, com $m_{F}=-4,-3, \ldots,+4$ indicando os subníveis magnéticos. Os átomos passam uma vez pela cavidade de Ramsey, entram em uma região livre de qualquer interação eletromagnética atingem o ápice e caem, passando pela segunda vez pela mesma cavidade de microondas. Após a interação de Ramsey, a transição relógio, $\left|3, m_{F}=0\right\rangle \rightarrow\left|4, m_{F}=0\right\rangle$ é excitada. Ao final da trajetória balística, os átomos são detectados nos dois estados $\left|3, m_{F}\right\rangle$ e $\left|4, m_{F}\right\rangle$. A figura 29 mostra os níveis de energia da linha $D_{2}$ do ${ }^{133} C s$ bem como os comprimentos de onda utilizados para o funcionamento do chafariz.

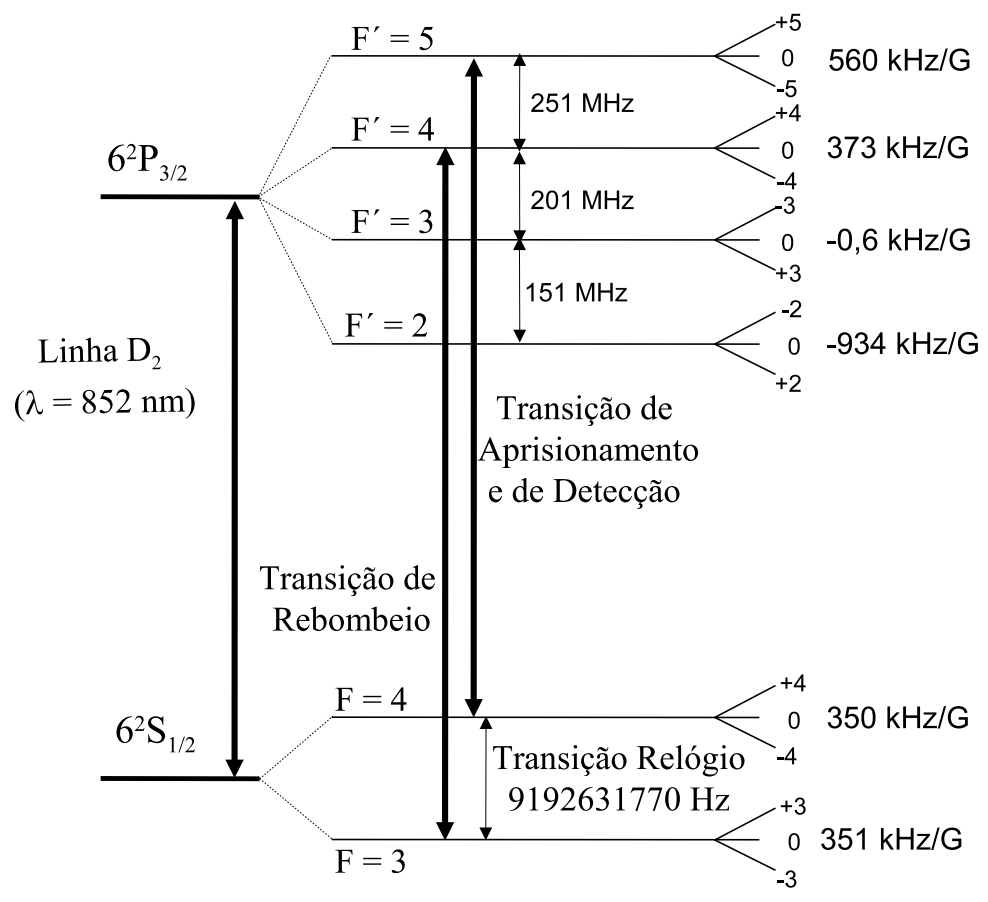

Figura 29: Níveis de energia da linha $D_{2}$ do ${ }^{133} C s$ com as transições utilizadas para resfriar e detectar os átomos. 
Neste capítulo discutiremos a disposição óptica sobre a mesa para a geração dos feixes laser estabilizados para as diferentes fases do ciclo de funcionamento do chafariz atômico. A montagem óptica deverá fornecer potência suficiente para os feixes laser com até alguns $\mathrm{mWcm}^{-2}$ para o feixe de resfriamento e alguns $\mu \mathrm{Wcm}^{-2}$ para o feixe de rebombeio. Além disso, é preciso fornecer os meios para variar a potência da luz laser e os deslocamentos de freqüência necessários para as diferentes fases do ciclo de operação do chafariz. Para a região de detecção, alguns $\mathrm{mW} \mathrm{cm}^{-2}$ de luz, na transição cíclica do césio indicada na figura 29, são necessários, além de luz de rebombeio de baixa intensidade. Além disso, os feixes ópticos precisam ser completamente bloqueados durante a interação dos átomos com a microonda, para garantir que a freqüência de transição não seja deslocada por efeito Stark AC. Também discutiremos a montagem experimental dos lasers de diodo utilizados e seu sistema de travamento de freqüência. A figura 30 mostra uma foto da disposição óptica atual sobre a mesa.

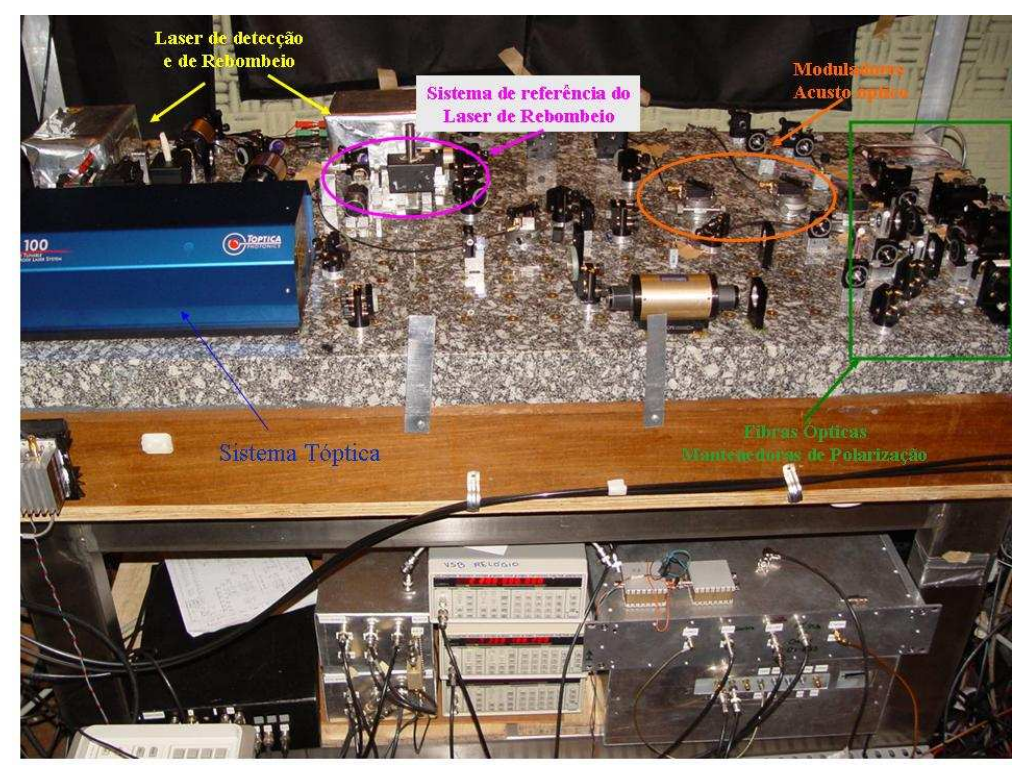

Figura 30: Visualização geral da mesa óptica.

\subsection{Montagem Óptica}

A figura 31 mostra o diagrama com a disposição dos componentes ópticos sobre a mesa. 


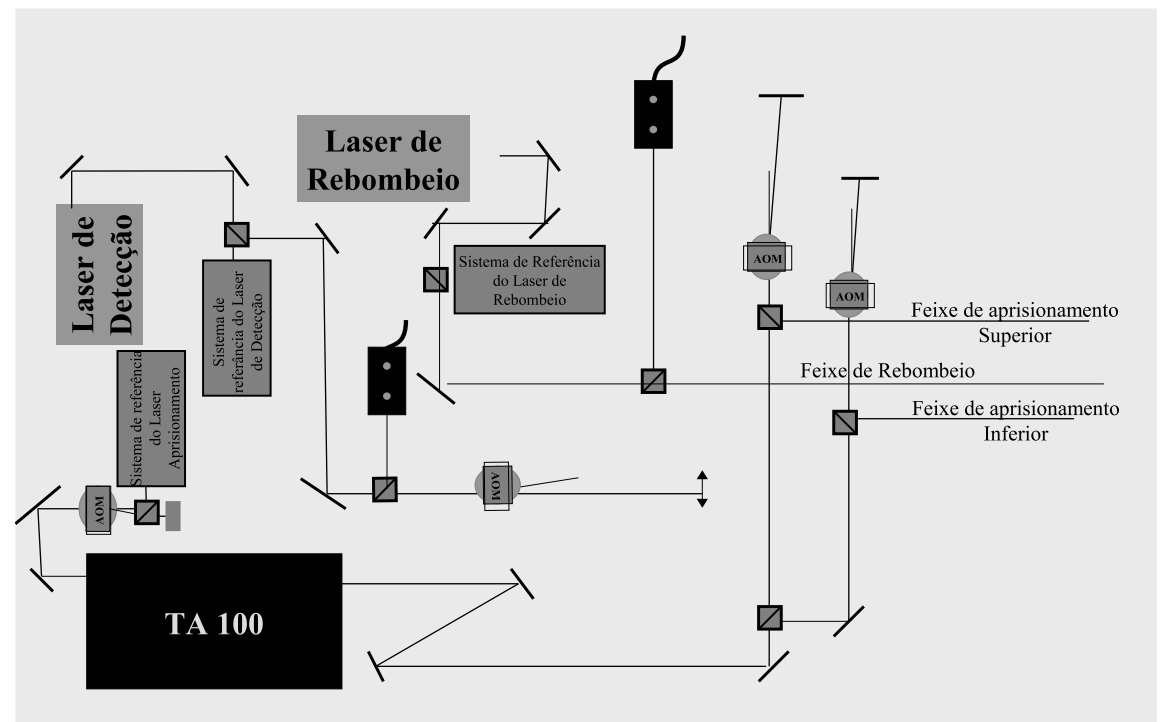

Figura 31: Diagrama esquemático da mesa óptica do padrão de átomos frios.

Para aprisionar e resfriar os átomos utiliza-se um sistema Tóptica (modelo TA 100) constituído por um laser de diodo montado na configuração de cavidade estendida, denominado de laser mestre, e um amplificador do tipo MOPA (Master Oscillator Power Amplifier). O laser mestre está travado por um sistema de referência de célula de absorção saturada. A absorção saturada do laser mestre foi implementada com um modulador acústico-óptico, AOM, para controlar os deslocamentos de freqüência do laser para os diferentes estágios do ciclo de operação, que vai desde a fase do aprisionamento magneto-óptico, para a captura dos átomos, passando pela fase de melado óptico até a fase de resfriamento sub-Doppler onde a freqüência do laser de resfriamento varia de $-2 \Gamma \mathrm{MHz}$ até $-8 \Gamma$ em intervalos de tempo de alguns ms. A frequiência do laser é deslocada em até $280 \mathrm{MHz}$ para o azul do crossover das linhas $6^{2} S_{\frac{1}{2}}(F=4) \longrightarrow 6^{2} P_{\frac{3}{2}}(F=5)$ e $6^{2} S_{\frac{1}{2}}(F=4) \longrightarrow 6^{2} P_{\frac{3}{2}}(F=4)$ que é a freqüência de referência utilizada. O crossover está deslocada de 125,5 $\mathrm{MHz}$ para o vermelho da transição atômica $6^{2} S_{\frac{1}{2}}(F=4) \longrightarrow 6^{2} P_{\frac{3}{2}}(F=5)$. Logo, a freqüência de saída do laser mestre é deslocada de $154 \mathrm{MHz}$ para o azul da linha $6^{2} S_{\frac{1}{2}}(F=4) \longrightarrow 6^{2} P_{\frac{3}{2}}(F=5)$ como mostra o diagrama da figura 32. O MOPA é alimentado com $35 \mathrm{~mW}$ da luz do laser mestre e gera até $750 \mathrm{~mW}$ no mesmo comprimento de onda de excitação.

O feixe de saída do MOPA é distribuído sobre a mesa óptica por meio de cubos 


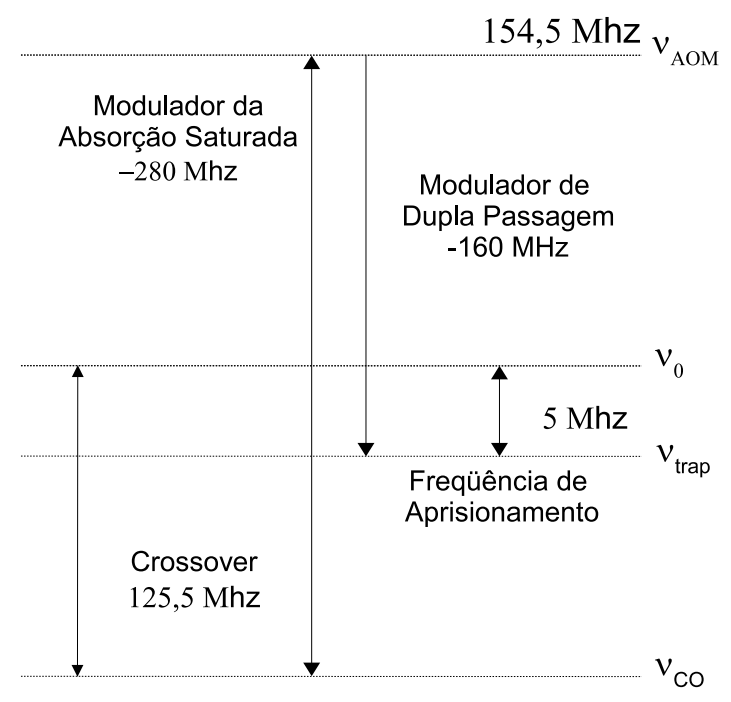

Figura 32: Diagrama esquemático com as frequiências de sintonia do feixe de resfriamento obtidas com os AOM de $280 \mathrm{MHz}$ e de $80 \mathrm{MHz}$ posicionados sobre a mesa óptica. $\quad v_{0}$ corresponde à freqüência de transição cíclica $6^{2} S_{\frac{1}{2}}(F=4) \longrightarrow$ $6^{2} P_{\frac{3}{2}}(F=5) . \quad v_{C O}$ corresponde a freqüência de referência, cross-over entre as transições $6^{2} S_{\frac{1}{2}}(F=4) \longrightarrow 6^{2} P_{\frac{3}{2}}(F=5)$ e $6^{2} S_{\frac{1}{2}}(F=4) \longrightarrow 6^{2} P_{\frac{3}{2}}(F=4)$, utilizada para travar o laser mestre. Assim, a freqüência de saída do feixe do MOPA está 154,5 $\mathrm{MHz}$ deslocado da transição atômica. Após a dupla passagem pelo modulador de 80 $\mathrm{MHz}$, o feixe de resfriamento está deslocado em frequiência da ordem de uma largura de linha natural da transição do ${ }^{133} \mathrm{Cs}, \approx 5,3 \mathrm{MHz}$.

polarizadores e lâminas de meia onda. Fibras ópticas do tipo monomodo e mantenedoras de polarização levam a luz laser da mesa óptica até a câmara de vácuo. Antes de acopladas nas fibras ópticas, o feixe de saída do MOPA é dividido em dois. Cada um desses feixes passa por AOMs distintos alinhados em dupla passagem (61). Esses AOMs operam em 80 MHz e são alinhados para difratar a ordem -1. Portanto, o deslocamento total do feixe laser do MOPA é de $160 \mathrm{MHz}$ para o vermelho e a luz acoplada na fibra óptica está deslocada em freqüência da ordem de uma largura de linha natural da transição do ${ }^{133} \mathrm{Cs}\left(\frac{\Gamma}{2 \pi}=5,3 \mathrm{MHz}\right)$, como mostrado no diagrama da figura 32 . Por fim cada um desses feixes é divido em três, por meio de cubos polarizadores em associação a lâminas de meia onda, formando um conjunto de três feixes superiores e outro conjunto de três feixes inferiores. Antes de acopladas nas fibras, o feixe de rebombeio é sobreposto a dois feixes de aprisionamento do conjunto superior.

Outro laser de diodo SDL-5412-HI, também montado na configuração de cavidade 
estendida mas sem amplificação, é usado para o rebombeio dos átomos e está travado por um sistema de referência de absorção saturada na transição $6^{2} S_{\frac{1}{2}}(F=3) \longrightarrow$ $6^{2} P_{\frac{3}{2}}(F=4)$. Por meio de uma lâmina de meia onda associada a um cubo polarizador, uma parte dessa luz vai para o sistema de aprisionamento magneto-óptico e outra parte para o sistema de detecção. Um terceiro laser de diodo SDL-5412-H1 é usado para a detecção dos átomos e está travado na transição $6^{2} S_{\frac{1}{2}}(F=4) \longrightarrow 6^{2} P_{\frac{3}{2}}(F=5)$.

No sistema de vácuo, as fibras ópticas são conectadas a expansores de luz, montados na câmara de aprisionamento e no sistema de detecção, produzindo feixes colimados de aproximadamente $26 \mathrm{~mm}$ de diâmetro $\left(\frac{1}{e^{2}}\right)$. Nos expansores foram montados cubos polarizadores e lâminas de quarto de onda para gerar feixes circularmente polarizados para o aprisionamento magneto-óptico. Os expansores foram fixados sobre uma base metálica que tem por finalidade sustentar o sistema de vácuo do chafariz atômico. A luz de saída desses expansores é introduzida na câmara de aprisionamento por meio de espelhos através de janelas montadas na câmara de vácuo.

O aprisionamento atômico é feito por meio de uma armadilha magneto-óptica, MOT, na configuração $(1,1,1)(62)$. Nesta geometria, a orientação dos feixes é tal que todos os três feixes superiores e os três inferiores fazem um ângulo de aproximadamente $35^{\circ}$ com o plano horizontal. As bobinas que geram o gradiente de campo magnético para o aprisionamento magneto óptico dos átomos estão posicionadas na direção-y, como mostra a figura 33. O ponto de zero do gradiente de campo coincide com a posição de interseção dos seis feixes de resfriamento.

As bobinas de confinamento dos átomos foram construídas de modo a gerar um gradiente de campo magnético até $20 \frac{G}{c m}(\approx 25 A)$ na direção do eixo das bobinas. A corrente tão elevada é necessária por causa da disposição das bobinas, que não se encontram em configuração anti-Helmholtz graças ao diâmetro da câmara de vácuo na região de aprisionamento. Devido a alta corrente necessária para gerar o campo magnético, um circuito simples de chaveamento de corrente com a utilização de um MOSFET de potência permite desligar a corrente das bobinas de aprisionamento em 
um intervalo de tempo da ordem de 40ms. O controle de campo magnético é feito através de um sinal TTL enviado por um microcomputador em sincronismo com as outras fases da seqüência temporal. A configuração (111) dos lasers de aprisionamento com o campo magnético faz com que o arranjo de polarização dos feixes $\left(\sigma^{+}-\sigma^{+}\right)$seja a mesma uma vez que o gradiente de campo magnético levanta a degenerescência dos subníveis Zeeman da mesma forma para cada uma das direções devido ao sentido de orientação das linhas de campo magnético.

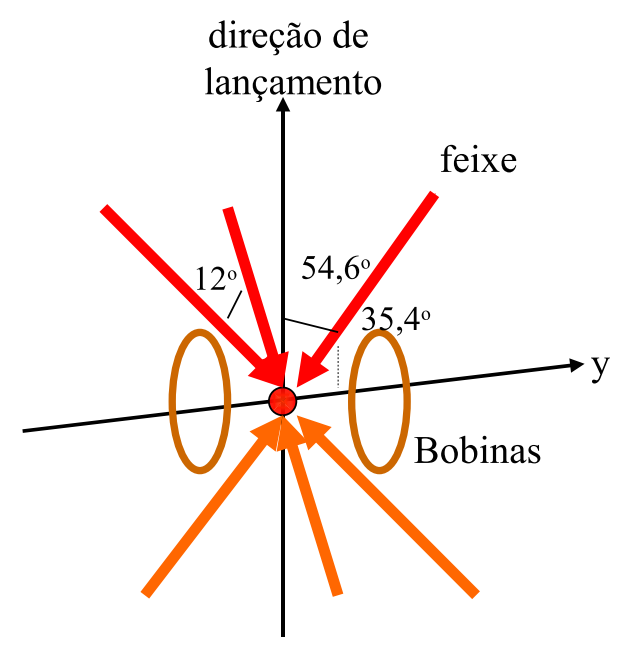

Figura 33: Orientação dos feixes superiores e inferiores que fazem um ângulo de aproximadamente $35^{\circ} \mathrm{com}$ a horizontal e a bobina de aprisionamento está no plano y.

O alinhamento dos expansores foi modificado com relação a montagem anterior (33). Elas eram conectadas diretamente na câmara de vácuo e ajustados através de suportes parafusados às janelas com pequenos ajustes para o direcionamento dos feixes. Uma vez que as janelas não estão alinhadas por construção e o arranjo das bobinas é limitado, o alinhamento entre o zero de campo e a interseção dos feixes de aprisionamento tornava-se difícil, resultando numa perda elevada de átomos durante as transferências entre a armadilha magneto óptica, o melado óptico e o lançamento. Dessa forma removemos os expansores da janela e as posicionamos sobre a base metálica. Os feixes laser são introduzidos na câmara de vácuo por meio de dois espelhos, permitindo o ajuste para o direcionamento dos feixes com o zero do gradiente de campo 
magnético. Além disso, devido a um dreno de corrente constituído por uma resistência variável em paralelo a uma das bobinas é possível introduzir pequenas correções na posição do campo. Uma imagem dos átomos aprisionados em uma armadilha magneto óptica é mostrada na figura 34 . Uma medida de fluorescência mostrou que o número de átomos conseguidos nessa configuração é de aproximadamente $10^{9}$.

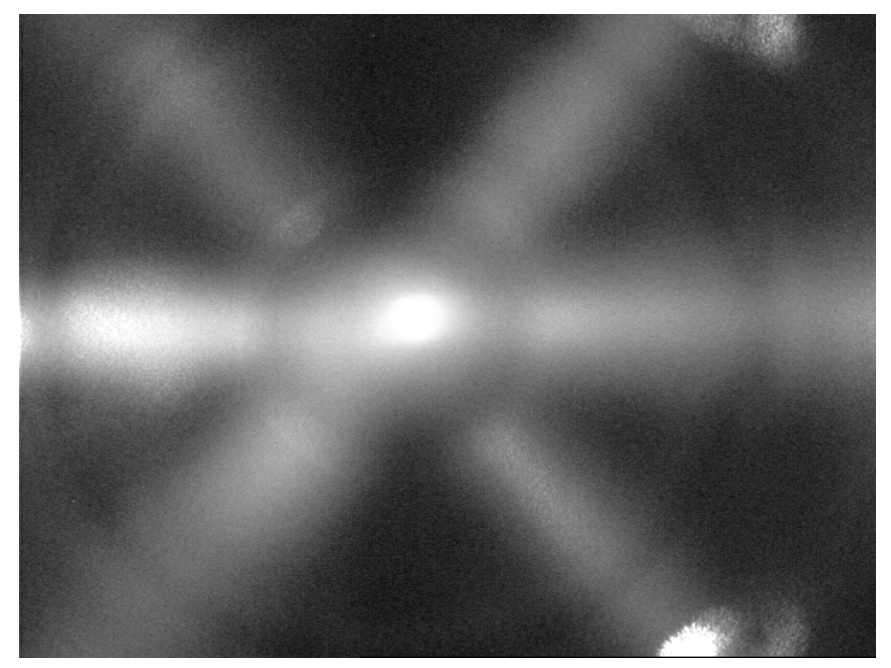

Figura 34: Imagem de átomos capturados na armadilha magneto-óptica.

Nessa configuração passamos a otimizar os passos da sequiência temporal de modo a maximizar o sinal de tempo de vôo observado na região de detecção. Inicialmente o objetivo principal é o de maximizar a quantidade de átomos aprisionados, além de proporcionar o melhor alinhamento entre a posição inicial da nuvem atômica e a região de detecção. Analisamos os limites de temperatura do sistema e a eficiência de captura, como função do deslocamento de frequiência e da atenuação dos feixes de aprisionamento durante a fase de aprisionamento magneto óptico.

No gráfico da figura 35(a) observamos que a temperatura cai com o deslocamento de freqüência. No entanto, para valores maiores do que 2,5Г a eficiência de captura dos átomos diminui muito, como observado no grafico da figura 35(b). Nesse gráfico, obtido através da área dos sinais de tempo de vôo normalizada, ( que é proporcional ao número de átomos ), observamos que a maior eficiência de captura é obtida para um deslocamento de freqüência dos feixes de resfriamento $1,7 \Gamma$. Durante a fase de melado óptico o campo é desligado e por meio da análise dos sinais de tempo de vôo, para a 


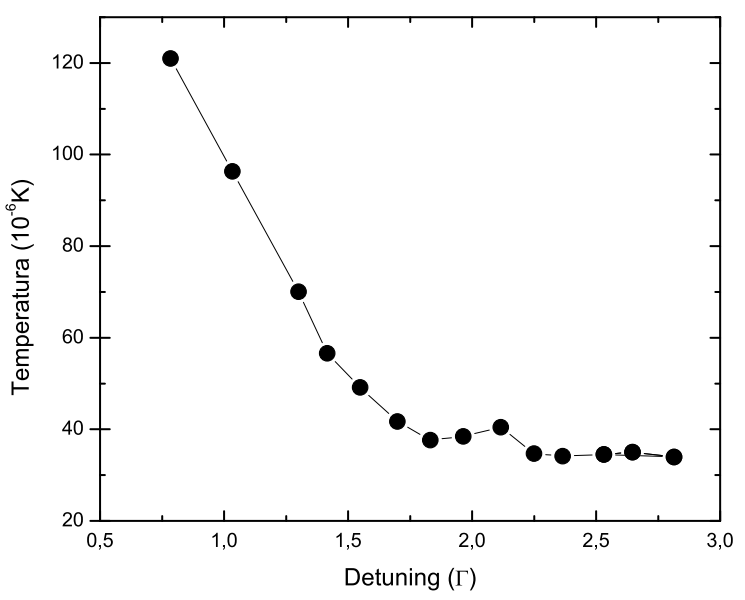

(a)

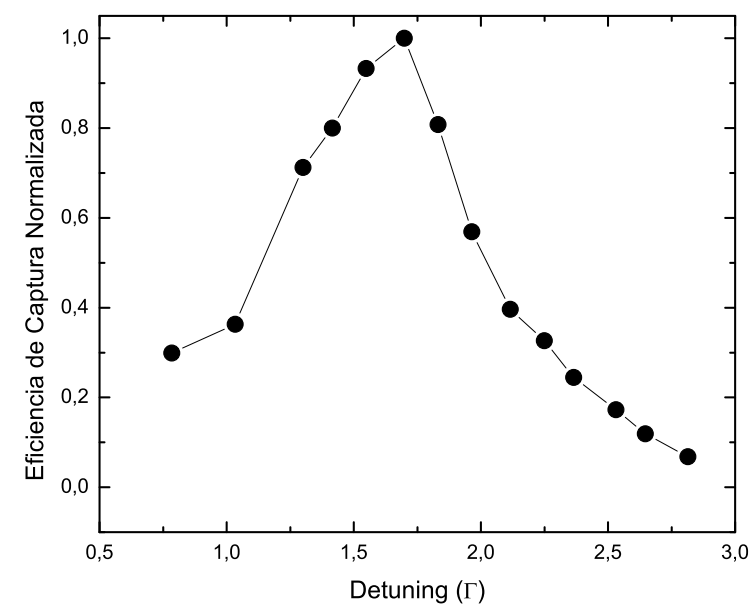

(b)

Figura 35: (a)Temperatura dos átomos para diferentes valores de deslocamento de freqüência, apenas com MOT. (b)Eficiência de captura para diferentes valores de detuning.

queda livre dos átomos, estudamos as melhores condições de freqüência e potência dos feixes de resfriamento para maximizar a transferência dos átomos durante a fase de transição entre MOT e melado óptico. Para analisar as melhores condições para a transferência de átomos da armadilha magneto óptica para o melado óptico mantivemos a frequiência dos feixes de resfriamento deslocados de $1,7 \Gamma$ durante a fase de aprisionamento magneto óptico e variamos a freqüência dos feixes de aprisionamento 
passando da fase de MOT para a fase de melado óptico e analisamos a temperatura e o número de átomos que atingem a região de detecção. No gráfico da figura 36(a) apresentamos a temperatura dos átomos como função dos diferentes valores de deslocamento de freqüência. Nela constatamos que os valores de temperatura obtidos caem ainda mais com relação aos valores obtidos anteriormente. A temperatura parece cair além do deslocamento de freqüência do nosso sistema. Esse limite é imposto pelo sistema comercial da TOPTICA, utilizado para produzir os feixes de resfriamento, que tem limites de velocidade de ajuste da fonte de corrente. Como o deslocamento de frequiência é feito atuando-se no AOM da absorção saturada do laser, ao atuar no modulador, o circuito de travamento age na corrente e no PZT do laser mestre para manter o laser sempre no pico da absorção saturada. Desse modo, para variações muito grandes de freqüência, o controlador não é capaz de manter o sinal travado na linha, limitando a região que podemos explorar $(<8 \Gamma)$. Devemos nos atentar para a diferença de limitações desta medida e da anterior. Na anterior a limitação era a eficiência de captura. Entretanto, nesse último gráfico, o sinal melhora sempre, mas o sistema não permite continuar o deslocamento de freqüência. Isto fica claro no gráfico da figura 36(b) onde o número final de átomos aumenta para valores maiores do deslocamento de frequiência.

O próximo passo é enviar a amostra de átomos frios lentos para a região de interrogação. O lançamento da nuvem dos átomos aprisionados é feita transferindo-se de momentum aos átomos na direção do eixo do chafariz atômico, como mostra a figura 33, por meio da técnica de melado em movimento. Utilizando-se os próprios feixes de resfriamento, introduz-se um deslocamento de freqüência para o vermelho nos três feixes laser superiores e para o azul nos três feixes inferiores, por meio dos moduladores acústico-ópticos de $80 \mathrm{MHz}$. Ao introduzir o deslocamento de freqüência, o referencial de repouso das átomos no feixe laser será deslocado, por efeito Doppler, pela mesma quantidade de diferença de frequiência introduzida nos feixes, colocandoos em movimento com uma velocidade de fase dada por $v=\frac{c \Delta v}{2 v}=\frac{\lambda \Delta f}{2}$, onde $\Delta f$ é 


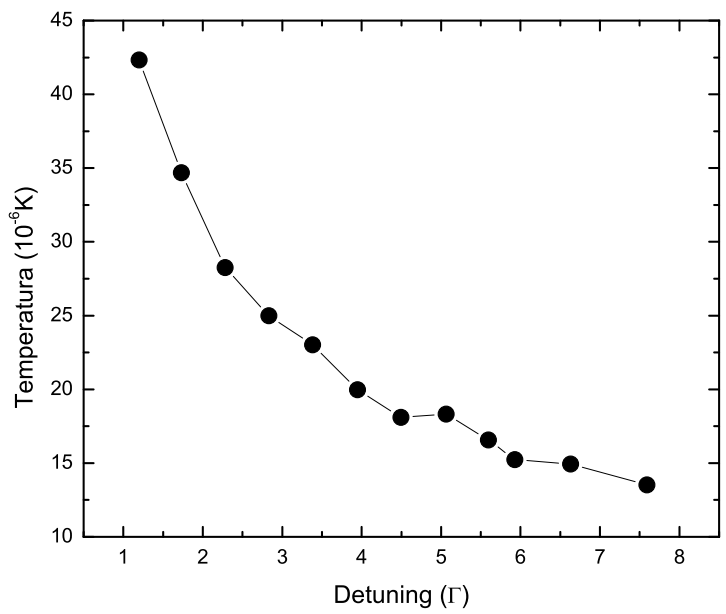

(a)

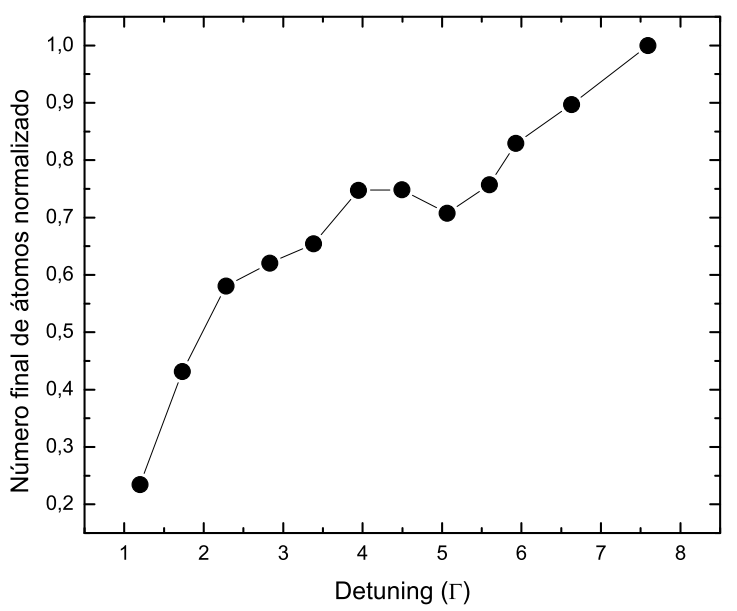

(b)

Figura 36: Temperatura dos átomos para diferentes valores de deslocamentos passando da fase de armadilha magneto óptica para a fase de molasses. Durante a fase de MOT a frequiência do laser de resfriamento foi mantida $1,7 \Gamma$ deslocada da transição de ressonância. Número final de átomos para diferentes valores de deslocamentos de frequiência passando da fase de MOT para a fase de melado óptico.

a diferença de freqüência dos dois feixes contrapropagantes e $\lambda$ é o comprimento de onda utilizado, $(852 \mathrm{~nm})(13)$.

Na configuração utilizada, em que os feixes estão em formação $(1,1,1)$, a velocidade inicial dos átomos é dada pela resultante da contribuição de cada um dos eixos de aprisionamento. Para os dois campos de diferentes freqüências a velocidade de fase da 
onda, no referencial dos átomos, é dada por (62)

$$
v=\frac{\sqrt{3} \lambda \Delta f}{2}
$$

onde $\Delta f$ é a diferença de freqüência entre os feixes superiores e inferiores e $\lambda$ é o comprimento de onda da luz utilizada.

É interessante salientar que durante a fase inicial de testes de lançamento no chafariz observou-se uma queda significativa no sinal de tempo de vôo à medida que a velocidade inicial da nuvem aumentava. Após diversas tentativas em melhorar o desempenho do lançamento observou-se um problema fundamental da câmara de vácuo: os braços de um dos eixos possuía angulação diferente dos demais com relação ao eixo vertical imprimindo à nuvem uma resultante de lançamento fora do eixo desejado. $\mathrm{O}$ método imediato utilizado para corrigir o lançamento foi feito através dos próprios feixes, inserindo mais dois AOMs nessa direção, com a alteração das freqüências individuais para compensar a diferença de ângulo. No entanto, há uma discrepância entre a componente de velocidade inicial calculada através do deslocamento freqüência e a velocidade real obtida através do tempo de vôo da nuvem de átomos aprisionados, como mostra o gráfico da figura 37(a) e apresentado em (33). A discrepância foi atribuída principalmente à eficiência de arrasto do melaço em movimento, feito conjuntamente ao resfriamento sub-Doppler, uma vez que a rádio- freqüência que alimenta os osciladores de radio frequiência não estavam travados em fase entre si.

Dessa forma, decidimos reparar a câmara de vácuo e corrigir o ângulo do braço de lançamento, permitindo reduzir a complexidade no alinhamento da mesa óptica e no controle de um maior número de moduladores e por implementar um travamento de fase entre feixes superiores e inferiores durante o processo de lançamento atômico. No gráfico 37(b) vemos que a discrepância observada anteriormente foi corrigida e como resultado dessa mudança somos capazes de lançar eficientemente a nuvem atômica em até $75 \mathrm{~cm}$ acima da região de MOT e após $820 \mathrm{~ms}$ do lançamento observar um sinal de TOF razoável a $19 \mathrm{~cm}$ abaixo do MOT como mostrado no gráfico da figura 38 . 


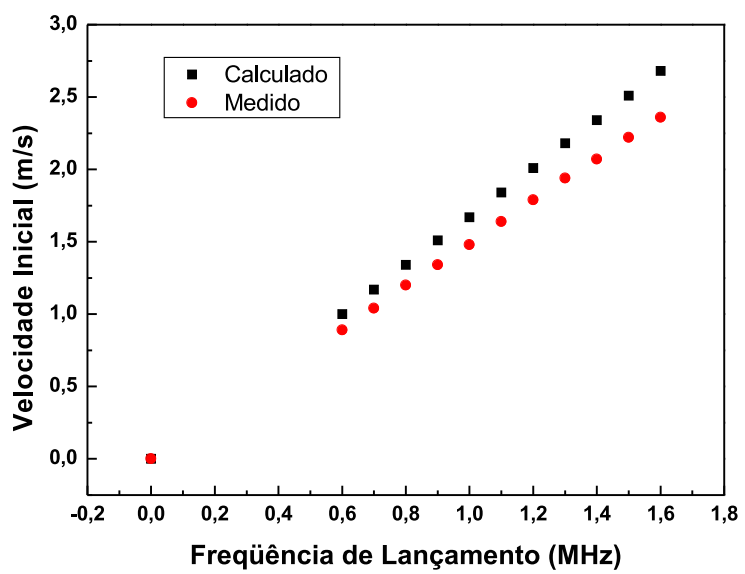

(a)

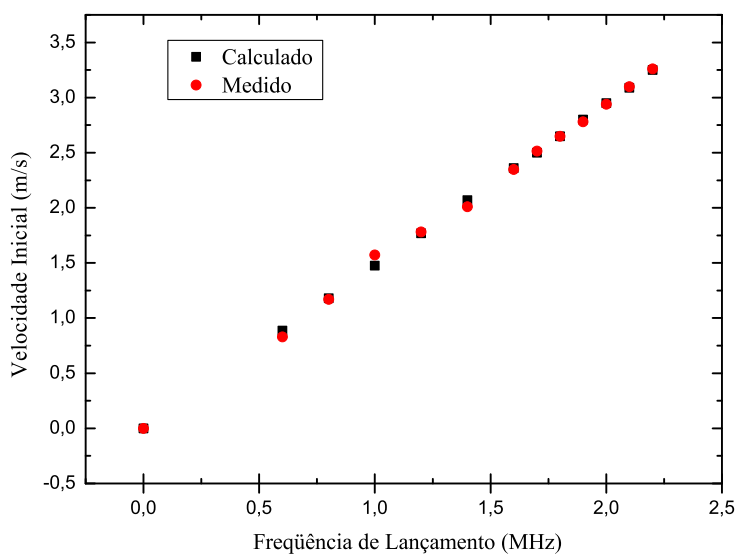

(b)

Figura 37: (a)Velocidades iniciais obtidas anteriormente com o valor de freqüência de lançamento e com o tempo de vôo dos átomos. A discrepância entre o valor teórico e experimental é atribuído ao não travamento de fase entre os diferentes $\mathrm{VCO}$ s que fazem o lançamento dos átomos. (b)Velocidades iniciais obtidas após a correção do ângulo do braço de lançamento.

Por fim passamos para o estágio de resfriamento sub-Doppler, onde variamos a rampa de frequiência de $-2 \Gamma$ até $-8 \Gamma$ simultaneamente com a redução da intensidade dos feixes para $0,5 \mathrm{~mW} \mathrm{~cm}^{-2}$ em alguns ms. O resfriamento sub-Doppler é aplicado somente após o lançamento dos átomos, uma vez que a aceleração obtida é maior para altas intensidades da laser e pequenos deslocamentos. Vamos analisar a temperatura e o número de átomos capturados variando dois parâmetros: frequiência e potência dos 


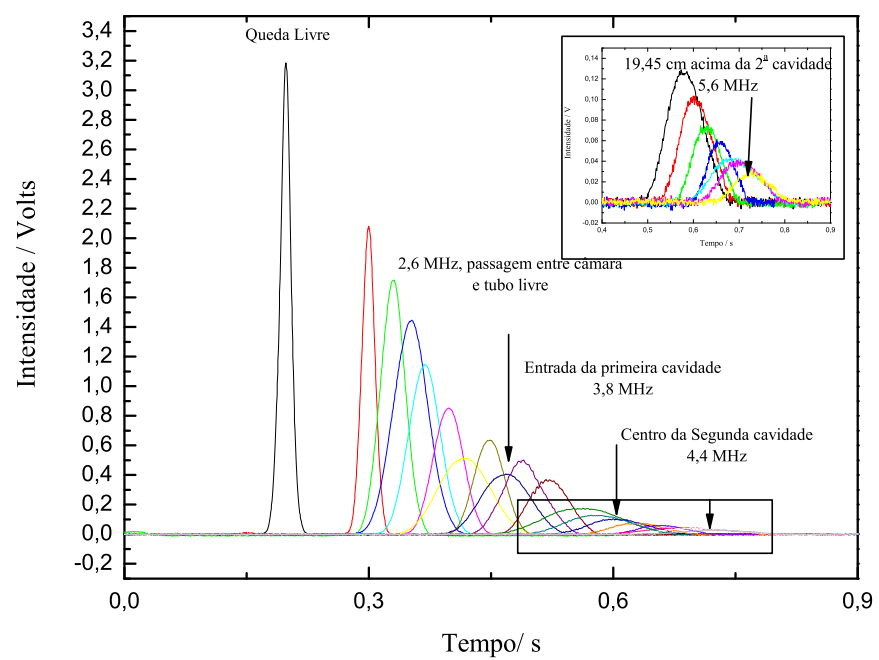

Figura 38: Sinal de TOF para diferentes alturas de lançamento.

feixes. Começamos variando a freqüência do resfriamento sub-Doppler como mostra o gráfico da figura 39. A segunda otimização que fizemos foi com relação à rampa de

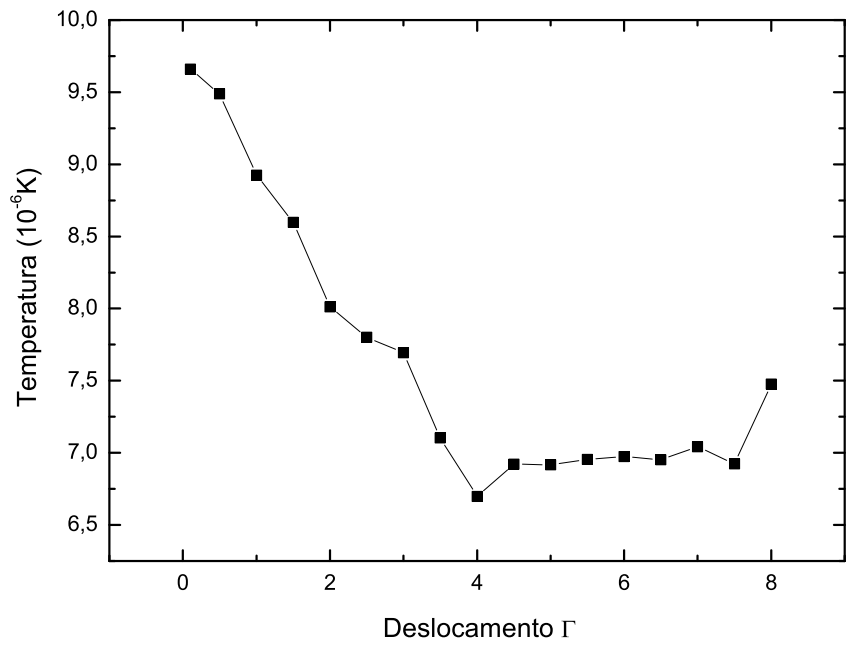

Figura 39: Temperatura dos átomos para diferentes valores de deslocamento de freqüência durante o processo do resfriamento sub-Doppler.

potência. Segundo o gráfico da figura 40, observamos que ao diminuirmos a potência dos lasers antes do bloqueio dos feixes conseguimos obter temperaturas menores do que apenas com a variação de freqüência. Para atenuar os feixes de resfriamento vari- 
amos a potência do sinal de RF injetada no AOM de $80 \mathrm{MHz}$. Nosso sistema de controle possui uma saída analógica que atua na entrada de modulação de amplitude do VCO. Portanto, o gráfico está com os valores de tensão da saída analógica do sistema de controle. Obtivemos valores de temperaturas próximas a $4 \mu \mathrm{K}$ e comparando

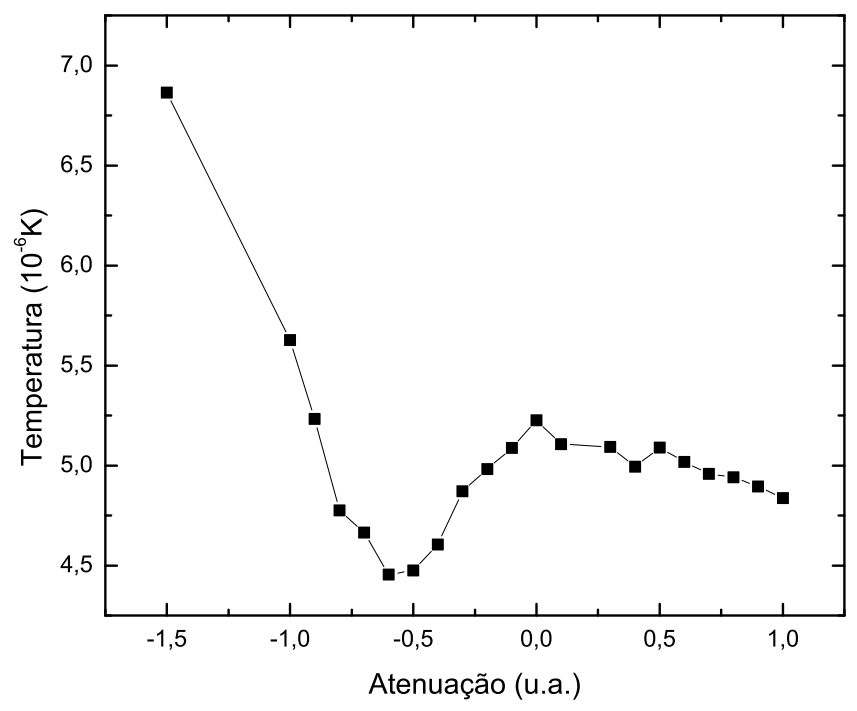

Figura 40: Temperatura dos átomos para diferentes valores de atenuação de potência..

esse valor com o limite de recuo do átomo para os átomos de ${ }^{133} C s$ que é da ordem de $0,2 \mu K$, vemos que a temperatura obtida em nosso experimento está próxima do limite para um sistema baseado em melado óptico.

Por fim, todos os feixes laser são bloqueados para a fase seguinte do chafariz atômico: a interação dos átomos com a microonda. Os AOMs de $80 \mathrm{MHz}$ em associação com dois VCXO, Voltage Controled Oscillators, controlam a frequiência e amplitude dos feixes de aprisionamento, de modo que além de deslocar a freqüência do laser de aprisionamento para a fase de lançamento, podemos reduzir a sua potência até o desligamento desses feixes para a fase seguinte. Além disso, obturadores eletromecânicos foram posicionados no caminho óptico dos feixes de aprisionamento e do feixe de rebombeio para eliminar qualquer luz remanescente que ainda passe pelos AOMs.

A mesa óptica foi protegida para evitar que correntes de ar incidam sobre os com- 
ponentes ópticos e os lasers. As correntes de ar ocasionam flutuações térmicas sobre os componentes ópticos que causam variações de freqüência e polarização dos feixes laser que fazem o aprisionamento atômico. Além de provocar essas flutuações causam, variações no número de átomos que são aprisionados e, conseqüentemente, no número de átomos que participam da interrogação de Ramsey. Esta última é uma função complicada do tamanho inicial da nuvem de átomos, da abertura da cavidade de Ramsey, da altura da cavidade e da velocidade térmica média da nuvem atômica. Além disso, passamos cada uma das fibras ópticas por canaletas posicionadas sobre a estrutura de sustentação do chafariz para proporcionar maior estabilidade mecânica as fibras e que induzem flutuações de polarização na luz de saída das fibras.

\subsection{Laser de Diodo de cavidade estendida e o seu sis- tema de controle}

Os lasers de diodo utilizados para o rebombeio e detecção dos átomos são chips comerciais da SDL 5412-H1, com potência máxima de saída 100mW, largura de linha típica de $15 \mathrm{MHz}(33,63)$. Para corrigir a divergência do feixe laser produzido pelo diodo, foi utilizada uma lente objetiva da Melles Griot modelo 06 GLC002/D. Para a configuração de cavidade estendida formam a cavidade: o laser de diodo, que possui um tratamento anti-refletor na sua face de saída, e um elemento seletivo em comprimento de onda (uma grade de difração Edmund Scientifics 1200 linhas). O laser é operado na configuração de cavidade estendida de Littrow, isto é, o feixe de primeira ordem difratado pela grade é retrorefletido no diodo e o feixe de saída do laser de diodo nesta configuração é o de ordem zero.

A grade de difração é montada sobre uma cerâmica piezoelétrica (MD-44-Jordan), o que permite ajustar o comprimento de onda em até $3 \mathrm{~nm}$. O PZT é alimentado com uma fonte de alta tensão de até $500 \mathrm{~V}$ e a modulação do sinal de alta tensão é em torno de $30 \mathrm{~Hz}$. O conjunto grade de difração mais cerâmica piezoelétrica é montado num suporte óptico Lees LM-2, o que permite melhor ajuste do feixe de retorno. 
Para o controle de temperatura, o laser de diodo é munido de um termistor e de um elemento Peltier dentro do seu encapsulamento. Além disso, ele é fixado em uma caixa de alumínio com $23 \mathrm{~cm}$ de comprimento, 12,5 cm de largura e 11,5 de altura, com um controle de temperatura a fim de minimizar a sensibilidade térmica da variação do tamanho da cavidade devido às variações externas de temperatura. $\mathrm{O}$ seu controle é feito através de um sensor de temperatura, LM35 National Semiconductor com resposta de $10 \mathrm{mV} /{ }^{\circ} \mathrm{C}$. O circuito de temperatura da caixa tem uma estabilidade melhor que $0,1^{\circ} \mathrm{C}$. Como o processo de estabilização da temperatura da caixa é bastante lento, montamos um controle rigoroso da temperatura ambiente. Com essa última sempre abaixo da temperatura da caixa. A temperatura da sala é mantida sempre a $21^{\circ} \mathrm{C}$ com variações menores do que $1^{\circ} C$.

Para estabilizar a freqüência dos lasers na transição hiperfina $6^{2} S_{\frac{1}{2}} F=4 \longrightarrow$ $6^{2} P_{\frac{3}{2}} F=5$ (laser de resfriamento e laser de detecção), e $6^{2} S_{\frac{1}{2}} F=4 \longrightarrow 6^{2} P_{\frac{3}{2}} F=4$ (laser de rebombeio), utiliza-se a técnica de absorção saturada em uma célula de vapor de átomos de ${ }^{133}$ Cs. A montagem óptica do sistema de travamento está esquematizada na figura 41. A célula de césio é colocada no interior de uma blindagem magnética a fim de evitar os alargamentos das transições atômicas por causa de campos magnéticos. O feixe de saída do laser de diodo de cavidade estendida passa através de um isolador óptico, assegurando uma isolação de 40dB no retorno. Por meio de uma lâmina de meia onda, associada a um cubo polarizador, enviamos em torno de $800 \mu \mathrm{W}$ da potência de saída à célula de césio. O feixe passa através da célula, satura a transição e é retrorefletido para sondar o vapor. Por meio da modulação do sinal de alta tensão é possível visualizar o perfil Doppler inteiro, permitindo sintonizar melhor a linha de travamento. A detecção do sinal de fluorescência é feito por um fotodetector (InfineonOsram BPW34FA) com sensibilidade de 0,9 para 850nm e de menos de 0,01 para 700nm. Esse sinal é amplificado e enviado a um demodulador síncrono.

O sinal de erro é obtido modulando-se a corrente do laser de diodo de cavidade estendida a um freqüência em torno de $100 \mathrm{kHz}$. Essa modulação dá origem a uma 


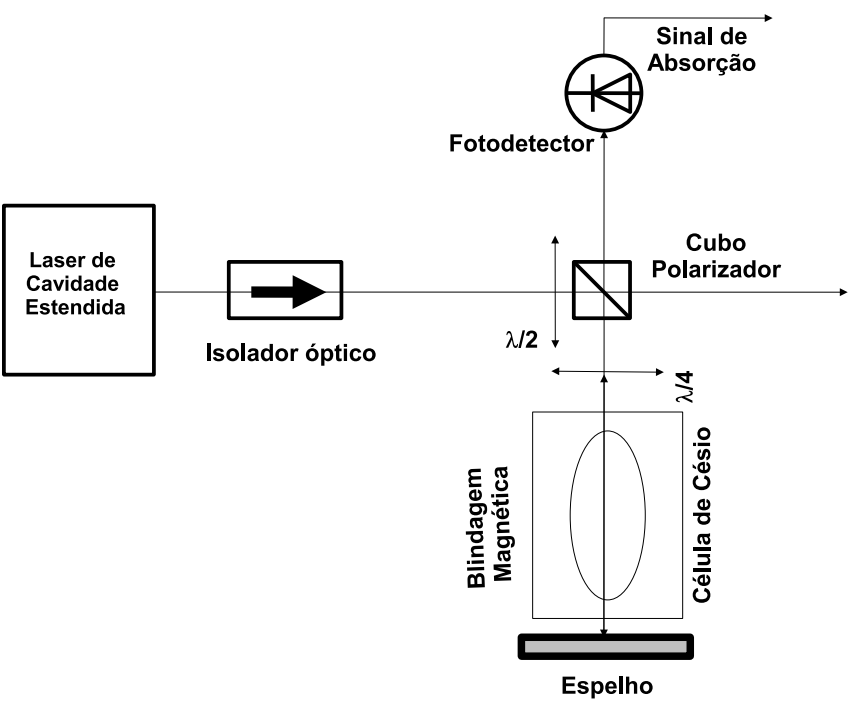

Figura 41: Diagrama do sistema de absorção saturada em célula de vapor de ${ }^{133} \mathrm{Cs}$ utilizado para travar o laser de diodo na linha $D_{2}$.

modulação na freqüência da luz emitida pelo laser diodo. Assim, qualquer flutuação na frequiência do laser produzirá uma flutuação no sinal de saída do demodulador, que deixará de cruzar o zero de tensão e irá gerar um sinal proporcional ao deslocamento da freqüência do laser. O sinal de saída do detetor síncrono é utilizado como um sinal de erro do nosso sistema de realimentação tanto para a corrente de alimentação do diodo como para o PZT. A figura 42 mostra o sistema eletrônico do controle. No estágio de entrada do circuito de travamento, o sinal de saída do demodulador passa por um filtro passa baixa que atenua as componentes de alta frequiência. Em seguida, um integrador de ganho variável permite o chaveamento do circuito de travamento. Na saída desse integrador, o sinal de correção da corrente passa por um somador para adicionar a modulação da corrente. O sinal de correção de corrente é integrado novamente para controlar o PZT. O segundo integrador também possui uma chave de liga/desliga. Enfim, um ajuste adicional a uma oscilação lenta da varredura. Esse sinal amplificado é utilizado para modular a alta tensão e controla a amplitude de oscilação do PZT. 


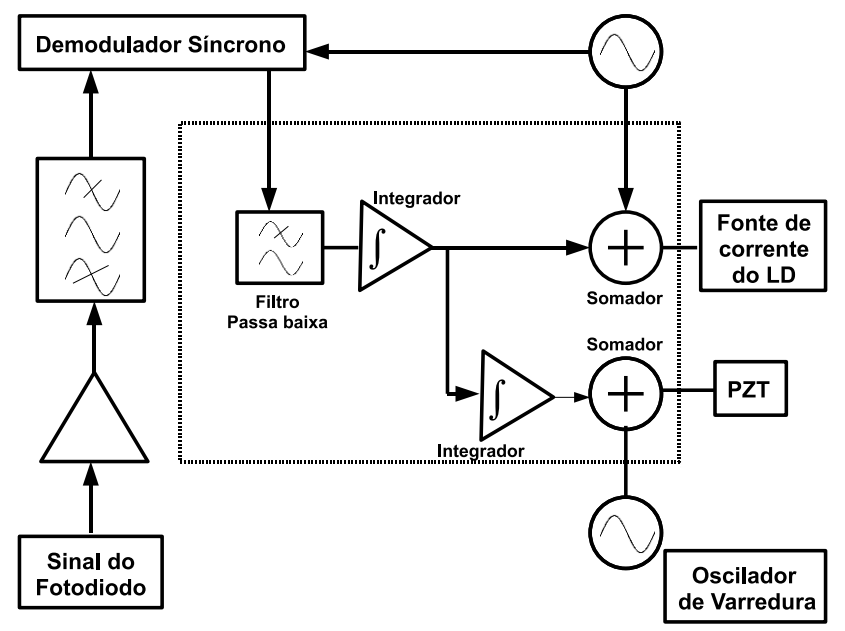

Figura 42: Diagrama esquemático do sistema de travamento do laser de diodo de cavidade estendida.

\subsection{Circuitos de controle e Suprimento de Rádio-Fre- qüência para Moduladores Acusto-Ópticos}

Para adequar a frequiência e controlar a potência do feixe laser a cada uma das diferentes etapas do ciclo de funcionamento do chafariz atômico, utilizamos um AOM de $280 \mathrm{MHz}$ em associação a um VCO (Voltage Controlled Oscillators) no sistema de referência de absorção saturada do laser de aprisionamento e outros dois AOMs de $80 \mathrm{MHz}$ em cada um dos braços do feixe de saída do MOPA. A vantagem dessa montagem é a possibilidade de se utillizar uma única fonte de luz laser travada no pico de ressonância dos átomos de ${ }^{133} C s$ que serve de referência absoluta das frequiências utilizadas em relação aos picos de absorção dos átomos. Além disso, os AOMs são capazes de cortar rapidamente os feixes, com capacidade para extinguir a luz em $1 \mu s$ com uma taxa de extinção de 60 a $80 \mathrm{~dB}$.

Para a fase de MOT, os feixes são deslocados da ordem de duas larguras de linha, $-2 \Gamma$, para o vermelho. A seguir é preciso deslocar em freqüência a luz do laser de aprisionamento de $-2 \Gamma$ até $-8 \Gamma$ para as fases de melado óptico e resfriamento subDoppler em alguns ms, a fim de obter temperaturas mais baixas da nuvem de átomos. 
Esse controle é feito com o modulador de $280 \mathrm{MHz}$ disposto no sistema de absorção saturada e um VCO da mini-circuits (modelo POS 300) para gerar o sinal de freqüência de $280 \mathrm{MHz}$.

Para o lançamento dos átomos à região de interrogação são utilizados dois AOMs de $80 \mathrm{MHz}$ em associação com dois VCXO’s, um em cada braço dos feixes de aprisionamento. Dessa forma podemos obter um deslocamento de freqüência diferente para cada um dos braços. Um diagrama esquemático do circuito de travamento é mostrado na figura 43. O travamento entre os dois osciladores pode ser de fase ou de frequiência,

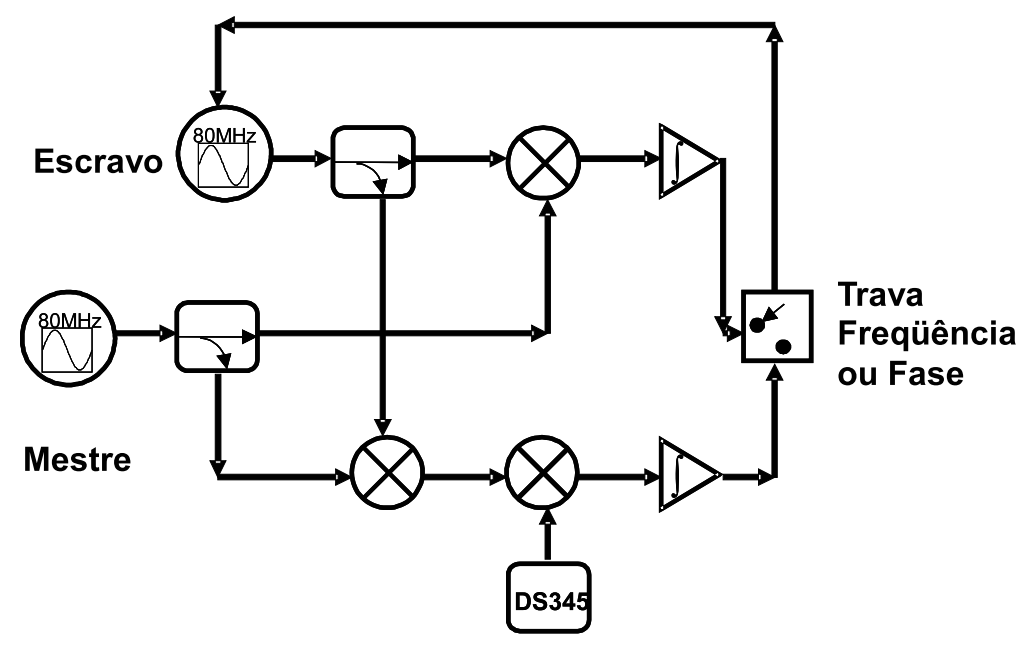

Figura 43: Diagrama esquemático do controle de travamento de fase e de freqüência entre dois AOMs dos feixes de aprisionamento

dependendo do período de ciclo de funcionamento. Durante a fase de aprisionamento magneto-óptico, o VCO mestre é mantido em uma determinada frequiência e o VCO escravo está travado em fase com o mestre, através de um circuito PLL (Phase Locked Loop). Para o lançamento atômico, o VCO mestre tem a tensão de controle alterada e a freqüência da radio freqüência é deslocada para o vermelho da freqüência de aprisionamento. Nessa fase, o VCO escravo está travado em freqüência ao VCO mestre e a sua freqüência é deslocada para o azul de ressonância. A diferença de freqüência entre os dois VCO nessa fase é dada por um sintetizador externo (SR 345 Stanford) e um sinal de correção gerado realimenta o VCO escravo. A troca entre o travamento de freqüência e de fase é feito através de um sinal TTL de entrada. Para o desligamento 
dos feixes de aprisionamento dois atenuadores variáveis foram adicionados aos VCOs, que são chaveados através da entrada do sinal de TTL. Isso proporciona um controle rápido no desligamento dos feixes de aprisionamento junto com os obturadores mecânicos. 


\section{Detecção e Controle no Chafariz de Átomos}

\subsection{Introdução}

Nesses últimos anos trabalhamos intensamente para reproduzir a franja de Ramsey e obter uma boa relação sinal ruído. As primeiras medidas foram tomadas com relação à captura e o lançamento dos átomos de ${ }^{133} C s$ a região de interação. Trabalhamos principalmente para ajustar melhor o lançamento dos átomos conseguindo um sinal de tempo de vôo com qualidade suficiente para obter uma franja de Ramsey em lançamento maiores.

Além da fase de preparação da nuvem fria de átomos de ${ }^{133} C s$, o sistema de deteção também foi otimizado. Nessa fase, medimos a população atômica nos dois níveis hiperfinos do estado fundamental, $(|F=3\rangle \mathrm{e}|F=4\rangle)$, através da fluorescência do sinal de tempo de vôo dos átomos por meio de um fotodetetors, quando os átomos interagem com feixes laser ressonantes com os respectivos átomos. Para extrair informações desse sinal é necessário que as partes desde a montagem do laser de detecção até a fase de coleta da fluorescência, estejam estáveis e livres de qualquer ruído.

A óptica de coleta desse sinal, como será explicado adiante, foi otimizada para reduzir os vestígios de cross talk observados nas primeiras tentativas de observação da fluorescência dos átomos. Além disso, muitos átomos durante o processo de detecção são perdidos, o que prejudica em muito a relação sinal ruido das franjas de Ramsey. Após a otimização feita, a robustez do sistema de deteção melhorou, aumentando a 
nossa capacidade de reprodutibilidade das franjas.

Nesse capítulo também descreveremos o sistema de controle utilizado no chafariz. Para a realização de todas as etapas do ciclo de funcionamento, um microcomputador equipado com placas de aquisição de dados é capaz de gerar padrões digitais e analógicos para o controle de frequiência e potência dos feixes laser, além de se comunicar com equipamentos externos, como sintetizadores de freqüência externos utilizados para modular o sinal de microonda usado na interrogação atômica.

Por fim apresentaremos os resultados experimentais obtidos com o chafariz atômico. Franjas de Ramsey com 1,4 Hz de largura e reprodutíveis foram obtidas. Entretanto a relação sinal ruído ainda é um fator limitante, deixando o sistema com uma estabilidade da ordem $10^{-12}$. A exatidão do padrão também já começou a ser medida, através do cálculo de alguns deslocamentos de freqüência.

\subsection{Montagem Óptica do Sistema de Detecção}

O sistema de detecção fica na extremidade inferior do câmara de vácuo rigidamente acoplado à estrutura. Foi colocado um cilindro de grafite entre a câmara de vácuo e a região de detecção, com o intuito de minimizar o vapor de fundo na região de detecção. Uma visão geral do sistema de detecção é mostrada na figura 44 .

No sistema de detecção são criados dois feixes de luz separados de $6 \mathrm{~mm}$, como mostra a figura 6.2 , com seção transversal retangular de $8 \mathrm{~mm}$ por $14 \mathrm{~mm}$ e intensidades de $22,72 \mathrm{~mW} / \mathrm{m}^{2}$ e $0,49 \mathrm{~mW} / \mathrm{m}^{2}$ para os feixes de detecção e de rebombeio respectivamente. Os átomos no chafariz são lançados no estado $|F=4\rangle$ e durante seu vôo balístico passam duas vezes pela mesma cavidade de interrogação. Por fim, caem na região de detecção, onde cruzam os feixes do sistema de fluorescência. O primeiro deles, sintonizado com a transição $6^{2} S_{1 / 2}|F=4\rangle \leftrightarrow 6^{2} P_{3 / 2}|F=5\rangle$, permite a detecção por fluorescência dos átomos no estado $6^{2} S_{1 / 2}|F=4\rangle$. O segundo feixe é uma composição do feixe de rebombeio, para bombear os átomos remanes- 


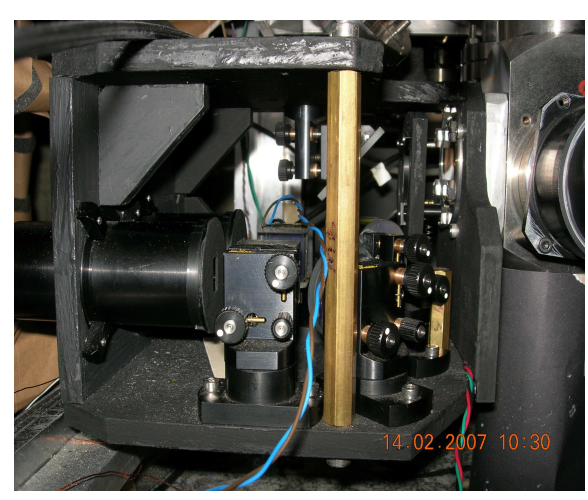

(a)

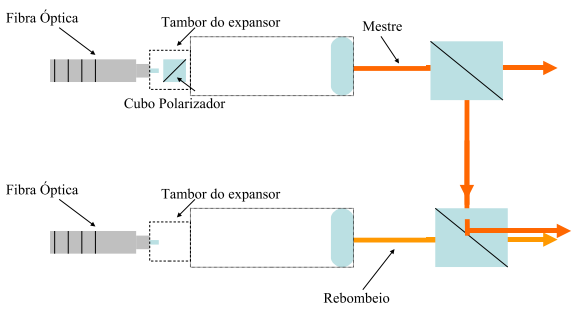

(b)

Figura 44: (a) Sistema de detecção do chafariz atômico do CePOF. Ele está fortemente acoplado ao sistema de vácuo (b) Diagrama esquemático do sistema de detecção. Nele são gerados dois feixes de luz, O primeiro contém apenas a luz do laser mestre, $6^{2} S_{1 / 2}|F=4\rangle \leftrightarrow 6^{2} P_{3 / 2}|F=5\rangle$, o segundo é uma composição do laser mestre e do laser de rebombeio, $6^{2} S_{1 / 2}|F=3\rangle \leftrightarrow 6^{2} P_{3 / 2}|F=4\rangle$. Uma parte do feixe mestre é desviado por um cubo polarizador.

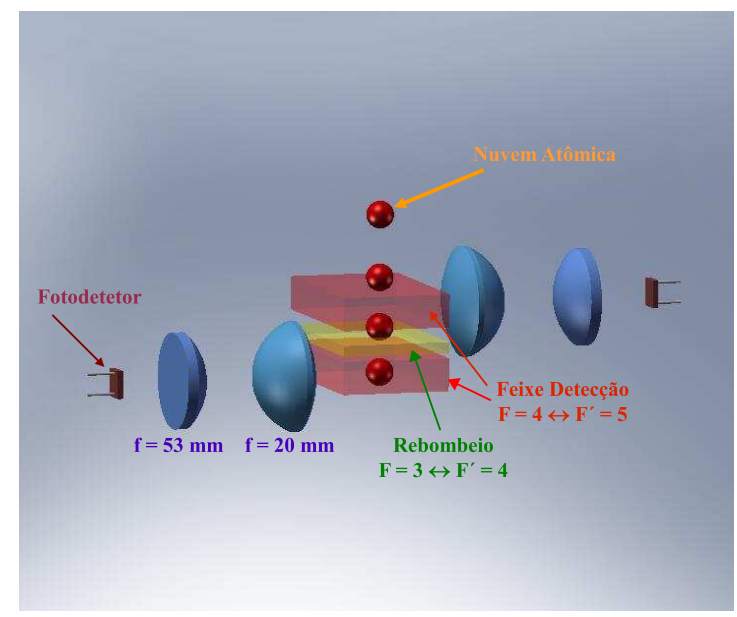

Figura 45: A detecção no chafariz atômico é feita por meio da medida da fluorescência dos átomos por dois feixes de luz laser separados de $6 \mathrm{~mm}$. Um deles é ressonante com a transição $6^{2} S_{1 / 2}|F=4\rangle \leftrightarrow 6^{2} P_{3 / 2}|F=5\rangle$ e o outro é uma superposição deste com um feixe de rebombeio $\left(6^{2} S_{1 / 2}|F=3\rangle \leftrightarrow 6^{2} P_{3 / 2}|F=4\rangle\right.$ ) .

centes em $6^{2} S_{1 / 2}|F=3\rangle$ e que não sofreram a transição relógio na passagem pela cavidade, e o feixe do laser de detecção ressonante com a transição $6^{2} S_{1 / 2}|F=4\rangle \leftrightarrow$ $6^{2} P_{3 / 2}|F=5\rangle$. Os átomos que passam através do segundo feixe são bombeados para o estado $6^{2} S_{1 / 2}|F=4\rangle$ e interagem então com o feixe sobreposto ao do rebombeio sendo detectados pelo outro detector. Dessa forma, o segundo feixe de detecção mede a população total de átomos que chega na região de detecção. Todos os dois feixes são 
retro-refletidos por um espelho, criado uma onda estacionária.

Uma parte do feixe do laser de detecção é desviada, para sobrepor o feixe de rebombeio, por meio de um cubo polarizador como visto no diagrama esquemático da figura 44. Assim, os dois feixes principais de detecção são provenientes da mesma fonte, reduzindo a influência de oscilações temporais muito maiores que o tempo de trânsito da nuvem pela região de detecção, que é da ordem de 10 ms.

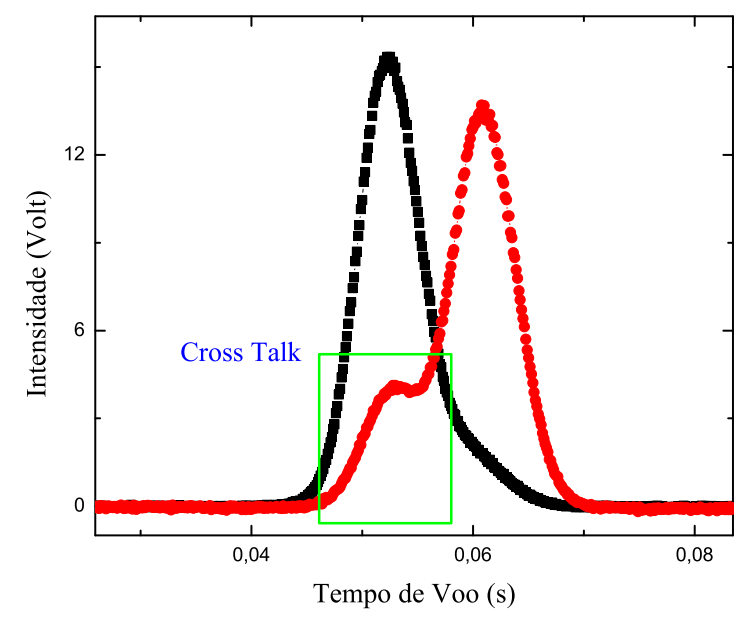

Figura 46: Sinal de fluorescência dos átomos em queda livre. A região em destaque mostra o efeito de crosstalk entre as duas regiões de detecção.

Inicialmente, a coleta do sinal de fluorescência era feita com uma lente de $50 \mathrm{~mm}$ de diâmetro e distância focal $f_{1}=20 \mathrm{~mm}$ para cada um dos feixes. Os fotodetectores utilizados são de modelo Hamatsu Si 3337-1010Br, com eficiência 0,508 A/W e o sinal amplificado possui um ganho $G=10^{8} \mathrm{~V} / \mathrm{A}$. Um sinal de queda livre obtido para as duas zonas de detecção é visto na figura 46, onde observa - se a característica crosstalk entre os dois fotodetectores. A otimização do sistema de coleta de fluorescência foi feita adicionando uma outra lente de $65 \mathrm{~mm}$ de diâmetro e distância focal $f_{2}=53 \mathrm{~mm}$ em cada uma das regiões de coleta resultando num ângulo sólido de 0,09 srad. Um sinal típico obtido com esse novo sistema é mostrado na figura 47 onde pode-se verificar a sensível redução no efeito crosstalk após a otimização do óptica de coleta. O sinal da franja de Ramsey, assinatura característica de um relógio atômico, é calculado a partir 


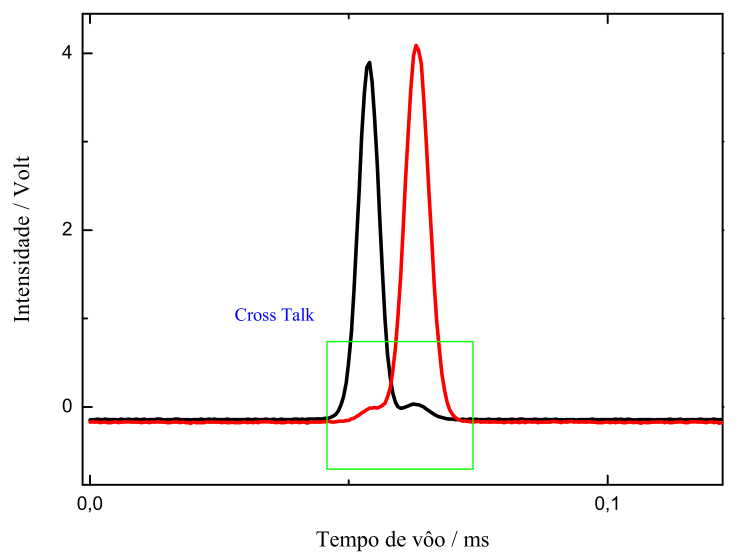

Figura 47: Sinal de fluorescência dos átomos em queda livre após a otimização da coleta do sinal de detecção. A região em destaque mostra a redução do efeito de crosstalk entre as duas regiões de detecção.

da fluorescência dos dois sinais de tempo de vôo (TOF) coletados no fotodetetor. Os sinais de TOF são proporcionais ao número de átomos em cada um dos dois níveis hiperfinos do estado fundamental $\left(N_{|F=3\rangle}\right.$ e $\left.N_{|F=4\rangle}\right)$. O sinal do fotodetetor é ampificado e medido em tempo real por um microcomputador. A partir da integração temporal do sinal de tempo de vôo calcula-se a probabilidade de transição $(46,56)$,

$$
P=\frac{N_{|F=3\rangle}}{N_{|F=3\rangle}+N_{|F=4\rangle}}
$$

onde cada $\mathrm{N}$ é diretamente proporcional ao sinal medido na detecção. Esse procedimento de normalização reduz os ruídos proveniente das flutuações no número de átomos detectados entre um ciclo e outro. A probabilidade de transição medida a cada ciclo do padrão de átomos frios é usada para estabilizar a frequiência do oscilador de interrogação.

O feixe laser de detecção está deslocado em freqüência de 0,5 Г para o vermelho da transição atômica $6^{2} S_{1 / 2}|F=4\rangle \leftrightarrow 6^{2} P_{3 / 2}|F=5\rangle$. Isso é feito por meio de um modulador acústico-óptico de $80 \mathrm{MHz}$, introduzido no caminha óptico do feixe sobre a mesa óptica e alinhado em dupla passagem. A finalidade desse procedimento é de evitar o aquecimento dos átomos ao longo da direção do feixe laser durante a 
sua interação com a radiação eletromagnética. Além disso, esse alinhamento servirá para implementar, num futuro próximo o travamento de potência do feixe de deteção evitando assim flutuações no número de átomos detectados.

A partir do sinal de tempo de vôo extraímos o número de átomos que atingem a região de detecção como função da altura de lançamento. Vamos supor que a fração de átomos $(\beta)$ que atravessa o feixe laser de detecção com seção transversal de $8 \mathrm{~mm}$ por $14 \mathrm{~mm}$ e é medida em um fotodiodo (supondo que a temperatura é isotrópica) é dada por,

$$
\beta=\operatorname{Erf}\left(\frac{4}{\sqrt{2} \sigma(t)}\right) \operatorname{Erf}\left(\frac{7}{\sqrt{2} \sigma(t)}\right)
$$

onde $\sigma(t)$ está em mm na expressão ( 6.2) e corresponde ao diâmetro da nuvem atômica. $\sigma(t)$ dado por: $\sigma^{2}(t)=\sigma_{0}^{2}+v_{r m s}^{2} t^{2}$ com $\sigma_{0}=3,695 m m$ sendo o diâmetro inicial da nuvem atômica que foi determinada por meio da imagem da armadilha magneto óptica coletada por uma câmera CCD. O número total de átomos detectados $\left(N_{D}\right)$ é dado por:

$$
N_{D}=\beta^{-1} \frac{P}{P_{0}}
$$

onde $\mathrm{P}$ é a potência associada aos fótons emitidos espontâneamente pelos átomos que passam pelo feixe de detecção e coletado pelo fotodetetor:

$$
P=\frac{S}{\left(\frac{d \Omega}{4 \pi}\right) \eta_{e f f} t_{i n t}}
$$

$\operatorname{com} t_{\text {int }}$ sendo a duração da interação dos átomos com o feixe de prova, $S=\sqrt{2 \pi} \Delta t V_{\max }$ a área do sinal de tempo de vôo ( $V_{\max }$ é a amplitude máxima do sinal de TOF detectado) e $\Delta t$ sua largura temporal a $\frac{1}{\sqrt{e}}$ do pico do sinal e $\eta_{e f f}=R \eta=0,508 \times 10^{8} \mathrm{~V} / \mathrm{W}$ é a eficiencia do fotodetetor dado pelo produto entre a resistência de carga e $\eta$ o rendimento $(A / W) \cdot \frac{d \Omega}{4 \pi}=0,09$ é o ângulo sólido de coleta da detecção. O sinal passa por um estágio de amplificação de ganho total $2,8 \times 10^{9} . P_{0}$ é a potência emitida por um único átomo dada por:

$$
P_{0}=\frac{\Gamma}{2} \frac{s}{s+1} h v
$$


$\operatorname{com} \Gamma=5,3 \mathrm{MHz}$ é a largura de linha natural do césio para o estado excitado $6^{2} P_{3 / 2}$, $h$ é a constante de Planck, $v$ é a freqüência de transição óptica do ${ }^{133} C s, 6{ }^{2} S_{1 / 2} \mid F=$ $4\rangle \leftrightarrow 6^{2} P_{3 / 2}|F=5\rangle$, s é o parâmetro de saturação da transição dada por

$$
\mathrm{s}=\mathrm{c}_{0}^{2} \frac{\frac{\Omega_{R}^{2}}{2}}{\delta_{d}^{2}+\frac{\Gamma^{2}}{4}}
$$

onde $c_{0}^{2}$ é o termo de correção calculado para a estrutura Zeeman e $\delta_{D}=2,65 \mathrm{MHz}$ deslocamento de freqüência do feixe de detecção, $\Omega_{D}=\Gamma \sqrt{2} I_{D} I_{S}$ é a frequiência de Rabi óptica. Nessa última, $I_{D}=4,23 \mathrm{Wm}^{-2}$ é a intensidade do feixe de detecção e $I_{S}=1,1 \mathrm{mWcm}^{2}$ é a intensidade de saturação do átomo de césio. Finalmente, o número de átomos detectados é dado por:

$$
N_{D}=\frac{S}{\frac{d \Omega}{4 \pi} \eta_{e f f}} \frac{2(s+1)}{\Gamma s} \frac{1}{h v \beta}
$$

Através do gráfico da figura 48 observamos que, para distâncias percorridas superiores a 136,26 cm, ou seja, para alturas de lançamento superiores a 58,63 cm do plano de captura, o número de átomos cai em uma ordem de grandeza. Devido à velocidade transversal dos átomos, o diâmetro da nuvem aumenta para valores muito maiores que a abertura dos guias de corte da cavidade de microondas, representando uma grande fonte de perda de átomos em um chafariz atômico. Esta perda está dire-

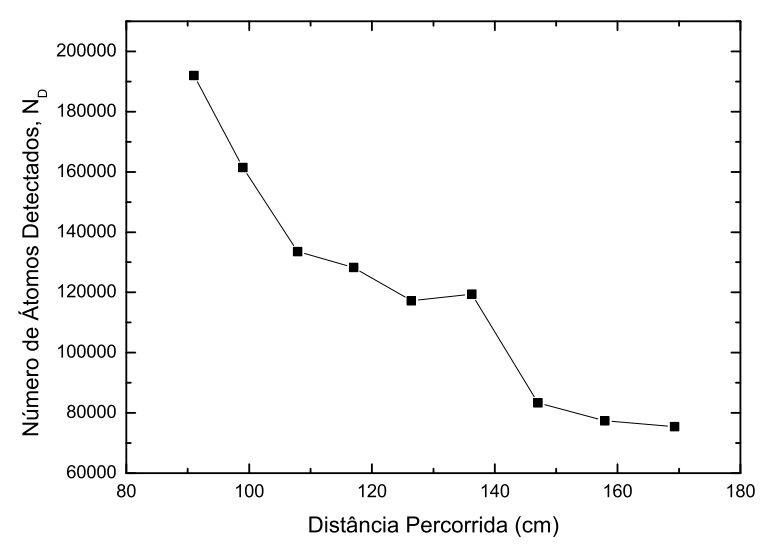

Figura 48: Número de átomos detectados como função da distância percorrida pelo átomo após o lançamento. Esse número cai em uma ordem de grandeza para distâncias superiores 136,26 cm, isto é, $15,58 \mathrm{~cm}$ acima da primeira cavidade. 
tamente relacionada com a temperatura transversal dos átomos. Para as condições do resfriamento sub-Doppler implementado no nosso sistema, a temperatura longitudinal dos átomos para a altura de lançamento utilizada ainda é de $15,55 \mu \mathrm{K}$. O próximo passo será otimizar a fase de lançamento da nuvem de átomos e do resfriamento subDoppler para reduzir a temperatura longitudinal dos átomos na região de detecção e, conseqüentemente, aumentar o número de átomos na região de detecção. Dessa forma, será possível utilizar a cavidade de preparação dos átomos.

Para um lançamento com uma diferença de freqüência de 4,6MHz entre os feixes superiores e inferiores, a velocidade de lançamento é $v_{0}=3,39 \mathrm{~m} / \mathrm{s}$. Nesse caso, os átomos atingem o ápice a 15,58 $\mathrm{cm}$ acima da primeira cavidade, isto é, $60 \mathrm{~cm}$ acima da região de captura, passando 17,27 ms durante cada passagem pela cavidade e 220,38 ms na região de vôo livre. A franja de Ramsey obtida é mostrada na figura 49.

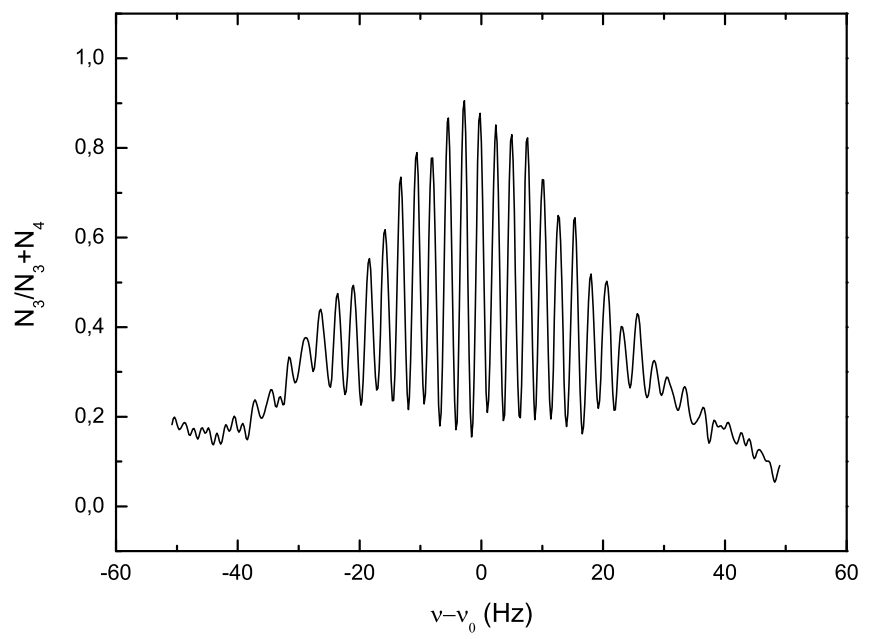

Figura 49: Franja de Ramsey obtida com uma velocidade de lançamento é $v_{0}=$ $3,39 \mathrm{~m} / \mathrm{s}$. Os átomos atingem $15,58 \mathrm{~cm}$ acima da cavidade de preparação, passam 17,27 ms durante cada passagem pela cavidade de interrogação e 220,38 ms na região de vôo livre.

Nessas condições, a largura de linha da franja central é de $1,4 \mathrm{~Hz}$ como mostra a figura 50 e a largura a meia altura do envelope de Rabi é de $35 \mathrm{~Hz}$. O grande número de oscilações é devido à baixa distribuição de velocidades da nuvem atômica. 


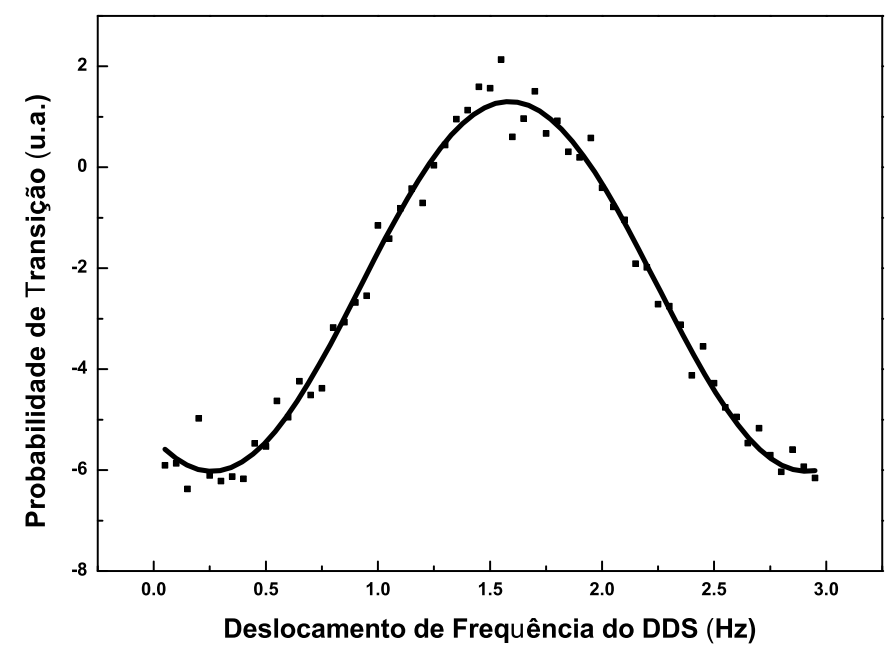

Figura 50: Franja central da ressonância de Ramsey com uma largura de aproximadamente $1,4 \mathrm{~Hz}$.

O sinal da franja central é utilizado para travar o oscilador local na freqüência de ressonância dos átomos e a correção é feita por meio de um sintetizador externo, controlado por um microcomputador. Para isso, a amplitude de modulação é ajustada para deslocamentos à meia altura da ressonância atômica. A diferença entre as duas probabilidades de transição, fornece o sinal de erro para controlar numericamente a freqüência central do sintetizador como será descrito adiante.

\subsection{Estabilidade de Frequiência do Chafariz de Átomos}

O chafariz atômico opera em modo seqüencial, com seis fases diferentes para completar seu ciclo de funcionamento, desde a captura de átomos até a detecção atômica, passando pelas fases de lançamento, resfriamento sub-Doppler, interrogação e detecção. O controle é realizado através de um microcomputador, equipado com placas de aquisição de dados e a comunicação com equipamentos feita através de uma placa de interface PCI-GPIB (National Instruments). O programa de controle foi totalmente implementado em LabView. A figura 51 mostra a interface do programa de controle utilizado onde pode-se verificar o controle dos deslocamentos de freqüência 
do laser mestre e a atenuação do sinal de radio-freqüência. A placa de aquisição utilizada é um modelo PCI-6025. A implementação desse sistema permite gerar padrões digitais e analógicos para o controle de freqüência e atenuação dos feixes de aprisionamento.

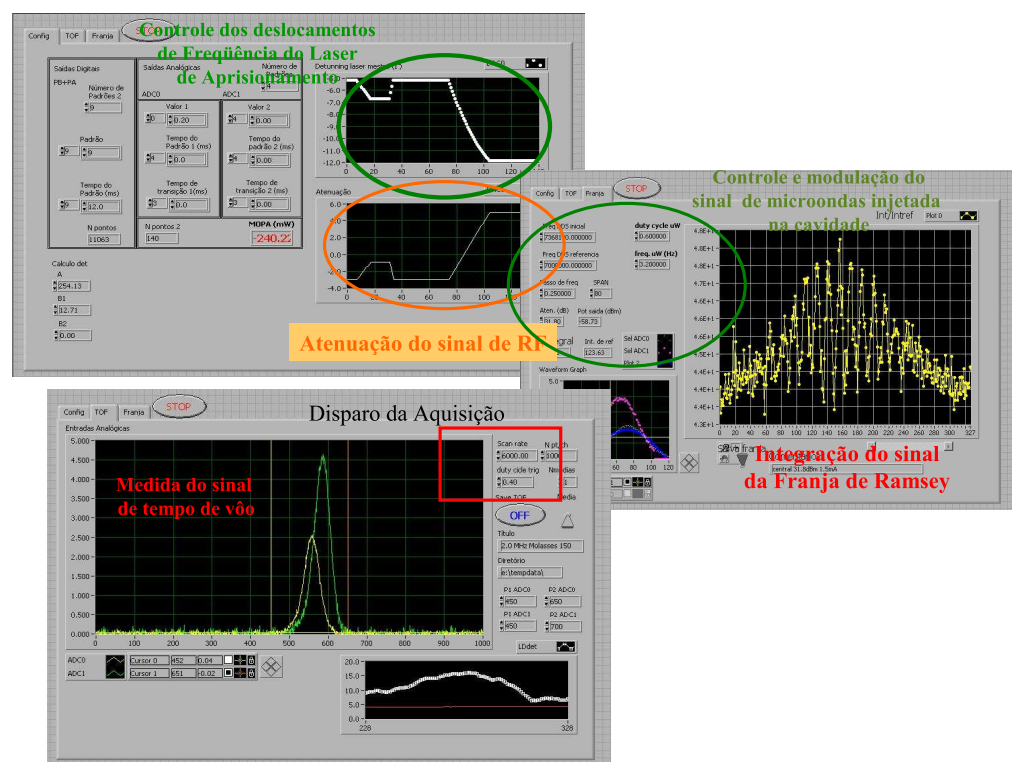

Figura 51: Interface do programa de controle do chafariz atômico do CePOF implementado em LabView que mostra também o controle dos deslocamentos de freqüência do laser mestre e a atenuação do sinal de rádio-freqüência.

Quando o chafariz de átomos é utilizado como um padrão de freqüência modulamos a franja de Ramsey central alternativamente a $1 / 2$ altura a cada ciclo e geramos um sinal de erro. No k-ésimo ciclo, a dessintonia do gerador de microondas é dada por $\delta=\delta_{k}+(-1)^{k} v_{m}$ e a freqüência de modulação é $v_{m} T_{e f f}=\frac{\pi}{2}$. A probabilidade de transição $P_{k}$ medida nos ciclos $k$ e $k-1$ é utilizada para ajustar o valor da freqüência central do ciclo $k+1$ por meio da equação:

$$
\delta_{k+1}=\delta_{k}+(-1) G\left(P_{k}-P_{k-1}\right)
$$

O ganho digital $\mathrm{G}$ é ajustado para que a escravização funcione em regime crítico. No nosso caso esse valor é dado por 0,03. A seqüência de correções aplicadas refletem as flutuações de freqüência da ressonância atômica com relação à frequiência do oscilador local. Essas seqüências de correção são armazenadas para se determinar em tempo real 
a variancia de Allan, que determina a estabilidade do padrão de freqüência atômico. A estabilidade de freqüência do chafariz é escrita da seguinte forma (64):

$$
\sigma_{y}(\tau)=\frac{1}{\omega_{a t}} \frac{\sigma_{\delta P}}{\frac{d P}{d \delta}} \sqrt{\frac{T_{C}}{\tau}}
$$

onde $\frac{d P}{d \delta}$ corresponde às flutuações da freqüência de ressonância dos átomos a meia altura da franja central, $\sigma_{\delta P}$ é traduzido como o tipo de flutuação da probabilidade de transição entre dois ciclos consecutivos, como as flutuações devido ao ruído de freqüência do oscilador de interrogação e o ruído proveniente da detecção dos átomos. $T_{C}$ é a duração de um ciclo do relógio. No caso de nosso chafariz, $T_{C}=5,2 m s, \tau$ é o tempo de integração total. $\frac{\tau}{T_{C}}$ representa o número de ciclos efetuados, $N_{c}$, onde cada ciclo tem duração $\tau$. Esse fator descreve a redução em $\frac{1}{\sqrt{N_{c}}}$ nas flutuações de freqüência para uma média de $N_{c}$ medidas. Da análise feita no Apêndice A.2, $\frac{d P}{d \delta}=\frac{\pi}{2 \Delta v_{\text {Ramsey }}} \mathrm{e}$ lembrando que $Q_{a t}=\frac{v_{0}}{\Delta v}$, reescrevemos a equação 6.9 como

$$
\sigma_{y}(\tau)=\frac{2}{\pi} \frac{\sigma_{\delta P}}{Q_{a t}} \sqrt{\frac{T_{C}}{\tau}}
$$

onde $Q_{a t}$ é o fator de qualidade atômico dada pela largura a meia altura da linha de ressonância $v_{0}$. O gráfico da figura 52 mostra da estabilidade do nosso padrão de freqüência, dada pela variância de Allan, como função do tempo de integração. Para $T_{C}=5,2 s$ e $Q_{a t}=6,56 \times 10^{9}$ a estabilidade medida $\sigma_{y}(\tau)=5,18 \times 10^{-12} \tau^{-1 / 2}$.

O baixo valor da estabilidade a curto prazo é atribuido principalmente à baixa relação sinal ruído que ainda possuímos no sinal das franjas de Ramsey. Como ainda não possuímos um processo de seleção de estado no chafariz atômico encontramos um ruído adicional devido à variação na ocupação dos diferentes subníveis magnéticos. O sinal de TOF medido no chafariz não discrimina entre os átomos que se encontram distribuídos entre todos os sete subníveis Zeeman dos dois níveis hiperfinos do estado fundamental $6^{2} S_{1 / 2}, F=3$ e $6^{2} S_{1 / 2}, F=4$. Como a transição relógio é definida na transição entre os subníveis insensíveis ao campo magnético $\left(6^{2} S_{1 / 2}, F=3, m_{F}=0\right.$ e $6^{2} S_{1 / 2}, F=4, m_{F}=0$ ) o sinal da franja de Ramsey corresponde a apenas $10 \%$ do sinal 


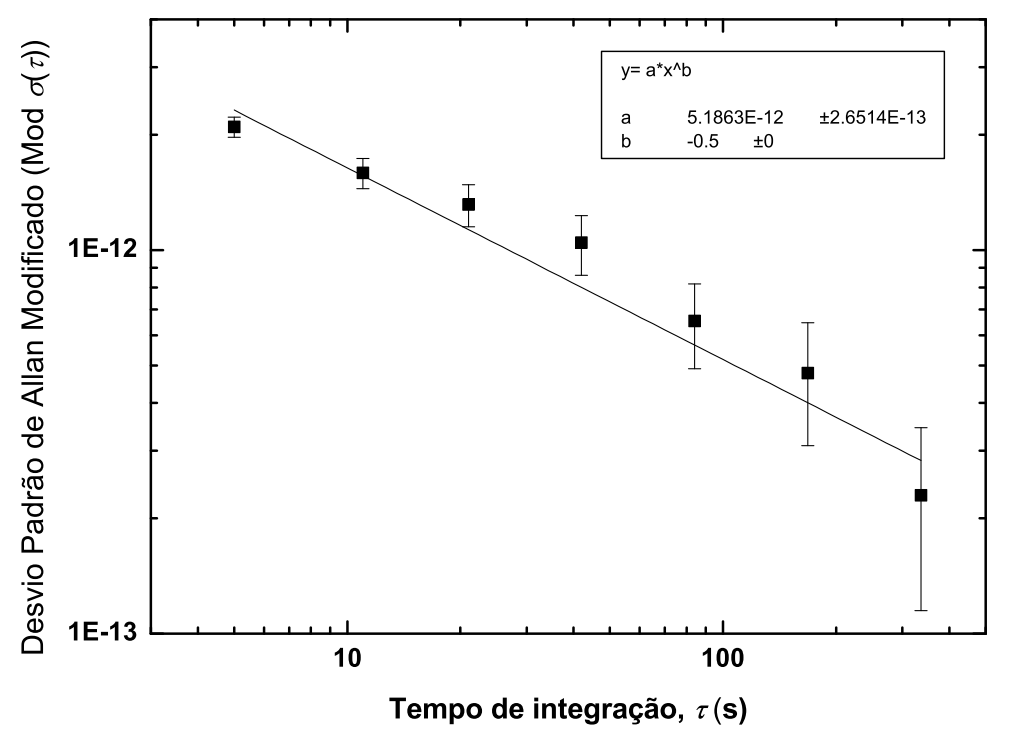

Figura 52: Estabilidade calculada através da Variância de Allan como função do tempo de integração e para $T_{C}=5,2 s$ e $Q_{a t}=6,56 \times 10^{10}$ a estabilidade $\sigma_{y}(\tau)=5,18 \times$ $10^{-12} \tau^{-1 / 2}$

de TOF medido.

Além disso, o tempo de ciclo no nosso chafariz é longo $T_{c}=5,2 \mathrm{~s}$. Dessa forma, o tempo em que o oscilador de referência, BVA de $10 \mathrm{MHz}$, fica livre é muito longo. O ideal é conseguir operar o chafariz com tempos de ciclos da ordem de $T_{c}=1,5 \mathrm{~s}$. Dessa forma, durante o tempo em que o oscilador fica livre, o campo de microonda produzido fica sujeito a variações na sua fase e, consequentemente, uma variação da probabilidade de transição, $\delta P$, é observada ao final da interrogação atômica. Essa flutuação na freqüência, $\delta \omega$, está relacionada com a flutuação da probabilidade de transição da seguinte forma (49),

$$
\delta P=\frac{1}{2} \int g(t) \delta \omega(t) d t
$$

e a equação ( 6.11) define uma função sensibilidade, $g(t)$. Ela assume que todos os átomos estão sujeitos à mesma perturbação de fase do campo de interrogação. $g(t)$ é calculada considerando-se que num tempo $t$ uma perturbação infinitesimal na fase $\Delta \phi$ do sinal do oscilador é expressa como uma variação de freqüência $\delta \omega(t)=\Delta \phi \delta\left(t-t^{\prime}\right)$. 
Isso produzirá uma variação $\delta P(t, \Delta \phi)$ na probabilidade de transição. Dessa forma, podemos definir a função sensibilidade $g(t)$ como:

$$
g(t)=2 \lim _{\Delta \phi \rightarrow 0} \frac{\delta P(t, \Delta \phi)}{\Delta \phi}
$$

e $g(t)$ pode ser interpretada como a resposta do sistema atômico a uma variação de fase do oscilador de interrogação. Esse efeito é inerente ao caráter pulsado de operação do chafariz atômico e também é conhecido como efeito Dick (49).

\subsection{Exatidão do Chafariz Atômico}

As franjas de Ramsey permitem avaliar os diversos deslocamentos de freqüência que afetam a transição relógio. Na aproximação de um átomo de dois níveis, a idéia do método de interrogação de Ramsey consiste em preparar os átomos em um estado hiperfino, deixar que os átomos evoluam livremente, através da região de vôo livre acima da cavidade de interrogação durante um intervalo de tempo $T$, onde eles se encontram em uma superposição coerente dos dois estados hiperfinos $F=3$ e $F=4$ do estado fundamental $6 S_{1 / 2}$ do átomo de césio, e em seguida, aplicar a segunda interação com a microonda. Devido a diversas imperfeições instrumentais e ambientais, como flutuações do campo magnético local, variações térmicas nas vizinhanças do dispositivo experimental, a transição relógio medida é deslocada de seu valor nominal. Nesta seção relacionaremos alguns efeitos que deslocam a frequiência de transição relógio.

\subsubsection{Efeito Gravitacional e o Efeito Doppler de segunda ordem}

Em um chafriz atômico, os átomos são lançados a uma velocidade inicial $v_{0}=$ $3,39 \mathrm{~m} / \mathrm{s}$. O deslocamento de freqüência relativístico é dado por: 


$$
\begin{array}{r}
\frac{v_{R}-v_{0}}{v_{0}}=-\frac{1}{T} \int_{t_{1}}^{t_{2}}\left[\frac{v^{2}(t)}{2 c^{2}}-\frac{g z(t)}{c^{2}}\right] \\
\frac{v_{R}-v_{0}}{v_{0}}=g \frac{h_{2}-h_{1}}{c^{2}}-\frac{v_{0}^{2}}{2 c^{2}}
\end{array}
$$

$\operatorname{com} v(t)=-g t+v_{0}$ e $z(t)=-\frac{g t^{2}}{2}+v_{0} t$, onde $g=980,665 \mathrm{cms}^{-2}$ é a aceleração da gravidade terrestre. $v_{0}$ e $v_{R}$ são, respectivamente, as freqüência de transição natural e a frequiência deslocada por esses dois efeitos e $c=299.792 .458 m / s$, é a velocidade da luz.

O primeiro termo da equação ( 6.13) é o deslocamento de frequiência devido ao efeito gravitacional. O efeito gravitacional é uma correção relativística devida às variações do potencial gravitacional dependendo da altitude em que se encontra o relógio. Este efeito provoca um deslocamento na freqüência de qualquer oscilador com relação a uma freqüência fixada em um potencial de referência, seja independendente da velocidade atômica. O efeito apenas translada as franjas de Ramsey, sem no entanto, deformá-la. Independentemente de sua natureza, a freqüência de um oscilador depende do potencial gravitacional U da posição ocupada por ele. De acordo com a definição do BIPM, a origem do deslocamento do potencial gravitacional para um relógio sobre a superfície da Terra, ou bastante próxima à sua superfície, é definida com relação à superfície do geóide. A altitude de São Carlos, é h = 850m com uma incerteza de 50m. Esta altitude foi medida com um GPS (9390-6000 Datum). Desta forma, o deslocamento de frequencia devido ao efeito gravitacional é de $\frac{\Delta v_{R}}{v_{0}}=-1,0 \times 10^{-17}$.

O efeito Doppler de segunda ordem está relacionado com a dilatação temporal prevista pela teoria da relatividade. Cada uma das componentes da velocidade no feixe contribui com um deslocamento. Como a distribuição de velocidades em um chafariz atômico é estreita, a incerteza medida com relação à distribuição de velocidades é da ordem de alguns $\mathrm{cms}^{-1}$ e ela introduz um deslocamento por efeito Doppler de segunda ordem de $\frac{\Delta v_{D}}{v_{0}}=2,08 \times 10^{-18}$. 


\subsubsection{Radiação de Corpo Negro}

O deslocamento de freqüência devido à radiação de corpo negro é dado por (3),

$$
\frac{\Delta v}{v_{0}}=\beta\left(\frac{T}{T_{0}}\right)^{4}\left[1+\epsilon\left(\frac{T}{T_{0}}\right)^{2}\right]
$$

onde $T$ é a temperatura em Kelvin, $T_{0}=300 K, \beta=-1,69(4) \times 10^{-14}$ e $\epsilon=1,4 \times 10^{-2}$. Como mostrado na seção 4.1 , o valor médio da temperatura é $41,06 \pm 0,14^{\circ} \mathrm{C}$ e o deslocamento de freqüência devido a radiação de corpo negro é $\frac{\Delta v_{B B R}}{v_{0}}=-2,22 \times 10^{-14}$. A incerteza na medida do deslocamento devido à radiação de corpo negro é consequiência na incerteza para se determinar temperatura efetiva na região de interrogação. No gráfico da figura 26 medimos a variaçào temporal da temperatura ao longo de alguns dias. Uma flutuação de $d T=0,35^{\circ} C$ na temperatura medida é observada durante esse período. Isso resulta numa incerteza na medida da temperatura de $\frac{d \Delta v}{v_{0}} \cong 10^{-17}$. Como descrito anteriormente, toda a região de interrogação é mantida a uma temperatura ligeiramente superior à temperatura ambiente para sintonizar a cavidade de interrogação na transição atômica. Para reduzir mais ainda essa sensibilidade implementaremos um controle ativo de temperatura para compensar quaisquer variações na temperatura da sala e que possam afetar a medida da transição relógio.

\subsubsection{Efeito Zeeman de Segunda Ordem}

Para interrogar os átomos de Césio é preciso aplicar um campo magnético estático com o intuito de tirarmos vantagem sobre as regras de seleção e separar as sete transições hiperfinas $\Delta m_{F}=0$. No entanto, é impossivel idealizar uma situação em que o campo magnético local seja completamente nulo e que os átomos sintam apenas a presença do campo magnético estático aplicado pelo $C$ - field. Por isso é necessário conhecermos o valor deste deslocamento e determinar como a sua variação espacial e temporal afeta o nosso padrão.

Na prática, o campo magnético é medido por intermédio das transições que de- 
pendem linearmente com o campo magnético. No entanto, medimos a estabilidade temporal e espacial do campo na região externa das blindagens magnéticas por meio de uma sonda Hall Mag 01H. A estabilidade média do campo magnético local é de $(-0,30 \pm 0,01) \mu T$ e estimamos o campo na região de interrogação pela atenuação medida previamente das blindagens magnéticas $\left(10^{6}\right)$

O efeito Zeeman quadrático é proporcional ao valor médio do campo magnético quadratico aplicado pelo C-field, $B_{0}=0,8 \mu T$ dada pela seguinte equação (3),

$$
\frac{\Delta v_{Z}}{v_{0}}=427,25 \times 10^{8}\left\langle B_{0}^{2}\right\rangle
$$

e o valor do deslocamento Zeeman para esse valor de campo é $\frac{\Delta v_{Z}}{v_{0}}=2,97 \times 10^{-12}$ e a incerteza relativa em torno desse valor é $\frac{\delta v_{z}}{v_{0}}=4,16 \times 10^{-13}$.

$\mathrm{Na}$ tabela abaixo apresentamos o conjunto de incertezas obtidas até agora.

Tabela 1: Deslocamentos de Freqüência

\begin{tabular}{|c|c|c|}
\hline Efeito Físico & Correção $\times 10^{-12}$ & Incerteza $\times^{-12}$ \\
Efeito Gravitacional & $-1,0 \times 10^{-2}$ & $-1,0 \times 10^{-3}$ \\
Efeito Doppler de segunda ordem & $2,08 \times 10^{-3}$ & 0 \\
Efeito Zeeman & 2,97 & 0,41 \\
Radiação de Corpo negro & $-2,22 \times 10^{-2}$ & $10^{-17}$ \\
\hline
\end{tabular}

Vemos que a incerteza com que a frequiência de transição relógio é medida é limitada pelo efeito Zeeman de segunda ordem. 


\section{Conclusão e Próximos Passos}

O Grupo de Óptica do Instituto de Física de São Carlos possui um programa para o desenvolvimento de padrões de freqüência atômicos tendo em vista sua utilização como padrões primários. Neste trabalho apresentamos o sistema experimental de chafariz de átomos a ser utilizado como um padrão de freqüência atômico.

Dando continuidade a trabalhos anteriores, o sistema experimental do chafariz de átomos foi otimizado para obter franjas de Ramsey reprodutíveis e com qualidade. Para as condições atuais de operação, em que a velocidade de lançamento é de 3,39 $\mathrm{m} / \mathrm{s}$, a nuvem atinge o ápice a $60 \mathrm{~cm}$ acima da região de captura e após a interrogação de Ramsey, franjas de interferência com 1,4 Hz de largura e uma estabilidade em curto prazo de $5,18 \times 10^{-12}$. Esta estabilidade está limitada principalmente pela baixa relação sinal ruído das franjas de Ramsey. A continuidade de sua implementação diz respeito à reparação de alguns problemas detectados.

Para otimizar o chafariz de átomos deve-se primeiramente incluir uma fase de seleção de estado atômico, para preparar os átomos em $\left|F=3, m_{F}=0\right\rangle$. A cavidade de preparação já está na torre de vôo livre e será utilizada para transferir átomos no estado $\left|F=4, m_{F}=0\right\rangle$ para $\left|F=3, m_{F}=0\right\rangle$ por meio de um pulso $\pi$ de microondas. Além disso, um feixe laser, denominado de Push laser, será usado para empurrar os átomos que não foram preparados no estado certo para fora da nuvem. O objetivo é dar um pulso de luz quando os átomos estiverem entre a cavidade de preparação e a cavidade de interrogação de maneira que os átomos em $\left|F=4, m_{F} \neq 0\right\rangle$ e que ainda se encontram na nuvem são removidos. Esse procedimento evita as transições parasitas 
melhorando a relação sinal ruído das franjas de Ramsey. Para implementar a fase de preparação do estado atômico precisamos usar um sintetizador de microondas para gerar um pulso $\pi$. Já dispomos de outro sintetizador de microondas de performance similar ao que estamos utilizando atualmente. Para o Push laser usaremos uma parte do feixe de aprisionamento. Esse feixe será levado até a parte superior da torre de lançamento, onde encontra-se uma janela, e direcionado para baixo passando através das cavidades. Como o pulso de luz desse laser tem de ser rápido, deverá ser utilizado um modulador acústico-óptico para funcionar como interruptor rápido e um obturador mecânico para bloquear completamente o feixe laser.

Tanto o efeito Zeeman de segunda ordem como a radiação de corpo negro constituem os dois mais importantes deslocamentos de freqüência durante o processo de interrogação atômica. Para reduzir o seu efeito, um controle ativo de campo magnético e temperatura será implementado para controlar o ambiente dos átomos. O sistema de compensação de campo magnético está implementado. No entanto, ele opera em condição de laço aberto, sem um controle de realimentação contra possíveis variações temporais de campo externo. Para a temperatura, ao longo do tubo de vôo livre e das cavidades de interrogação foram posicionadas cintas térmicas. Elas tem a finalidade de homogeneizar a temperatura ao longo dessa região e mantê-la em $38,8^{\circ} \mathrm{C}$ que corresponde à temperatura de sintonia da cavidade de Ramsey. Além disso, três resistências de platina são utilizadas para medir precisamente a temperatura. Esse controle também funciona em condição de laço aberto e um controle de realimentação contra possíveis variações temporais de temperatura faz-se necessário.

Para reduzir as flutuações de freqüência no sistema de deteção deverá ser introduzido um travamento de potência do feixe de detecção. Esse sistema começou a ser implementado com a adição de um modulador acústico-óptico no caminho óptico do feixe de detecção sobre a mesa óptica. O feixe de detecção está alinhado em dupla passagem através do modulador e maximizamos a ordem +1 do feixe de saída. Atualmente ele tem a finalidade de deslocar ligeiramente a freqüência do laser de detecção para evi- 
tar o aquecimento dos átomos na região de detecção. Para o controle de potência, o sinal de um fotodetetor perto da região de detecção será comparado com o sinal de um set-point. O sinal de erro gerado nessa comparação atuará na entrada do modulador de tensão do VCO, controlando assim a potência desviada por ele.

Finalmente, o MASER de hidrogênio, recém adquirido, será utilizado para travar o oscilador de referência do nosso sintetizador de microondas e proporcionará uma referência com nível de estabilidade de $10^{-13}$.

Naturalmente, com a otimização da relação sinal ruído da franja de Ramsey o grupo dará continuidade ao trabalho desenvolvido até hoje e iniciará a caracterização do chafariz de átomos para estudar completamente os efeitos físicos que deslocam a frequiência de transição relógio. Dentre os que são as maiores fontes de limitação para a exatidão do chafariz podemos citar o efeito Zeeman de segunda ordem, a radiação de corpo negro, o efeito das colisões frias e o cavity pulling. Devido às instabilidades do nosso chafariz não foi possível determinar todos os desvios de freqüência aos quais ela está sujeita. Esse procedimento será essencial para sua futura utilização como padrão primário, bem como a realização de experimentos mais fundamentais.

Um sistema experimental desse porte é extremamente complexo, exigindo performance elevadas de cada um dos subsistemas. O esforço que nosso grupo vem dispensando à realização do primeiro chafariz a ser utilizado como padrão primário em nosso país, é denotado pelo trabalho ao longo de alguns anos. Temos demonstrado uma constante evolução no desenvolvimento do sistema experimental, com a resolução de problemas técnicos e implementação de novas partes. Cada experimento desse tipo tem suas particularidades, sendo necessário desenvolver o know-how próprio de cada grupo de pesquisa na área. No desenrolar dos últimos anos, enfrentamos problemas relacionados a um sistema de vácuo que utiliza diferentes materiais (aço inoxidável, cobre, titânio), por exemplo.

Depois de conseguir com sucesso, há alguns anos, realizar os primeiros lançamentos da amostra de átomos frios, desenvolvemos nosso sistema para torná-lo capaz de atin- 
gir alturas de lançamento de até $90 \mathrm{~cm}$ da zona de aprisionamento, obtendo sinais de tempo de vôo de boa amplitude. Problemas relacionados ao sistema de interrogação foram também resolvidos, com a colocação de um novo sistema de cavidades de microondas e a implementação de uma dupla blindagem magnética. Conseguimos implementar o sistema de detecção com todos os seus componentes planejados (dois feixes de fluorescência, laser de rebombeio e maior lente de coleta). Isso fez com que fosse possível obter maiores sinais de tempo de vôo, aumentando também a relação sinal/ruído.

Com essas e outras ações pudemos obter os primeiros sinais de franjas de Ramsey nesse experimento. Nossas estimativas são de que, em aproximadamente dois anos, esse sistema seja capaz de realizar suas primeiras contribuições com a coordenada de tempo atômico internacional (TAI), contando com a utilização dos equipamentos já adquiridos de comparação (MASER de H e sistema de transferência de tempo). Além disso, temos um sistema de excelente qualidade de sinal para diversos outros experimentos de física fundamental. 


\section{Referências}

1 JESPERSEN, J.; FITZ-RANDOLPH, J. From Sundials to Atomic Clock:

Understanding Time and Frequency. [S.1.]: Dover, 1999.

2 AUDOIN, C. Caesium beam frequecy standards: Classical and optically pumped. Metrologia, v. 29, n. 2, p. 113-134, 1992.

3 VANIER, J.; AUDOIN, C. The Quantum Physics of Atomic Frequency Standards V1. [S.1.]: IOP Publishing LTD, 1989.

4 RAMSEY, N. F. A molecular beam resonance method with separated oscillating fields. Phys. Rev., v. 78, n. 6, p. 695-699, June 1950.

5 RAMSEY, N. F. The method of successive oscillatory fields. Physics Today, v. 80, p. 25-30, 1980.

6 RAMSEY, N. F. Molecular Beams. [S.1.]: Oxford University Press, Oxford, 1985.

7 VANIER, J.; AUDOIN, C. The classical caesium beam frequency standard: fifty years later. Metrologia, v. 42, p. 31-42, 2005.

8 KASTLER, A. Quelques suggestions concernant la production optique et la détection optique d'une inégalité de population des niveaux de quantification spatiale des atomes. application a l'expérience de stern et gerlach et a la résonance magnétique. Journal de physique et le radium., v. 11, p. 255, 1950.

9 BERGQUIST, J.; JEFFERTS, S.; WINELAND, D. Time measurement at the millenium. Physics Today, p. 37-42, March 2002.

10 CASTIN, Y.; WALLIS, H.; DALIBARD, J. Limit of doppler cooling. Journal of Optical Society of American B, v. 6, n. 11, p. 2046-2057, November 1989.

11 DALIBARD, J.; COHEN-TANNOUDJI, C. Laser cooling below the doppler limit by polarization gradients: simple theorical models. J. Opt. Soc. Am. B, v. 6, n. 11, p. 2023-2045, November 1989.

12 WYNANDS, R.; WEYERS, S. Atomic fountain clocks. Metrologia, v. 42, p. S64-S79, 2005.

13 RIIS, E. et al. Atom funnel for the production of a slow, high-density atomic beam. Physical Review Letters, v. 64, n. 14, p. 1658-1662, April 1990.

14 CLAIRON, A. et al. Ramsey resonance in a zacharias fountain. Europhysics Letters, v. 16, n. 2, p. 165-170, September 1991. 
15 JEFFERTS, S. R. et al. Accuracy evaluation of nist-f1. Metrologia, v. 39, p. 321-336, 2002.

16 WEYERS, S. et al. First performance results of ptb's atomic caesium fountain and a study of contributions to its frequency instability. IEEE Transactions on Ultrasonics, Ferroelectrics and Frequency Control, v. 47, n. 2, p. 432-437, March 2000.

17 LEVI, F. et al. Systematic shift uncertainty evaluation of ien csf1 primary frequency standard. IEEE Transactions on Instrumentation and Measurement, v. 52, n. 2, p. 267-271, April 2003.

18 SZYMANIEC, K. et al. Evaluation of the primary frequency standard npl-csf1. Metrologia, v. 42, p. 49-57, 2005.

19 KUROSU, T. et al. Preliminary evaluation of the cs atomic fountain frequency standard at nmij/aist. IEEE Transactions on Instrumentation and Measurement, v. 53, n. 2, p. 466-471, April 2004.

20 WANG, Y. On the development of frequency standards in china. In: Proceedings of the IEEE. [S.1.: s.n.], 2004.

21 KWON, T. Y. et al. Development of a cesium atomic fountain frequency standard. IEEE Transactions on Instrumentation and Measurement, v. 52, n. 2, p. 263-266, April 2003.

22 HOLLBERG, L. et al. Optical frequency/wavelength references. Journal of Physics B: Atomic, Molecular and Optical Physics, v. 38, p. S469-S495, 2005.

23 WOLF, P. et al. Testing lorentz invariance using zeeman transitions in atomic fountains. In: 2005 IEEE Proceedings. [S.1.: s.n.], 2005.

24 BIZE, S. et al. Cold atom clocks and applications. Journal of Physics B: Atomic, Molecular and Optical Physics, v. 38, p. S449-S468, 2005.

25 TELES, F. et al. Evaluation of the first brazilian atomic clock. IEEE Transactions on Ultrasonics, Ferroelectrics and Frequency Control, v. 47, p. 1111-1114, 2000.

26 TELES, F. et al. Analysis of the signal obtained with the cs-brazilian atomic clock. Proceedings of $14^{\text {th }}$ European Frequency and Time Forum, April 2000.

27 TELES, F. et al. Characterization of the brazilian cs atomic-frequency standard: Evaluation of major shifts. Metrologia, v. 39, p. 135-141, 2002.

28 BEBEACHIBULI, A. et al. Characterization of the main frequency shifts for the brazilian ${ }^{133} \mathrm{cs}$ atomic frequency standard. Brazilian Journal of Physics, v. 35, n. 4A, p. 1010, 2005.

29 MAGALHãES, D. et al. Progress towards a ${ }^{133} \mathrm{cs}$ fountain as frequency standard in brazil. Laser Physics, v. 14, n. 1, p. 1-4, 2004.

30 BEBEACHIBULI, A. et al. The brazilian atomic fountain primary frequency standard. In: Proceedings of the IEEE International Frequency Control Symposium. [S.l.: s.n.], 2006. 
31 MAGALHãES, D. et al. Comparative short-term stability for the cs beam and an expanding cold atomic cloud of cs used as atomic frequency standard. Laser Physics, v. 16, n. $8,2006$.

32 MüLLER, S. et al. Demonstration and observatios of a frequency standard based on an expanding cold atoms cloud of cesium. In: Proceedings of the IEEE International Frequency Control Symposium. [S.1.: s.n.], 2005.

33 MAGALHãES, D. V. Desenvolvimento de uma fountain atômica para utilização como padrão primário de tempo. Tese (Doutorado) — Instituto de Física de São Carlos da Universidade de São Paulo, 2004.

34 LEVINE, J. Introduction to time and frequency metrology. Review of Scientific Instruments, v. 70, n. 6, p. 2567-2596, June 1999.

35 WEIGHTS, R. . 13th Generale Conference on; 1967-1968”, M. Definition of basic si unit (translated from the french). Metrologia, v. 4, n. 3, p. 147, 1968.

36 STECK, D. A. Cesium D Line Data em http://steck.us/alkalidata/1998. [S.1.], 2003.

37 RAMSEY, N. F. A new molecular beam resonance method. Physical Review, p. $996,1949$.

38 VANIER, J.; AUDOIN, C. The Quantum Physics of Atomic Frequency Standards V2. [S.1.]: IOP Publishing LTD, 1989.

39 BUREAU International de Poids et Mesures: The International System of Units (SI). 8th edition.

40 BEBEACHIBULI, A. Relógio Atômico a Feixe Efusivo de Césio: Estudo da estabilidade e da Acurácia como função do deslocamento da freqüência Atômico devido ao efeito Zeeman de segunda ordem, ao Cavity Pulling e ao Rabi Pulling. Dissertação (Mestrado) - Instituto de Física de São Carlos na Universidade de São Paulo, 2003.

41 MAKDISSI, A. Traitement Du Signal Appliquée Aux Etalons Primaires de Fréquences: Amelioration de Leur Exactitude et de Leur Stabilité. Tese (Doutorado) — Université Paris XI - Orsay, september 1999.

42 MAKDISSI, A.; CLERQ, E. de. Evaluation of the accuracy of the optically pumped caesium beam primary frequency standard of the BNM-LPTF. Metrologia, v. 38, p. 409-425, 2001.

43 ALLAN, D. W. Time and frequency (time domain) characterization, estimation, and prediction of precision clocks and oscillators. IEEE Transactions on Ultrasonics, Ferroelectrics and Frequency Control, UFFC-34, n. 6, p. 647-654, November 1987.

44 ALLAN, D. Statistics of atomic frequency standard. Proceedings of the IEEE, v. 54, n. 2, p. 221-231, 1966. 
45 BARNES, J. A. Characterization of frequency stability. IEEE Transactions on Instrumentation and Measurement, IM-20, n. 2, 1971.

46 ZHANG, S. Dèplacement de Fréquence dû au Rayonnement du Corps Noir dans une Fontaine Atomique à Césium et Amélioration des Performances de l' Horloge. Tese (Doutorado) — Université de Paris VI, 2004.

47 Y.SORTAIS et al. Cold atoms clocks. Physica Scripta, T-95, p. 50-57, 2001.

48 ITANO, W.; AL et. Quantum projection noise: Population fluctuations in two-level systems. Physical Review A, v. 47, n. 5, May 1993.

49 SANTARELLI, G. et al. Frequency stability degradation of an oscillator slaved to a periodically interrogated atomic resonator. IEEE Transactions on Ultrasonics, Ferroelectrics and Frequency Control, v. 45, n. 4, p. 887-894, July 1998.

50 GODONE, A.; MICALIZIO, S.; LEVI, F. Pulsed optically pumped frequency standard. Physical Review A, v. 70, p. 023409-1 to 11, 2004.

51 VANIER, J.; GODONE, A.; LEVI, F. Coherent population trapping in cesium: Dark lines and coherent microwave emission. Physical Review A, v. 58, n. 3, p. 2345-2358, September 1998.

52 METCALF, H.; STRATEN, P. van der. Laser Cooling and Trapping. [S.1.]: Springer-Verlag New York, Inc., 1999.

53 METCALF, H.; STRATEN, P. van der. Laser cooling and trapping of atoms. $J$. Opt. Soc. Am. B, v. 20, n. 5, 2003.

54 TELES, F. et al. Construção de um sintetizador de microondas com vistas à aplicação em metrologia. Revista de Física Aplicada e Instrumentação, v. 15, 2002.

55 KLIPSTEIN, W. M. et al. Progress towards a laser-cooled cesium atomic fountain frequency standard at nist, gaithersburg. In: 1998 IEEE International Frequency Control Symposium. [S.1.: s.n.], 1998.

56 BIZE, S. Test fondamentaux à l'aide d'horloges à atomes froids de rubidium et de césium. Tese (Doutorado) — Universidade de Paris VI, 2001.

57 JEFFERTS, S.; DRULLINGER, R.; MARCHI, A. Nist cesium fountain microwave cavities. In: Proceedings of the 1998 IEEE International Frequency Control Symposium. [S.1.: s.n.], 1998. p. 6-8.

58 ITANO, W. M.; LEWIS, L.; WINELAND, D. Shift of ${ }^{2} s_{1 / 2}$ hyperfine splittings due to blackbody radiation. Physical Review A, v. 25, n. 2, p. 1233-1235, February 1982.

59 EISBERG, R.; RESNIK, R. Física Quântica. [S.1.]: Editora Campus Ltda, 1979.

60 ROVERA, G. D.; SANTARELLI, G.; CLAIRON, A. Frequency synthesis chain for the atomic fountain primary frequency standard. IEEE Transactions on Ultrasonics, Ferroelectrics and Frequency Control, v. 43, n. 3, p. 354-358, May 1996. 
61 DONLEY, E. A. et al. Double-pass acousto-optic modulator system. Review of Scientific Instruments, v. 76, p. 063112-1 to 6, 2005.

62 DONLEY, E. et al. Laser cooling and launching performance in a $(1,1,1)$ geometry atomic fountain. In: Proceedings of the IEEE. [S.1.: s.n.], 2005.

63 TUBOY, A. Preparação de laser de diodo e sua utilização no aprisionamento e estudo de átomos frios. Tese (Doutorado) — Instituto de Física de São Carlos na Universidade de São Paulo, 1996.

64 AUDOIN, C. et al. Properties of an oscillator slaved to an periodically interrogated atomic oscilator. IEEE Transactions on Ultrasonics Ferroelectrics and Frequency Control, v. 45, n. 4, p. 877-886, July 1998.

65 RAMSEY, N. Resonance transitions induced by perturbations at two or more different frequencies. Physical Review, v. 100, n. 4, p. 1191-1194, November 1955.

66 METCALF, H.; STRATEN, P. van der. Laser cooling and trapping of atoms. Journal of Optical Society of America B, v. 20, n. 5, May 2003.

67 LETT, P. D. et al. Optical molasses. Journal of Optical Society of America B, v. 6 , n. 11, p. 2084-2107, November 1989.

68 CODATA. http://physics.nist.gov/cuu/Constants/index.html. [S.1.], 1998.

Disponível em: <http://physics.nist.gov/cuu/Constants/index.html>. 


\section{APÊNDICE A - Probabilidade de Ramsey}

\section{A.1 Interrogação de Ramsey}

A transição atômica entre os dois níves hiperfinos do estado fundamental dos átomos de ${ }^{133} C s, F=4, m_{F}=0 \leftrightarrow F=3, m_{F}=0$, reproduz a definição primária do segundo e é definido como transição relógio. Esses níveis serão denotados por $|F=4\rangle$ e $|F=3\rangle$. Para excitar essa transição utiliza-se o método de interrogação de Ramsey, onde os átomos são sujeitos a duas perturbações oscilatórias separadas por uma região livre de perturbação. Ao longo de toda a região de interrogação, os átomos sentem uma fraca indução magnética. Essa indução magnética separa cada uma das sete transições $\Delta F= \pm 1, \Delta m_{F}=0$ de suas vizinhas. Logo, a aproximação de um sistema de dois níveis que interagem com um campo magnético osclatório é válida. Nesta seção calcularemos a probabilidade do átomo transitar entre esses dois estados utilizando o método descrito por N.F. Ramsey em $(4,6,65)$.

O campo magnético oscilatório é paralelo à direção z do campo magnético estático e tem a seguinte forma,

$$
B_{r f}(r)=B_{z}(r) \cos (\omega t+\phi)
$$

onde $\omega$ é a freqüência angular do campo e $\phi$ é a sua fase. O termo de fase foi introduzido para levar em conta uma possível diferença de fase entre as duas regiões de interação, ou uma onda propagante residual ao longo da trajetória atômica. O Hamiltoniano de perturbação é dado por,

$$
V_{34}=\langle 3|H| 4\rangle=-\frac{1}{2} \mu_{B} g_{J} B_{z}(r) \cos (\omega t+\phi)
$$

onde $\mu_{B}$ é o magnéton de Bohr e $g_{J}$ é o fator giromagnético do spin e igual a dois. A freqüência de Rabi é definida como,

$$
b=\frac{\mu_{B} B_{z}(r)}{\hbar}
$$

O termo coseno na equação A.2 pode ser escrito em termos exponenciais. Usando a aproximação da onda girante, a perturbação definida pela equação ( A.3) e a equação 
( A.2) pode ser reescrita como,

$$
V_{34}=b \hbar \exp (-i \omega t)
$$

A função de onda do átomo, após a interação com a perturbação, é escrita como,

$$
\Psi(t)=c_{3}(t) \Psi_{3}+c_{4}(t) \Psi_{4}
$$

$\Psi_{3}$ e $\Psi_{4}$ são as funções de onda do átomo nos estados $|3\rangle$ e $|4\rangle$ respectivamente. A evolução da função de onda no tempo é descrita pela equação de Schrödinger

$$
\imath \frac{\partial|\Psi(t)\rangle}{\partial t}=H|\Psi(t)\rangle
$$

onde $H$ é o Hamiltoniano total formado pelo Hamiltoniano não perturbado mais o termo do Hamiltoniano perturbador.

$$
H=H_{0}+V_{34}
$$

Usando as equações ( A.4) a ( A.7), a variação temporal das amplitudes $c_{3}(t)$ e $c_{4}(t)$ é escrita da forma,

$$
\begin{aligned}
& \imath \hbar c_{3}(t)=E_{3} c_{3}(t)+c_{4}(t) \hbar b \exp (\imath \omega t) \\
& \imath \hbar c_{4}(t)=c_{3}(t) \hbar b \exp (\imath \omega t)+E_{3} c_{3}(t)
\end{aligned}
$$

Assumindo que em $t=0$, todos os átomos encontram-se populados no mesmo nível hiperfino do estado fundamental,

$$
c_{3}\left(t_{0}\right)=1 \quad, \quad c_{4}\left(t_{0}\right)=0
$$

e a solução das equações ( A.8) em um tempo $t$ qualquer é dada por,

$$
\begin{array}{r}
c_{3}(t)=\left[l \frac{\omega_{0}-\omega}{\left[\left(\omega_{0}-\omega\right)^{2}+2 b^{2}\right]^{\frac{1}{2}}} \sin \left\{\left[\left(\omega_{0}-\omega\right)^{2}+2 b^{2}\right] \frac{t^{\prime}}{2}\right\} \times\right. \\
\left.\times \cos \left\{\left[\left(\omega_{0}-\omega\right)^{2}+2 b^{2}\right] \frac{t^{\prime}}{2}\right\}\right] \exp \left\{l\left[\frac{\omega}{2}-\frac{\left(\omega_{3}+\omega_{4}\right)}{2 \hbar}\right]\right\} \\
c_{4}(t)=\left\{l \sin \left[\frac{2 b}{\left[\left(\omega_{0}-\omega\right)^{2}+2 b^{2}\right]^{\frac{1}{2}}}\right] \sin \left[\left[\left(\omega_{0}-\omega\right)^{2}+2 b^{2}\right] \frac{t^{\prime}}{2}\right]\right\} \times \\
\times \exp \left\{l\left[-\frac{\omega}{2}-\frac{\left(\omega_{3}+\omega_{4}\right)}{2 \hbar}\right] \tau\right\}
\end{array}
$$

A probabilidade da transição ocorrer entre os estados $|3\rangle \leftrightarrow|4\rangle$ após um tempo $t$ que a perturbação tenho sido aplicada é dada por,

$$
\left|c_{3}(t)\right|^{2}=\text { probabilidade de ocupação do estado }|3\rangle
$$




$$
\left|c_{4}(t)\right|^{2}=\text { probabilidade de ocupação do estado }|4\rangle
$$

com

$$
\left|c_{3}(t)\right|^{2}+\left|c_{4}(t)\right|^{2}=1
$$

Para um tempo posterior $t+T$, as soluções da equação ( A.11a) são escritas como

$$
\begin{aligned}
& c_{3}(t+T)=c_{3}(t) \exp \left[-\imath\left(\frac{E_{3}}{\hbar}\right) T\right] \\
& c_{4}(t+T)=c_{4}(t) \exp \left[-\imath\left(\frac{E_{4}}{\hbar}\right) T\right]
\end{aligned}
$$

$\mathrm{Na}$ interrogação de Ramsey, o átomo de ${ }^{133} C s$ entra em uma região em que a perturbação $V_{34}$, dada pela equação ( A.4), age enquanto ela percorre uma distância $l$, em um tempo $\tau$. Depois disso, o átomo transita por uma região de comprimento $L$ durante um tempo $T$ no qual $b=0$, e, finalmente, ele sofre novamente a ação da perturbação durante um tempo $\tau$. Se a equação ( A.10) é válida, a aplicação das equações ( A.11a) e ( A.13), com $t=0$ e $T=\tau$, dá a amplitude de cada um dos estados quando o átomo sai da primeira região de interação,

$$
\begin{aligned}
c_{3}(t) & =\left\{l \frac{\left(\omega_{0}-\omega\right)}{\left[\left(\omega_{0}-\omega\right)^{2}+2 b^{2}\right]^{\frac{1}{2}}} \sin \left[\left[\left(\omega_{0}-\omega\right)^{2}+2 b^{2}\right] \frac{\tau}{2}\right] \times\right. \\
\times & \left.\cos \left[\left[\left(\omega_{0}-\omega\right)^{2}+2 b^{2}\right] \frac{\tau}{2}\right]\right\} \exp \left\{l\left[\frac{\omega}{2}-\frac{\left(\omega_{3}+\omega_{4}\right)}{2 \hbar}\right]\right\} \\
c_{4}(t) & =\left\{l \frac{\omega_{0}-\omega}{\left[\left(\omega_{0}-\omega\right)^{2}+2 b^{2}\right] \frac{1}{2}} \sin \left[\left[\left(\omega_{0}-\omega\right)^{2}+2 b^{2}\right] \frac{1}{2}\right] \times\right. \\
& \left.\times \cos \left[\left[\left(\omega_{0}-\omega\right)^{2}+2 b^{2}\right] \frac{\tau}{2}\right] \exp \left\{l\left[\frac{\omega}{2}-\frac{\omega_{3}+\omega_{4}}{2 \hbar}\right]\right\}\right\}
\end{aligned}
$$

Durante a região de vôo livre, $b=0$ e a função de estado do átomo evolui livremente. Como o campo magnético estático não é perfeitamente uniforme ao longo da região de interação, a energia entre os estados $|3\rangle$ e $|4\rangle$ não é constante onde $b=0$. Portanto, a região será subdividida em k sub-regiões de duração $\Delta t_{k}$. As energias em cada uma delas será $E_{3, k}$ e $E_{4, k}$. Após um tempo de transito $\tau+T$, as amplitudes $c_{3}(t)$ e $c_{4}(t)$ são dadas por,

$$
\begin{aligned}
c_{3}(\tau+T)=\prod_{k}\left[\exp \left(-\imath \frac{E_{3, k}}{\hbar} \Delta t_{k}\right)\right] c_{3}(\tau) & =\exp \left(-\imath \frac{\bar{E}_{3}}{\hbar} T\right) c_{3}(\tau) \\
c_{4}(\tau+T) & =\exp \left(-\imath \frac{\bar{E}_{4}}{\hbar} T\right) c_{4}(\tau)
\end{aligned}
$$

Finalmente, em $\tau+T$ o átomo entra na segunda cavidade de interrogação e após um 
tempo $\tau$ em que a perturbação $V_{3,4}$ age sobre o átomo, a amplitude de cada um dos estados $c_{3}(2 \tau+T)$ e $c_{4}(2 \tau+T)$ é escrito da seguinte forma,

$$
\begin{array}{r}
c_{3}(2 \tau+T)=\left[\imath\left(\frac{\omega_{0}-\omega}{\left[\left(\omega_{0}+\omega\right)^{2}+2 b^{2}\right]^{\frac{1}{2}}}\right) \sin \frac{1}{2} \tau\left[\left(\omega_{0}+\omega\right)^{2}+2 b^{2}\right]^{\frac{1}{2}}+\right. \\
\left.+\cos \frac{1}{2} \tau\left[\left(\omega_{0}+\omega\right)^{2}+2 b^{2}\right]^{\frac{1}{2}}\right] c_{3}(\tau+T)+\left\{-\imath\left(\frac{\omega_{0}-\omega}{\left[\left(\omega_{0}+\omega\right)^{2}+2 b^{2}\right]^{\frac{1}{2}}}\right) \times\right. \\
\left.\left.\times \sin \frac{1}{2} \tau\left[\left(\omega_{0}+\omega\right)^{2}+2 b^{2}\right]^{\frac{1}{2}} \exp (\imath \omega(\tau+T)) c_{4}(\tau+T)\right\} \exp \left\{l\left[\frac{1}{2} \omega-\frac{E_{3}+E 4}{2 \hbar}\right] \tau\right\}\right)
\end{array}
$$

$\mathrm{e}$

$$
\begin{array}{r}
c_{4}(2 \tau+T)=\left\{\left[-l \frac{2 b}{\left[\left(\omega_{0}-\omega\right)^{2}+(2 b)^{2}\right]^{\frac{1}{2}}} \sin \frac{1}{2} \tau\left[\left(\omega_{0}-\omega\right)^{2}+(2 b)^{2}\right]^{\frac{1}{2}} \times\right.\right. \\
\left.\times \exp [-l \omega(\tau+T)] c_{3}(\tau+T)\right]+ \\
+\left[-\imath\left(\frac{\omega_{0}-\omega}{\left[\left(\omega_{0}-\omega\right)^{2}+(2 b)^{2}\right]^{\frac{1}{2}}}\right) \sin \frac{1}{2} \tau\left[\left(\omega_{0}-\omega\right)^{2}+(2 b)^{2}\right]^{\frac{1}{2}}+\right. \\
\left.\left.+\cos \frac{1}{2} \tau\left[\left(\omega_{0}-\omega\right)^{2}+(2 b)^{2}\right]^{\frac{1}{2}}\right] c_{4}(\tau+T)\right\} \exp \left\{l\left[-\frac{1}{2} \omega-\frac{E_{3}+E_{4}}{2 \hbar}\right] \tau\right\}
\end{array}
$$

A probabilidade do átomo transitar do estado $|3\rangle$ para o estado $|4\rangle$ é dado por,

$$
\begin{gathered}
P_{34}(2 \tau+T)=\left|c_{4}(2 \tau+T)\right|^{2} \\
P_{34}(2 \tau+T)=\left[-\frac{2 b}{\left[\left(\omega_{0}-\omega\right)^{2}+2 b^{2}\right]^{\frac{1}{2}}}\right]^{2} \sin ^{2} \frac{\tau}{2}\left[\left(\omega_{0}-\omega\right)^{2}+2 b^{2}\right]^{\frac{1}{2}} \times \\
\times\left[\frac{\omega_{0}-\omega}{\left[\left(\omega_{0}-\omega\right)^{2}+2 b^{2}\right]^{\frac{1}{2}}} \sin \frac{\Omega_{0} T}{2} \sin \frac{\tau}{2}\left[\left(\omega_{0}-\omega\right)^{2}+2 b^{2}\right]^{\frac{1}{2}}-\right. \\
\left.-\cos \frac{\tau}{2}\left[\left(\omega_{0}-\omega\right)^{2}+2 b^{2}\right]^{\frac{1}{2}} \cos \frac{\Omega_{0} T}{2}\right]^{2}
\end{gathered}
$$

onde, $\Omega_{0}=\omega_{0}-\omega$ é a deslocamento entre a freqüência de ressonância atômica e a freqüência de interrogação.

\section{A.2 Cálculo de Erro do Deslocamento da Freqüiência Atômica}

Para travar o oscilador de microonda, modulamos por onda quadrada o campo de interrogação em torno da freqüência da transição relógio. A freqüência de modulação é $\frac{1}{2 T_{c}}$ e a amplitude de modulação, $v_{m}$, é ajustada para deslocamentos a meia altura da 
ressonância atômica, $v_{m}=\frac{\Delta v_{\text {Ramsey }}}{2}$, região onde há a maior sensibilidade do descriminador de freqüência. O oscilador macroscópico é corrigido com base nesse sinal de erro de modo a ser escravizado à transição atômica. De forma geral, a freqüência medida não é exatamente $v_{0}$, que é a frequiência de ressonância do átomo em repouso e livre de qualquer perturbação, mas deslocada por uma quantidade $\delta v_{s}$ devido a todas as perturbações sistemáticas sobre a ressonância atômica. O resultado da escravização é igual ao balanço de duas medidas sucessivas da probabilidade de transição

$$
P\left(\delta v_{0}+v_{m}\right)=P\left(\delta v_{0}-v_{m}\right)
$$

Na aproximação de primeira ordem obtemos,

$$
\begin{array}{r}
P\left(v_{0}+\delta v_{F}+v_{m}\right)=P^{(0)}\left(\delta v_{0}+v_{m}\right)+\delta P_{+}= \\
=P^{(0)}\left(v_{m}\right)+\delta v_{0} \frac{d P^{0}}{d \delta}\left(v_{m}\right)+\delta P_{+} \\
P\left(v_{0}+\delta v_{F}-v_{m}\right)=P^{0}\left(\delta v_{0}-v_{m}\right)+\delta P_{-}= \\
=P^{(0)}\left(-v_{m}\right)+\delta v_{0} \frac{d P^{(0)}}{d \delta}\left(-v_{m}\right)+\delta P_{-}
\end{array}
$$

Da equação ( A.22) podemos escrever,

$$
\delta v_{0}=-\frac{\delta P_{+}-\delta P_{-}}{2 \frac{d \delta P^{(0)}\left(+v_{m}\right)}{d \delta}}
$$

A derivada da probabilidade de Ramsey é dada por,

$$
\left.\frac{\partial P^{(0)}}{\partial v}\right|_{\nu=v_{0} \pm v_{m}}=\mp \frac{\pi}{2 \Delta v_{\text {Ramsey }}}
$$

onde $\Delta v_{0}=\frac{1}{2 T}$, e o deslocamento de freqüência é dado por,

$$
\delta v_{0}=\frac{\left(-\delta P_{+}-\delta P_{-}\right)}{\pi T}
$$

e em valor relativo,

$$
\frac{\delta v_{0}}{v_{0}}=\frac{\left(-\delta P_{+}-\delta P_{-}\right)}{Q_{a t}}
$$

Desse modo, podemos quantificar com base no sinal de probabilidade extraído da franja de Ramsey a diferença entre freqüência dos átomos e a produzida pelo oscilador macroscópico. 


\section{APÊENICE B - Manipulação Óptica dos Átomos em um Chafariz de Átomos}

Com o advento dos lasers de diodo foi possível programar as técnicas de resfriamento e aprisionamento atômico nos padrões de frequiência atômicos. Dessa forma, a obtenção de amostras de átomos à baixas temperaturas $(\mu K)$ tornou viável a proposta de Jerrold Zacharias em 1950 para criar um chafariz de átomos. Essas técnicas apresentam diversas vantagens frente aos outros padrões existentes, uma vez que é possível reduzir a velocidade dos átomos e a distribuição espacial da nuvem o que aumenta o fator de qualidade da linha da transição atômica. Vamos agora analisar brevemente alguns dos conceitos relacionados o resfriamento atômico.

\section{B.1 Resfriamento Doppler}

Nesse processo, o átomo é submetido a um campo de radiação cuja freqüência é ligeiramente inferior à freqüência de ressonância atômica, como ilustrado na figura 53. A absorção de um fóton propagando-se contra o movimento dos átomos ocorre preferencialmente por causa do efeito Doppler. A freqüência do laser $\left(v_{R}\right)$ está deslocada para o azul da transição de resfriamento, $6^{2} S_{1 / 2} F=4 \leftrightarrow 6^{2} P_{3 / 2} F=5$ de $\Gamma \approx 5,3$ MHz. Como a emissão espontânea é isotrópica, o momentum médio associado ao recuo é zero. O efeito resultante é a redução da velocidade do átomo na direção da luz devido ao processo de absorção atômica. Pela conservação de momentum entre átomo e fóton, durante o processo de absorção/emissão, o momentum do átomo é alterado pela quantidade $(52,66,67)$

$$
M \Delta v=-\frac{h}{\lambda}
$$

onde $M$ é a massa do átomo, $\lambda$ é o comprimento de onda da radiação e $\Delta v$ é a velocidade de recuo. A absorção de um fóton ressonante com a linha $D_{2}$ do átomo de ${ }^{133} \mathrm{Cs}$, $\lambda=852 \mathrm{~nm}$, a variação de velocidade é da ordem $\Delta v=-3,52 \times 10^{-3} \mathrm{~m} / \mathrm{s}$. A perda 


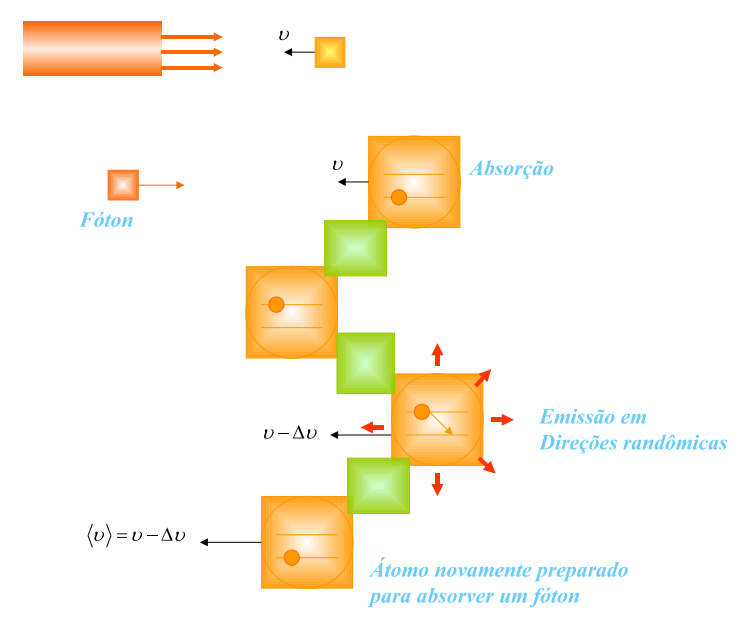

Figura 53: Princípio do Resfriamento Doppler.

de energia associada é de $-10^{-28} \mathrm{~J}$ ou $\Delta T=-0,05 \mathrm{~K}$. O processo de transferência de momentum é utilizado para diminuir a velocidade de um átomo que se propaga contra um feixe de luz ressonante. Para reduzir a velocidade do átomo de ${ }^{133} \mathrm{Cs}$ que se move a velocidade característica das partículas em um gás à temperatura ambiente, $T=300 \mathrm{~K}$, $v=\left(\frac{3 k_{B} T}{M}\right) \cong 237,78 \mathrm{~m} / \mathrm{s}$ para valores próximos de zero são necessários cerca de $\frac{v}{\Delta v}=67500$ ciclos de absorção/emissão. O tempo gasto neste resfriamento (levando-se em conta o tempo de decaimento do átomo, $\tau=\frac{1}{\Gamma}$, onde $\Gamma \cong 5,30 \mathrm{MHz}$ é sua largura de linha natural e $\tau$ é o tempo de vida do átomo no estado excitado) é de $\tau=30 \mathrm{~ms}$. Para uma transição saturada, o átomo passa, em média, metade do seu tempo no estado excitado e outra metade no estado fundamental. Dessa forma, o número de ciclos de fluorescência (absorção/emissão) por segundo chega a $\frac{\Gamma}{2}$. Portanto, o tempo mínimo para trazer o átomo ao repouso quase absoluto é $\Delta t=\frac{2 v}{\Gamma \Delta v} \approx 4,05 m s$. A pressão de radiação é máxima, $f_{s a t}=\frac{\hbar k \Gamma}{2}$, comunica ao átomo uma aceleração $\frac{f_{s a t}}{M} \approx 11,88 \mathrm{~m} / \mathrm{s}^{2}$.

No processo de resfriamento, seis feixes laser colimados, monocromáticos de intensidade e freqüências iguais, sintonizados abaixo da freqüência natural da transição $\left(\omega-\omega_{0}\right) \Gamma$, propagam-se em sentidos opostos, $+k \mathrm{e}-k$. Para um átomo em movimento ao longo da direção $+k$, as freqüências aparentes são deslocadas por efeito Doppler conforme o sentido da velocidade $v$, desigualando suas pressões de radiação. Um átomo com velocidade $v>0$ absorverá mais energia da onda $-k$, oposta à sua velocidade, pois o efeito Doppler aumenta a freqüência aparente desta onda, tornando-a mais próxima da ressonância, enquanto a freqüência aparente da onda $+k$ diminui e se afasta da ressonância. Nesse caso, a pressão de radiação da onda $-k$ é maior que da onda $+k$. Por outro lado, para $v<0,+k>-k$, de modo que o átomo sente uma força que é sempre oposta à sua velocidade. Dessa forma, os átomos são resfriados em um melado óptico ao longo das três direções espaciais localizado na intersecção desses eixos. A 
temperatura mais baixa produzida por esse processo será de

$$
T_{D}=\frac{\hbar \Gamma}{2 k_{B}} \cong 126,63 \mu K
$$

Para a transição $6^{2} S_{\frac{1}{2}} \rightarrow 6^{2} P_{\frac{3}{2}}$ do ${ }^{133} \mathrm{Cs}, \lambda_{D}=852 \mathrm{~nm}$, e a intensidade de saturação

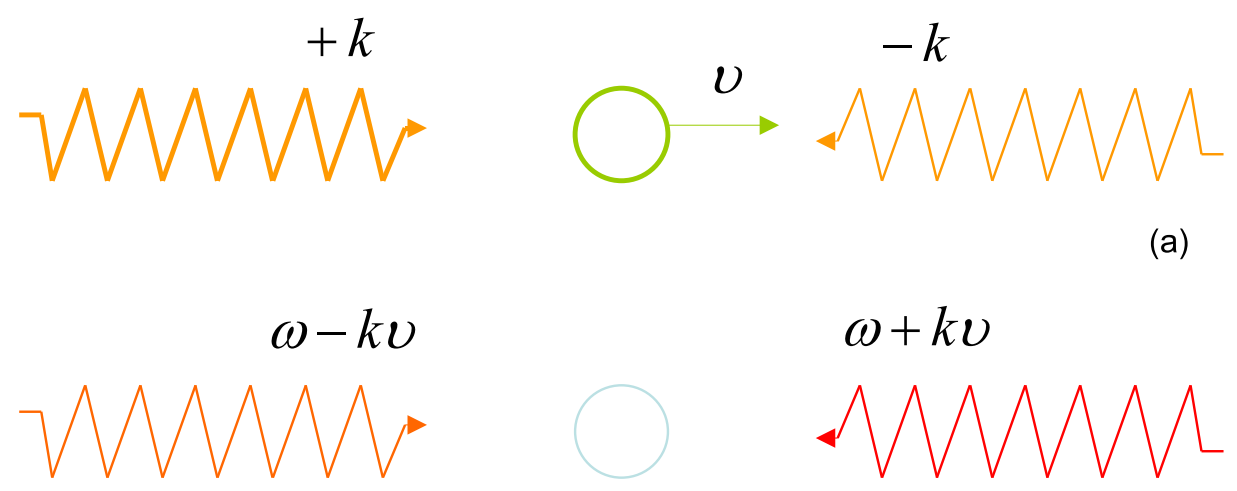

(b)

Figura 54: a) Resfriamento Doppler no referencial do laboratório; (b) No referencial próprio de um átomo com velocidade $v$.

desta transição é de $1,1 \mathrm{~mW}$, e a largura espectral do laser deve ser bem menor que a da transição atômica $(\Gamma \cong 5,3 \mathrm{MHz})$. A essa temperatura, a velocidade dos átomos é da ordem de $v \cong 15,43 \mathrm{~cm} / \mathrm{s}$ e $k v$ para que se possa desprezar o efeito do alargamento Doppler no perfil da transição atômica. Os átomos resfriados são muito mais seletivos no que diz respeito à absorção e à emissão de luz do que um gás a temperatura ambiente. Dessa forma, a sua utilização em um padrão de frequiência atômico permite maior resolução no espectro da transição relógio.

\section{B.2 Aprisionamento Magneto Óptico}

O melado óptico limita apenas a velocidade dos átomos. Para limitar o seu movimento espacialmente utilizam-se armadilhas magneto-ópticas, MOT. Essas armadilhas beneficiam-se da interação do momento magnético dos átomos com um gradiente de campo magnético $\vec{B}$, para criar um poço de potencial. Por meio de um MOT é possível acumular um maior número de átomos que irão participar do processo de interrogação de Ramsey. 
Para essa técnica, o momento angular da luz circularmente polarizada é utilizado para manipular os graus de liberdade externos dos átomos e confiná-los em uma determinada região do espaço. O gradiente de campo magnético externo $\vec{B}$ aplicado na direção $\widehat{z}$ sobre os átomos, quebra a degenerescência do nível excitado por meio do efeito Zeeman e desloca a energia dos seus subníveis. Dessa forma cria-se uma regra de seleção que depende da posição do átomo como mostra a figura 53.

O campo magnético está orientado na direção $\widehat{z}$, dado por $\vec{B}(z)=B_{0} \widehat{z}$, e os feixes $+k$ e $-k$ possuem polarização $\sigma^{+}$e $\sigma^{-}$, respectivamente. $\mathrm{O}$ hamiltoniano de interação entre o momento magnético e o campo magnético $\vec{B}(z)$ é dado por

$$
\vec{\mu} \cdot \vec{B}(z)=\mu_{g} g \vec{F} \cdot \overrightarrow{B(z)}
$$

onde $\mu_{B}$ é o magneton de Bohr, $g$ é o fator de Landé e $F$ é o momento angular total. A projeção do momentum $F$ ao longo do eixo de quantização assume valores discretos $m_{F} \hbar$, onde $F\left\langle m_{F}\langle+F\right.$. Na presença do campo magnético $B(z)$, o átomo tem a freqüência de ressonância $6^{2} S_{1 / 2} \leftrightarrow 6^{2} P_{3 / 2}$ alterada por uma quantidade $\pm m_{F} \mu_{B} g B_{0} z$. Como mostra a figura 54, para um átomo localizado no centro da armadilha $(z=0 \mathrm{e}$

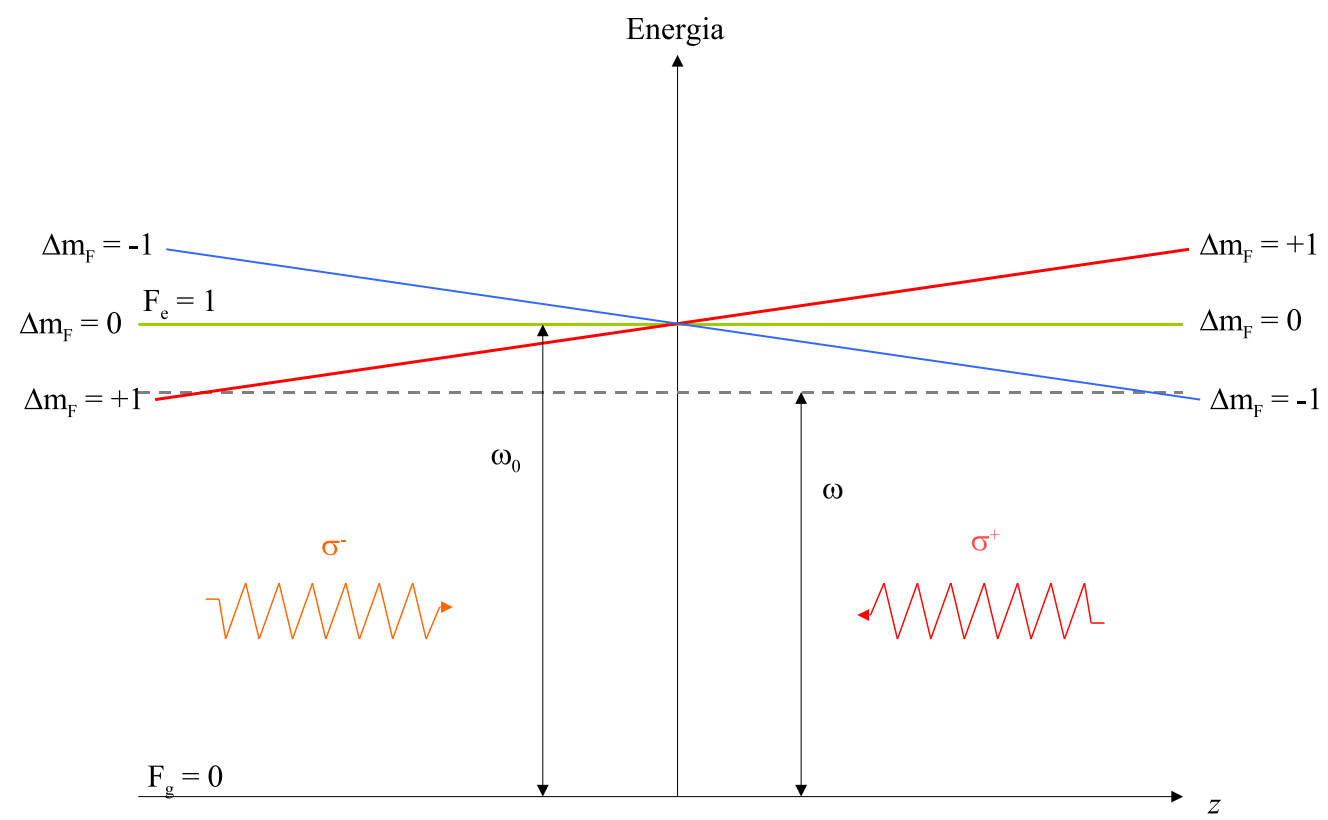

Figura 55: Esquema do processo de aprisionamento magneto-óptico sobre uma transição de freqüência $\omega_{0}$. Os feixes de aprisionamento $+k \mathrm{e}-k$ são circularmente polarizados, $\sigma^{+}$e $\sigma^{-}$, de modo que exercem também uma força de aprisionamento. 
$B=0$ ) a absorção independe do momento angular intrínseco e a força total é simplesmente a força de resfriamento. No caso de um átomo que se localiza em uma posição $z \neq 0$, a absorção de luz obedece a uma regra de seleção que depende da distância do átomo à origem. $\mathrm{O}$ átomo localizado em $z>0$ irá absorver mais fótons $-k$ (momentum intrínseco $-\hbar$ ) do que da onda $+k$ (momentum intrínseco $+\hbar$ ), pois o efeito Zeeman provocado pelo campo magnético $B(z)$ nesta região diminui a freqüência da transição $\Delta m_{F}=-1$ aproximando-o da ressonância com a luz, enquanto a transição $\Delta m_{F}=+1$ tem sua freqüência aumentada e é afastada da ressonância. Nesse caso, a pressão de radiação da onda $-k$ é maior do que da onda $+k$. Por outro lado, pelo mesmo argumento, para $z<0$ a pressão de radiação da onda $+k$ é maior do que da onda $-k$.

Dessa forma, o átomo sente uma força restauradora sempre em direção à origem. A força total é escrita na forma de uma força harmônica

$$
f_{M O T}=-\alpha_{D} v-K_{D} z
$$

onde $K_{D}$ é a constante de mola, dada por:

$$
K_{D}=\alpha_{D} \frac{\mu_{B} g B_{0}}{k}
$$

que depende do coeficiente de fricção $\alpha_{D}$, do momentum de dipolo do estado excitado e do gradiente do campo externo $B$. A relação entre força viscosa e força restauradora indica o tipo de movimento a que o átomo está sujeito dentro da região da armadilha. Para as condições $\Omega \approx \Gamma, \delta \approx \Gamma$ e $\mu_{B} g=1,41 M H z / G$, o gradiente deve ser $\left|B_{0}\right| \approx$ $22 \mathrm{G} / \mathrm{cm}$.

\section{B.3 Resfriamento sub-Doppler por Efeito Sisyphus}

Após esses dois processos de resfriamento e aprisionamento atômico, a nuvem atômica passa por um resfriamento adicional para limitar ainda mais a dispersão espacial. A velocidade residual dentro da nuvem é resfriada usando-se uma onda estacionária nas vizinhanças da nuvem. Essa onda estacionária possui um gradiente de polarização, de modo que os átomos movem-se em um campo potencial que varia espacialmente. $\mathrm{O}$ átomo move-se nesse campo e sente uma troca entre a sua energia cinética e energia potencial. Se esse potencial é periódico no espaço a variação entre as energias cinética e potencial do átomo também irá variar de forma periódica. O potencial senoidal do estado fundamental $\left(M_{g}=-\frac{1}{2}\right)$ está fora de fase do estado excitado $\left(M_{g}=+\frac{1}{2}\right)$ uma vez que o deslocamento luminoso do átomo de dois níveis tem sinal oposto. 
A presença de múltiplos potenciais induz mecanismos de perda de energia dependentes da velocidade quando a população dos estados possa ser manipulada de alguma forma. Por meio do bombeamento óptico, a população dos átomos está no estado $M_{g}=+\frac{1}{2}$. Para esse átomo movendo-se através do campo de luz, a energia potencial cresce conforme ele sobe pelo potencial e perde energia cinética, uma vez que a polarização da onda estacionária está mudando e esse estado torna-se cada vez menos acoplado ao campo da luz. Após percorrer uma distância de $\frac{\lambda}{4}$, os átomos atingem uma região onde a luz está polarizada $\sigma^{-}$. E eles são então bombeados opticamente para o estado $M_{g}=-\frac{1}{2}$ e ganham uma pequena quantidade de energia cinética. O estado $M_{g}=-\frac{1}{2}$ é menor que o estado $M_{g}=+\frac{1}{2}$ e novamente os átomos escalam o potencial e novamente a energia cinética é convertida em energia potencial. No processo de bombeamento óptico, a conversão de energia potencial é feita por meio da emissão espontânea onda a freqüência da luz emitida está deslocada para o azul, ou seja, a frequiência do fóton emitido é maior do que a do fóton absorvido, de modo que para o átomo ele está sempre subindo o potencial e perdendo energia com esse processo. Em suma, esse processo de resfriamento converte a energia cinética em energia potencial.

Verificou-se que a temperatura final dos átomos é proporcional à intensidade do laser e inversamente proporcional ao deslocamento de frequiência dos feixes durante o processo,

$$
T_{F} \propto \frac{1}{\Delta v}
$$

O resfriamento sub-Doppler é efetivo sobre um intervalo de velocidade bem limitado. A força é máxima quando os átomos são submetidos a um processo de bombeamento enquanto percorrem a distância de $\frac{\lambda}{4}$. Átomos muito lentos não conseguirão subir o potencial antes que o processo de bombeamento ocorra, enquanto os átomos muito rápidos estão sempre descendo o potencial antes de serem bombeados para o outro nível. Por isso é necessário que os átomos passem por um outro processo de resfriamento para que o resfriamento por efeito Sisyphus seja eficiente. 


\section{APÊEDICE C - Constantes Fundamentais da Física e do Átomo de ${ }^{133} \mathrm{Cs}$}

Os valores de cada uma das constantes físicas fundamentais utilizadas nessa tese correspondem a valores internacionalmente recomendados listadas na tabela de 1998 do CODATA $(36,68)$.

\section{C.1 Constantes Físicas}

Tabela 2: Constantes Fundamentais da Física

\begin{tabular}{|c|c|c|}
\hline Constante & Símbolo & Valor \\
Magneton de Bohr & $\mu_{B}$ & $9,27400899(37) \times 10^{-24} \mathrm{~J} \mathrm{~T}^{-1}$ \\
Velocidade da luz no vácuo & $\mathrm{c}$ & $299792458 \mathrm{~m} \mathrm{~s}^{-1}$ \\
Permeabilidade magnética do vácuo & $\mu_{0}$ & $4 \pi 10^{-7} \mathrm{~N} \mathrm{~A}^{-2}$ \\
Permeabilidade elétrica do vácuo & $\epsilon_{0}$ & $8,85401870817 \ldots 10^{-12} \mathrm{~F} \mathrm{~m}^{-1}$ \\
Constante de Planck & $\mathrm{h}$ & $6,62606876(52) 10^{-34} \mathrm{~J} \mathrm{~s}$ \\
Constante de Boltzmann & $k_{B}$ & $1,386503(24) 10^{-23} \mathrm{~J} \mathrm{~K}^{-1}$ \\
Carga Elétrica & $\mathrm{e}$ & $1,602176462(63) 10^{-19} \mathrm{C}$ \\
Constante de Estrutura fina & $\alpha$ & $7,297352533(27) 10^{-3}$ \\
Aceleração da Gravidade & $\mathrm{g}$ & $9,80665 \mathrm{~m} \mathrm{~s}^{-2}$ \\
\hline
\end{tabular}




\section{C.2 Átomo de ${ }^{133} \mathrm{Cs}$}

Tabela 3: Parâmetros do Átomo de ${ }^{133} \mathrm{Cs}$.

\begin{tabular}{|c|c|}
\hline Número Atômico & 55 \\
Massa Atômica & $2,20694650(17) \times 10^{-25} \mathrm{Kg}$ \\
Elétron de Valência & $6 s^{1}$ \\
Pressão de Vapor a $25^{\circ} \mathrm{C}$ & $1,3 \times 10^{-3}$ \\
Abundância do ${ }^{133} C s$ & $100 \%$ \\
Tempo de vida nuclear & Estável \\
Spin nuclear & $I=7 / 2$ \\
Fator de Landé nuclear & $g_{I}=-4,013 \times 10^{-4}$ \\
Fator de Landé Eletrônico $\left(6^{2} S_{1 / 2}\right)$ & $g_{J}=2,00254032(20)$ \\
Freqüência de transição hiperfina & $9192631770 \mathrm{~Hz}$ \\
Comprimento de onda da linha $D_{1}($ no vácuo $)$ & $\lambda_{D 1}=894,36 \mathrm{~nm}$ \\
Comprimento de onda da linha $D_{2}($ no vácuo $)$ & $\lambda_{D 2}=852,34727582(27) \mathrm{nm}$ \\
Número de onda da linha $D_{2}\left(2 \pi / v_{D 2}\right)$ & $k=7,0235 \times 10^{-6} \mathrm{~m}^{-1}$ \\
Freqüência da linha $D_{2}$ & $v_{D 2}=351,72571850(11) \mathrm{THz}$ \\
Tempo de vida do estado excitado $6^{2} P_{3 / 2}$ & $\tau=30,473(39) \mathrm{ns}$ \\
Largura de linha natural, linha $D_{2} 1 / \tau$ & $\Gamma=2 \pi \times 5,2152 \mathrm{MHz}$ \\
Intensidade de Saturação da linha $D_{2}\left(\pi h c / 3 \lambda^{3} \tau\right)$ & $I_{s}=1,09 \mathrm{mWcm} \mathrm{cm}^{-2}$ \\
Seção de choque de absorção $\left(D_{2}\right)$ & $\sigma_{g e}=346,9 \times 10^{-15}$ \\
Máxima aceleração da saturação da linha $D_{2}$ & $a_{m a x}=5,7 \times 10^{4} \mathrm{~ms}^{-2}$ \\
Velocidade de recuo do fóton $\left(D_{2}\right)$ & $v_{r}=3,52 \mathrm{mms} \mathrm{s}^{-1}$ \\
Temperatura de recuo & $T_{r}=0,198 \mu \mathrm{K}$ \\
Velocidade de captura $(1 / \tau k)$ & $v_{C}=4,42 \mathrm{mms}^{-1}$ \\
Temperatura Doppler & $T_{D}=124 \mu \mathrm{K}$ \\
\hline
\end{tabular}

